


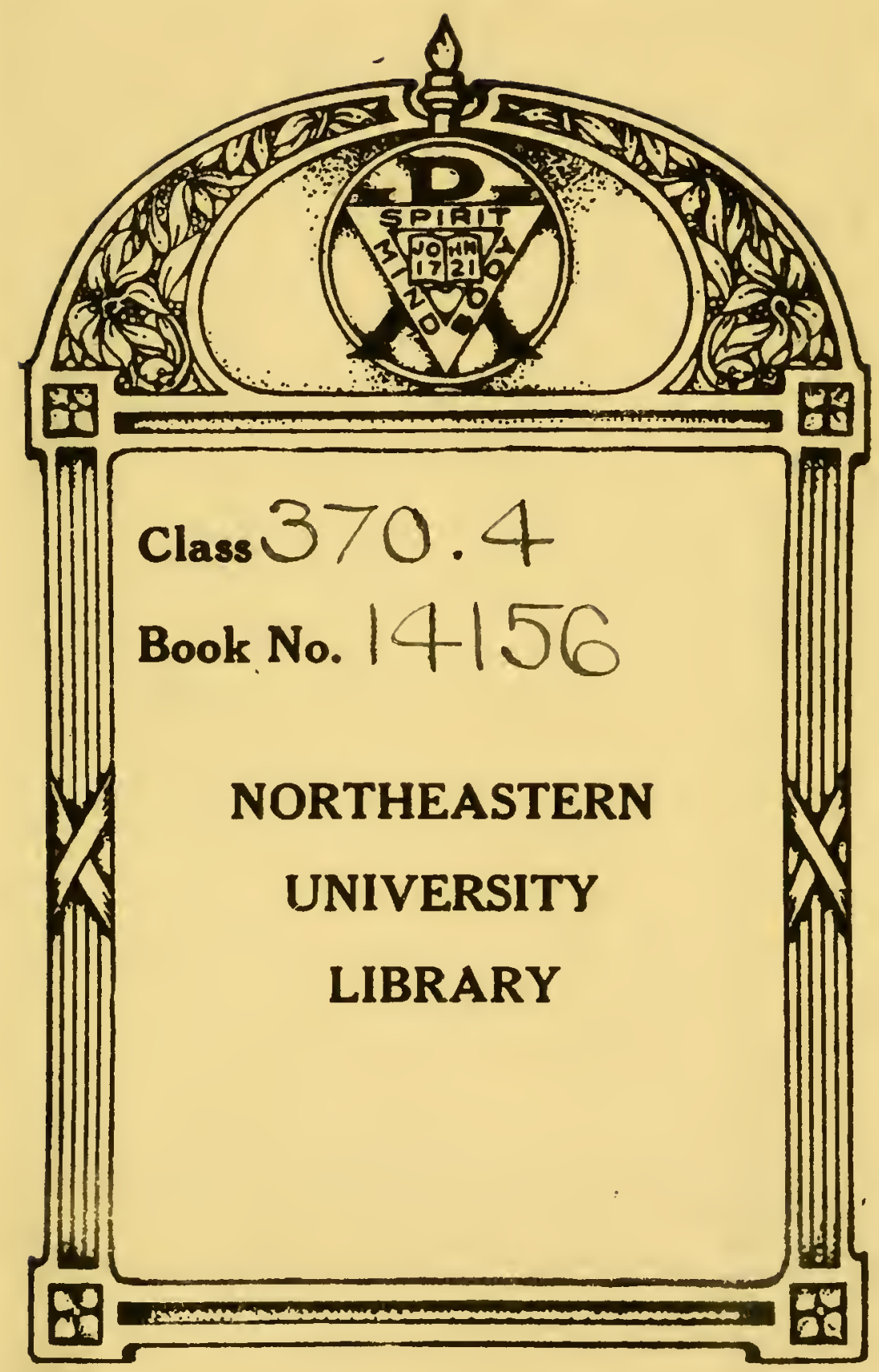




SCIENTIFIC METHOD 
A COURSE OF
LECTURES DELIVERED AT THE OHIO STATE UNIVERSITY
UNDER THE AUSPICES OF THE GRADUATE SCHOOL 


\section{SCIENTIFIC METHOD}

\section{ITS FUNCTION IN RESEARCH AND IN EDUCATION}

\section{TRUMAN LEE KELLEY \\ Professor of Education and Psychology \\ Stanford University}

\section{THE OHIO STATE UNIVERSITY PRESS

COLUMBUS , , , 1929




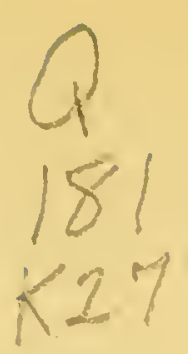

Copyright 1929

By The Ohio State University Press 
"For he that reads but Mathematicke rules Shall find conclusions that availe to work Wonders that passe the common sense of men."

Frier Bacon and Frier Bongay Robert Green, 1594. ACT 1, SCEne 1 



\section{PREFACE}

THE SUBJECT matter of these lectures has been I drawn from literature, class activities, and research work. I am indebted to my colleagues at Stanford University for their kindness in answering the questionnaire discussed in the second lecture. I have drawn freely from class reports of students for bibliographical data about men of science, and have especially profited by the reports of Mr. C. G. Shambaugh upon Charles Darwin and Francis Bacon. I am indebted to Dr. Lucia B. Mirrielees for suggesting the quotation which is introductory to this volume. I have been helped financially in the experimental work reported by two grants from the Stanford University Council of Research in the Social Sciences. Two of the lectures as here published are slightly extended from their form as given orally, but even so the reader is asked to be charitable in judging of the unity of this series. If the attempt to incorporate philosophical, historical, and very recent experimental material into a single structure has thrown any new light upon the immediate problems of research, education, and eugenics, no apology for its brevity and incompleteness need be made.

T. L. K.

December, 1928 



\section{CONTENTS}

LECTURE PAGE

I. Interrelationship between Method of ReSearch and Field of Investigation . . . . . 1

II. The Role of Judgment in "Objective Measurement" ................ 33

III. In What Units Shall We Measure INtelligence And Achievement? . . . . . . . 84

IV. The Bearing of Recent Scientific Development upon Problems of Education and INHERITANCE . . . . . . . . . . . . . 113

V. Mental Traits of Men of Science...... 143

Appendix ......................... 185

INDEX . . . . . . . . . . . . . . . . . . . . . . . . 193 



\section{LECTURE I}

\section{INTERRELATIONSHIP BETWEEN METHOD OF RESEARCH AND FIELD OF INVESTIGATION}

T IS ONLY within modern times that research acI tivity has attained a social importance which is not merely incidental to the older pursuits, religion, philosophy, education, politics, war, and commerce. Its present dignified position can be traced to the recent epochal advance in the physical and biological sciences. It is clearly a phenomenon of growth. If physics should ever reach such a stage that all a student's time would, in the judgment of teachers, need to be consumed in catching up to what the past had bequeathed, then physical research and experimentation in its truest meaning would languish. The essence of research is evolution.

To the sophisticated parent the growth of a child may seem to have many prosaic and predictable elements, but to the child growth consists in the flowering of new aspirations and the fruiting of new powers. Our civilization is like the child in its vitality and outlook, and not like the complacent retrospective parent, and the process of research is itself the bursting new tissue of the social body. Presumably most of our social life must be devoted to the maintenance of the status quo; but there is another, a growing part, and no matter what the magnitude of the major portion, if the minor portion is not allowed to flourish, to appease its gluttonous appetite to repair and improve the social structure, the entire body is sick, is in truth feeling 
the lingering, or perhaps the galloping, pains of mortal illness. What constitutes the proper balance between these two portions? We have no unit in which to compare the portion of social activtity devoted to maintenance and the portion devoted to growth; but axiomatically the greater the latter, the greater the expected growth. Taking money as a sort of unit, should we for every thousand dollars spent, for example, in electrical construction, spend one hundred dollars, ten dollars, or one dollar, in electrical research? Though we cannot answer this question, we may note some matters connected with the problem.

It unfortunately seems to be true that a law of diminishing return holds for scientific research. A small amount of time and effort will at one time yield an enormous result, while in a second instance time and effort a hundred, yes, a thousand times greater, will yield but a fraction of the earlier return. Surely in terms of time spent the geometry of Euclid, the celestial mechanics of Galileo, the laws of heredity of Mendel were not stupendous. What philanthropic foundation would not give its entire resources if it could thereby assure a modern discovery as important as one of these? Such, however, cannot be assured. The insurance company has not yet been established that guarantees valuable outcomes to research. It probably never will be; but society in the aggregate may well take the risk and underwrite research here, there, and in many places, confident that in the long run the return will be munificent. It does not seem that any quantitative rule for the division of funds between maintenance and research endeavors can be adopted, but with the brilliant last century behind us any procedure niggardly to research would be 
toolish. Organized and professional research can be overdone, and moneys devoted to it poorly spent. This is to be expected, for in its very nature it is difficult to establish a mill for its accomplishment. Probably no subsidy, however great, could stimulate even Euclid, Galileo, or Mendel, to make second contributions of equal moment with their first. Does it seem sordid to think of these great steps in human evolution in terms of money? If your answer is yes, I would ask you to reflect that within a decade epochal discoveries in chemistry, medicine, and other fields have very literally been bought and paid for. Uncertain though it be, real research can be subsidized, and we, the gainers, should be thankful that it is so. Though we cannot say that subsidized research is uneconomical because no other less wasteful means of accomplishing the same result exists as a standard, we can say that much, I will even say most, of subsidized research is a chasing down blind alleys. What can we expect when we give a man, a good man, food and raiment and a slide rule or other instrument, and instruct him to fructify as man has ne'er done before? If the product is still-born, we are not unfortunate; if a monstrosity, it may take much social agonizing before it is given its lethal dose. (Bewildered Russia is today in the throes of cutting, cauterizing, and patching a monstrosity with the hope of saving its life.) And if, as is rarely the case, the product is a fine healthy mutation which can endure, we are indeed blessed. Research that is worthy the name is the most difficult task that society has differentiated out from the total field of human activity and called upon certain of its members to perform. To die in war, to dedicate one's life to a religious cause, demand great human 
virtues; but they are known virtues, whereas to be original in a worth-while manner is a mystery. It is as easy and as predictable as that one should search for and find the Holy Grail.

I have tried thus far to convey two ideas: first, that the odds that called-for research will be fruitful are greatly against us; and second, that the odds are well worth taking, for when it is successful the winnings are great. In the not distant past the great discoveries were outcomes of individual projects. Today heavily financed, wellorganized group investigations are being undertaken in many fields. The consequences of this change upon individual endeavor are by no means altogether salutary. A very real sense of incapacity must come to the young unaided Ph.D. candidate when attempting to break into the field with an "original contribution to knowledge." Let us say that he is a Latin student investigating "objectives in the study of Latin." His work, the product of a little money skimped from his meager earnings and of many weary hours spent by himself and his self-sacrificing wife, takes its place in competition with the "Classical Investigation" which is the product of an organized effort having available hundreds if not in fact thousands of dollars where he had one. This situation is truly discouraging to the individual student. To him a glimmer of light exists when the organized effort is wasteful and more or less futile.

We must not, however, look forward to brightening the outlook of the student in this manner. Probably few will deny that in terms of expense and effort the real significance of the product of individuals engaged in organ- 
ized research has been much less than that of the same individuals working alone or with but little financial aid. There are probably reasons connected with group inertia and the leveling influence of an average why this is characteristic.

Though this issue is worthy of serious and many-sided investigation by agencies sponsoring research, I wish now to consider it only from the standpoint of the graduate student attempting to make a contribution to some field of knowledge. Research foundations do not generally, at the present time, give an opportunity for the young graduate student to develop and test his powers. In brief, they are not educational institutions, but factories whose "hands" are journeymen in the matter of investigation, not apprentices. The good student apprentice, unwilling to work more than sixteen hours a day and unable to provide himself with the tools of the master craftsman, even if able to use them, is hard put to it to produce a creditable masterpiece entitling him to enter into the select guild of journeymen. Though from the student's point of view the situation is already bad and is probably growing worse, at least for the present organized research is encamped upon relatively little of the vast field appropriate to investigation. If the student is very hardy he may brave these professional researchers upon their own ground; but if, because of financial reasons, timorousness, or independence, he is not of this mood, he may search some congenial spot not yet staked out.

Though this sounds rather simple, the actual discovery of this promising spot requires the highest order of ability, so that the student is called upon to exercise at the initial 
step rather more, not less, research ability, than the established professional worker. That he not uncommonly makes a failure of it is unfortunate rather than unexpected. It may be for the best that the difficulties are great, for society is under no obligation to grant doctor's degrees to all who come, and the very rigor of the course which must be followed may be the best means of selecting and training future research workers. This is not the only conceivable means. The incorporation of instructional departments for graduate students in connection with research foundations, thereby making available to the students the equipment and the problems of the foundation, might be a fair and effective means of training and selection. Though this is in a sense done with reference to post-Ph.D. workers, it might well be considered in connection with ordinary postgraduate work. Believing, for reasons which I will expand upon in a later lecture, that the highest talent is required in selecting a field and a method of research, I wish now to consider the various fields of human activity and what constitutes investigations in each.

There have been various classifications of knowledge, from Plato and Aristotle to Jeremy Bentham, Auguste Comte, Andre Marie Ampere, Herbert Spencer, and Melvil Dewey, the author of the much reviled Dewey Decimal Library Classification System. Though these systematists of human knowledge do not agree with each other, one finds many recurring lines of cleavage in their systems. In spite of the illustrious endeavors of the past, I have the hardihood to present a classification of my own. If it has merit, it is because it throws into relief certain radical 
differences in technique of research. I, however, do not claim that the lines of cleavage which I emphasize are original with me. It is probably the fact that each has been noted by early systematists.

If we start with a cross section of time represented by the present, we can immediately note a variety of different types of human activity. We may start with any one type and relate the others to it. Let me then ask you to think of the biological sciences as the starting point. Botany, zoology, physiology, anatomy, and medicine all deal with living organisms and phenomena of growth and decay. Quite distinct from this field is that of the physical sciences. Physics, chemistry, and astronomy deal with a larger unit that is growing or changing-the universe, and a smaller unit that is invariable-the element, whether the molecule, the atom, the proton, or what not. These two fields are neighboring. The chemist at times looks upon his atom as being built up or torn down, but, generally speaking, the atom is conceived of as an invariant, not at all showing the phenomena of growth of an amoeba or a man.

Quite distinct from these two is the field of the social sciences. Economics, political economy, and law are concerned with human achievements, with the state in its entirety and in its relationship to its individual members. To think of the state as a stable organization requires thinking in terms of invariants, as is so largely done in the physical sciences; and to think of it as growing and as composed of changing and growing members requires the concepts of biology. It is quite unique, however, in its concern with human relationships. 
In addition to biological, physical, and social sciences, we must provide for another field of human life-culture. This is concerned with individual values, and is particularly expressed in art, music, literature, and religion. Of course it touches each of the other fields. Music cannot be unrelated to physics, literature and art to growth, nor religion to the social sciences and law; but the field of culture is unique in that its ends are those of the individual. 'The veriest splotch of color on a canvas has served its cultural purpose if it creates a feeling in an individual quite

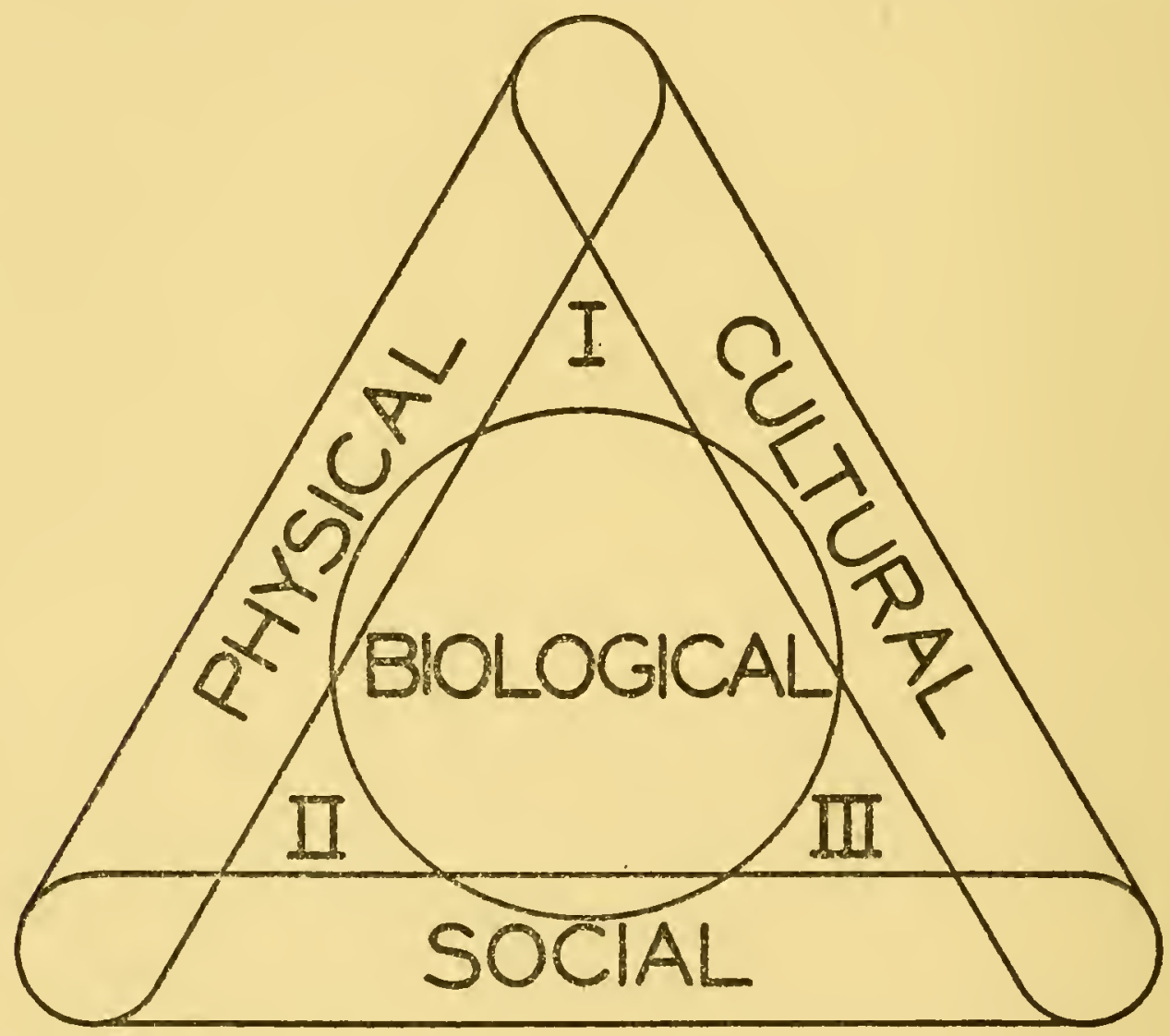

irrespective of any biological, physical, or social value inherent in it.

The accompanying chart indicates the relationships I have just mentioned. We may show by overlapping each 
section with each other that there are certain borderline activities which may be classified in either one of two ways. We may note that such human activities as mathematics, engineering, and business do not belong to a single one of the four fields indicated. They will, however, quite readily fit into the scheme. Let us characterize the spaces lettered I, II, and III service departments. Then space III is "The Adaptation of Human Talents to an End.", Psychology and commerce lie here. They are the adaptation of one's growing sensory motor equipment, drives, and capacities to social and cultural ends. Space II is "The Adaptation of Mental Concepts to an End." It is the field of applied logic, applied mathematics, and statistics. Space I is "The Adaptation of Physical Materials to an End." Herein is technology and engineering.

Even with these additions, our picture is not complete. History has been left out. To incorporate it, it is necessary to add another dimension. Think, if you will, of the chart entire as representing the present time only. Think of the triangle as being the base of a tetrahedron whose apex is in a dimension at right angles to the plane of the chart. It is the remote past. Back of biological science is a part of this tetrahedron which is its history. Back of the social sciences, back of the physical sciences, and back of each of the other regions, is the corresponding history. I would ask you to conceive at this point that the history of any one of these fields represented by the present-time cross section lies in the main, but not exclusively, back of the section in question. For example, astronomy in the physical sciences and religion in the cultural field are in the present-time chart substantially discrete, but in 
the past they were more closely related than at present. In the history of each there is much in common. Thus the tetrahedon back of the present-time surface must be thought of as an aggregate of strands and not as preserving inviolate the same lines of cleavage as those of the present time.

We have added history as a new dimension. Paralleling this difference in dimension is a difference in research technique. The historical method is not one with the experimental technique which is that of present-time investigations. It has seemed that some historians, with a desire to establish the excellence of their methods, have maintained that they engage in the scientific method just as does the physicist or the biologist. They may engage in it, but certainly not as does the experimentalist. It is more confusing than illuminating to attempt to describe a sound historical method and a sound method in physics as one and the same. The experimental technique is one in which the initial conditions, subsequent steps, and the final outcomes are all within the observation of the experimenter. Because of the completeness of control it is the technique par excellence, wherever possible. If any method is to be called "the" scientific method, it would seem that it should t.e. Historical research is more difficult and its conclusions less trustworthy. Even it, however, has a firmer foundation than does the technique investigating future conditions.

We must add to our tetrahedron a dimension opposite to that called the past, changing the figure into a hexahedron, the largest cross section of which represents the present, the longer tetrahedral portion the past, and the 
shorter the future. Thus, if we cut the solid with a plane representing the present time, the exposed face is the chart here shown. The apex of the tetrahedron which lies back of this plane represents that bit of historical evidence that deals with the most remote time. This chart is also the base of another tetrahedron which lies in front of the plane. It is the future, and the most distant future item reliably forecast is its apex. Though the detail of this picture may be greatly elaborated, for example, by greatly shortening the portions of the past and future tetrahedrons dealing with economics and lengthening those dealing with astronomy, etc., still the general picture will maintain, and we shall be left with three great divisions of human activity-that concerned with the history of a subject, that concerned with the relationships completely amenable to present observation, and that concerned with forecasting or estimation of future events.

These three divisions of human interest deal with the phenomenal world. Reality is the standard whereby each is judged. There is a field of human thought quite distinct from this. It is that of logic, pure mathematics, and a certain type of philosophy. It is a field wherein a certain set of conditions is postulated, and then the necessary consequences searched out. For example: If God is good, eternal, omnipotent, and omniscient, and if Adam fell, then-well, what then?-I will leave it to the dialecticians of the Middle Ages, who were facile in the mental gymnastics of logical deduction. Or again: If through a point exterior to a line one and only one line parallel to it can be drawn, and if certain other commonly accepted postulates hold, then the consequence is Euclid's geometry 
and immeasurably more Euclidian geometry than has yet been surmised. Both of these problems belong to the noumenal world. The rules of dialectic govern straight thinking in each, and the excellence of the process is to be judged by the rigor with which these rules of thought have been followed. This, then, is a fourth field of human investigation. It both permeates and lies outside of the hexahedron pictured. It will not be possible to investigate each of these four fields in detail, but I hope to show that each has its own peculiar hazards, methods, and standards. Every subject has a history to be investigrated by the historical method. Every still-existing subject shows relationships and is undergoing changes under our very eyes, and these are to be investigated by the experimental method. Every existing subject may be expected to have an influence upon the future, and this is to be studied by the much less tangible rules governing prognostication and probability. Finally, both independent of these three activities and in connection with each, hypotheses arise and conclusions are drawn to postulated premises, and when this is done the rules of logic should apply.

Instead of a single scientific method there are no less than four methods of research. The most pervasive is that of dialectic or logic. It finds its finest expression in human life in the wonderful pronouncements of pure mathematics. Its greatest hazard lies in the non sequitur; and other difficulties lie in the choice of non-independent or otherwise poor premises. The historian may pause in his study of a certain character and say, "If this character was a Jesuit, would he have done this thing?" The experimentalist may pause and ask, "If temperature influ- 
enced the reaction, would it account for this discrepancy?" And the prognosticator may inquire, "If condition $A$, assumed to hold in the future, does not hold, but is modified in a particular manner, then what is the consequence?" We see that the process of logical deduction is a common attendant of each of the other types of investigation. It is an indispensable adjunct guiding, as it were, mental exploration in the process of argument. In short, poor logic can vitiate any method-but good logic alone is insufficient for any except the dialectic method.

Second in definiteness and rigor is the experimental method; third, the historical; and last, the method of future estimation.

A person may become so interested in the history of a subject that it attains value to him on its own account, but more generally the value of history lies in its implications for the present and the future. One may become so interested in a particular experiment that it attains value on its own account, but more generally the value of it also lies in its implications for the future. From this point of view both historical and experimental investigations are initial steps in the investigation of future events. Surely there is no more fascinating investigation than that of the future, providing it is fruitful. But no intrinsic fascination of a subject can compensate for continued failure in investigation and make it worth while to pursue the subject. The question of individual survival of bodily death is perhaps per se the most interesting of all questions. Should we all therefore investigate it? Certainly not, for the promise of a fruitful investigation is very nearly nil. One hundred per cent of importance, times a magnitude either 
zero or in its neighborhood for probability of successful outcome, yields a negligibly small product. All future events hold the promise of weal or woe to individuals expecting to live on into the future, but it is the part of wisdom as well as of self-satisfaction to attempt to estimate only such as it is fairly reasonable to think can be measured. This is so restricting a condition that the estimation of the future represents but a small proportion of scientific endeavor. We may expect it to represent an everincreasing proportion as the means of estimation are improved and the data prerequisite to it are extended. I shall return to this question in connection with an investigation in the field of social science in my next lecture, but now I wish to consider the historical and experimental types of research.

To say that one is engaged in historical research does not define his activity, because the historian always comes to his task, or at least always should come, with a motive. The words of Darwin as to what a scientist should observe are equally applicable to what a historian should note. Darwin said: 1

About 30 years ago there was much talk that geologists ought only to observe and not theorize, and I well remember some one saying that at this rate a man might as well go into a gravel pit and count the pebbles and describe the colors. How odd it is that anyone should not see that all observation must be for or against some view if it is to be of any service.

Let us say that the historian's present purpose is to write a history of art ten thousand years ago. The most original documents that he finds, the stones of that age that he over-

${ }^{1}$ Darwin, Francis. More Letters of Charles Darwin. 1903. 
turns, tell him perchance of war, of architecture, of commerce, of culinary habits, etc., but not, directly, a word of art, except possibly with one exception. He finds one little splotch of black which might be interpreted as a face on a small portion of earthenware which might have been a vase, in the ruins of a building which might have been a temple. He makes a series of deductions from these bits of evidence which are the most reasonable which human mind can make. If we are to believe anything as to the art of the period, we should believe what he states. We cannot prove him wrong by showing that some other art situation is more reasonable. Under these conditions, is he a good historian, and should we believe him? We see that we are confronted with the same issue as in the estimation of future events. A probability should be attached to the past event as described. If the historian writes, "The people of that time decorated the vases used in their temples with crude human figures done in black," we might express the probability of this being a true statement somewhat as follows:

The probability, let us say, that the black splotch was made by human hands is 80 in 100 .

The probability that the black splotch was part of a human figure is 60 in 100.

The probability that the crudity of the black splotch was due to the originator of it and not to abrasion since is 75 in 100 .

The probability that the original pigment was black and has not been changed by time is 65 in 100 .

The probability that the fragment found was part of a vase is 60 in 100 . 
The probability that the fragment found was part of an article used in the building whose ruins were excavated is 55 in 100.

The probability that the ruins excavated were those of a temple is 65 in 100.

The probability that the earthenware and the ruins belong to the period under discussion is 80 in 100 .

Taking all of these things into consideration, the net probability that the statement is true, which is the product of these various probabilities, is but 4 in 100 , or but one chance in 25. Clearly we should not believe the statement, though we cannot formulate a substitute statement covering all of these facts which is more reasonable. In the illustration, the probabilities for each of the facts are listed. In actuality these would not be known, except in the most general way. The example given points out the unreliability of statements of relationship and of historical sequence, which are both things that the historian very commonly does, and perhaps should do, for the separate distinct facts are often of little interest. Certain writers maintain that it is the prime function of the historian to give the facts and not draw inferences. This, however, would seem to be an untenable position, for no writer can take the space to record all the possible facts. Just as pointed out by Darwin in the case of the scientific observer, he must select and give the pertinent ones only, but the very selection of these has involved a judgment, a drawing of an inference as to relevance, upon the part of the historian.

The historian must write with a motive; in one sense, this is to say, with a bias. There is a bias in his point of 
view, due to the fact that he lives in a certain time, in a certain place, and has been reared in a certain manner; and there is bias in his immediate interest. History should be written and read with a full knowledge of this. It is of great value for a twentieth-century chemist to interpret seventeenth-century alchemy as the beginnings of chemistry. We have profited by his bias, his twentieth-century understanding, and his realization that alchemy was, in one important sense, not religion or magic, but science. Certainly his account is not timeless; it is a twentieth-century account and not a seventeenth-century nor a twenty-fourthcentury recital. History must be rewritten for every generation, and readers of history should get a value from what they read inherent in the channel through which it comes to them.

Pertinence and bias may be differentiated by the writer, but not always by the reader. Suppose a typical honest Democrat writes an account of the United States oil reserves, and in his endeavor not to be biased selects his facts, places his emphasis, and moderates his utterances so that readers in general cannot tell whether the writer is a $\mathrm{Re}$ publican or a Democrat. The author believes that he has presented things in an unbiased manner, as also do Democratic and Republican readers-but probably not, say, a Socialist. The Socialist finds that pertinent facts have been omitted, that a capitalist emphasis runs throughout, etc. In short, the writer and the article are biased from the Socialist-non-Socialist point of view, but quite unbiased from the Democrat-Republican point of view. All that we can accurately mean when we say that a presentation is unbiased is that with reference to certain issues it gives a 
fair and balanced picture as judged by informed, impersonal, and competent critics.

It is commonly recognized that there is an obligation upon the historian to give a picture as little biased as possible. There are certainly two pre-requisites to the accomplishment of this. First, the author must be possessed of a wide culture and a deep understanding of his prospective readers, so that he knows the issues with reference to which his treatment must be unbiased; and second, he must be dominated by the will to be unbiased. The great Leopold von Ranke possessed these traits to a high degree. Even the historian of a very limited field should maintain a point of perspective which is beyond that field. The chemist writing upon alchemy should appreciate the stimulus of religion, the mystery of magic, the gullibility of peoples, the hazards of witchcraft, etc., or he cannot write truly of the strictly chemical developments in alchemy. Who can understand and describe Galileo's denial that the earth rotates, who only understands physics?

A Moseley was a great physicist in his early twenties, a Raphael a great artist in his teens, and a Mozart a great musician before then; but who has had the maturity, the breadth of view, the even temper, to be a great historian at so early an age? One is not unbiased because he is ignorant of his bias. The least biased man is the one who knows what bias is, from a first, a second, a third, and still other points of view, and then determinedly leans neither to the left nor the right, backward nor yet forward. What may be called leaning forward is the most insidious of all. As examples: Christianity is the goal of mankind, so note how the world moves toward the goal; democracy is good, 
so I will interpret everything in terms of a good democracy; the world is growing better, and I see improvement in all things; and so on. Of course, if the world does lean forward, these things should not be called bias; but certain it is that this leaning forward attitude is taken time and again with no apparent justification. It is well to be skeptical of it, for we know too little as to what is forward and what backward to place uncritical confidence in anyone's assertion that it lies straight ahead.

Most of what has been said applies to the historiographer, but much concerns likewise the historical investigator. The most important function that he exercises is that of selection of material. When a promising original document comes to hand, very great skill and judgment is called for in its internal and external criticism and evaluation, as has been so clearly pointed out by Bernheim. ${ }^{2}$ Possibly the talents involved in this process are even of a higher order than those involved in the selection of material. When dealing with periods of history in which sources are few, little judgment is called for in selection of matter, for all or nearly all must be studied; but a study of the later periods, wherein sources are innumerable, presents a different situation. The first task and probably the one calling for the highest ability is that of selection of sources. The writer upon the history of traffic regulation in the United States has his greatest task in selecting his sources and in detecting original and imitative procedures. He must be a genuine detective. Starting with a condition found to exist in a certain year he must follow it back through the 1908.

${ }^{2}$ Bernheim, E. Lehrbuch der historischen Methode. 1894, 1903, 
mass of antecedent recorded fact to an earlier source. The historian of this subject, or of any other, is not attempting to present a photograph of the past; rather, he is turning the spotlight upon one thread only, that weaves and divides and continues on and on into the past. Imagine a complex tapestry with a yellow cord appearing upon the righthand margin. Taking a position at the right hand, and without moving, attempt to trace this back to the left. It is now a part of a larger design, and now a lone thread, now not visible at all, but buried beneath the reds and blues which dominate the field. It ceases to be a single strand, and is divided, not once but many times, and is finally altogether lost to the eye, though the separate strands may still be threading their way farther and farther to the left. The tracing of this cord is history, partaking not at all of photography with its even toning and its non-revelant detail. The tapestry falls short as a picture of time, because it ends and is completed at the right-hand margin. The yellow strand so carefully traced abruptly terminates at the right. If this strand were living and growing on and on into the right, then our picture would be complete. Our chief interest in tracing it would be in the light it would give us as to its future growth. In this important aspect the growth of coral provides us with a truer picture. Its past is unchangeable and very dead, just its upper surface living, but that upper surface and the future is built upon the dead past. If this were not so, what interest as living and planning individuals would a study of the dead have for us?

We may point a difference here between history and literature. In history, the deadness of time's puppets, the 
rigidity of their bequeathal, fairly stuns us with a sense of verity; whereas in literature the vitality, the genuineness and immediate reality of their passions, and the freedom in their powers of choice make them one with us-untrustworthily one with us. The historical novel and the novel-like history do not preserve the distinction here made, but surely it is a distinction that cannot escape the historical investigator.

If we accept an understanding of the present and a forewarning of the future as the most important purposes of history, we can readily believe that we shall always be enriched by delving into the history of a subject. For this purpose the history of the immediate past is generally of more value than that of the remote past, but there are exceptions. If we thoroughly know the quarter-inch of coral below the growing surface, we know its present and prospective future as well as if we know the shape and structure of the entire coral column. Only when remote history aids in the understanding of less remote and that, in turn, in the understanding of still less remote, does it all contribute to the main purpose. History not written to give literary pleasure but to contribute to our understanding of the present and future should be judged by the extent to which each item in it supplements and develops subsequent items down to those of the living moment.

Nearly every experimental doctor's dissertation contains an historical introduction. It should be judged by the standard of relevancy, and when so judged it is commonly found that paragraph upon paragraph of trite and tiresome matter can be omitted. If the novitiate in historical research will bear in mind that he is aiming to increase the 
understanding of the future; that he is investigating one definite field; that he is tracing a thread, not making a photograph; that antecedent to original investigation along a line he should know all the important moot issues connected therewith; that he is morally obligated to present complete evidence or a fair sampling on both sides of these issues; that the probability of correct statement of related or sequential events is less than of the events singly; and that principles of temporal order, originality, independence, and creditability of evidence exist ${ }^{3}$ and are to be followed, he will be headed toward a scientific method in history.

I have no objection to calling the method outlined the scientific method in history, but I would agree with Pasquale Villari, W. S. Jevons, Henry Sidgwick, and other historians that it is not the scientific method of the physical or biological sciences.

Experimental research does not deal with dead and unique material. Napoleon is dead and Napoleon was unique. No similar man under similar conditions can be investigated again. Every experimental set-up made in the past can be made again; thus it is not unique. By repetition it can be made living if desired. Now I know that logically this statement is unsound, but practically it is defensible. A person observes the length of the meter bar in Washington, under standard conditions today. Tomorrow the gravitational systems of the universe are different. The bar has been changed by the earlier observation of it. The observer is older, and all of these things make an exact repetition of the first experiment impossible. Logically

${ }^{3}$ See for example, Langlois, Charles V. and Seignebos, Charles. Introduction to the Study of History. 1898, 1912, 1925. 
we can never secure two independent observations of the same thing. Logically we can never secure a population which is a homogeneous sample. Keynes has criticized statistical procedure because of this point. Why does he not go farther and criticize all of physical and biological science for the same reason? He should logically, as, from the standpoint of the philosopher or mathematician, whose concepts are exact, there is no possibility in the world we live in of exact experimental verification of anything. It is well to recognize that, in exact terms, no two things are samples of the same thing, and that no two experiments are the same. The recognition of this will lead the experimenter to make experiments as nearly the same as possible, and will lead him to investigate how well he has succeeded. In the physical sciences such investigation will quite universally be reassuring, in that there will be found to be a great agreement between conditions, as contrasted with the disagreement. In two experiments the gravitational field may vary by one part in a billion, the temperature by one part in one hundred thousand, the present accuracy of observation in a certain instrument by one part in a significant range of one hundred thousand. Physical science, based upon the logical premise of similarity in experimental conditions, need not greatly worry as to the practical identity of such investigations. In the biological sciences such high similarity in conditions is not obtainable. This colony of white rats varies from an earlier colony in certain small but unknown hereditary elements-in certain small but not exactly measured food, temperature, light, and exercise elements, etc. But whereas in the physical experiment an error of one-tenth of one per cent would prob- 
ably vitiate the investigation, in the biological study a 10 per cent error may not completely cloud the effect in question, so that again the logical weakness of the technique does not prevent its yielding an important practical outcome. In the social sciences the situation is less satisfactory. Under a first condition, increase in the price of beef was followed by an increase in the price of pork. Under a second seemingly similar condition, the price of beef increases. Will this again be followed by an increase in the price of pork? The conclusion is hazardous because of the difficulty of establishing that the elements of similarity are greater in number and more potent than the elements of dissimilarity. However, it is along this line that we are to look for progress in research in the social sciences.

One issue common to all experimental research and not found in dialectic or historical research is the establishment of approximate or at least sufficient similarity in successive trials or samplings. The issue is clear-cut, and the method is that of successive attempts to secure similar conditions coupled with a measuring of the failure of such attempts. In a certain experiment connected with the rate of growth of wheat, a certain temperature is to be maintained. Now it is nearly universal that our instruments of measurement are more precise than our mechanisms of production. Try cur best to maintain $40^{\circ} \mathrm{C}$., we shall not succeed within the limits that we are able to measure. Accordingly, we can measure our failure, even though we cannot correct it. We can commonly secure an estimate of our degree of success in maintaining a constant condition, in securing a comparable sample, or in employing the same technique. This process of verification of conditions of experiment is an 
integral part of the scientific method in experimental research. When measurable discrepancies are found, their investigation leads to a knowledge of their general order of magnitude. Here in connection with experimental science, we find for the first time the concept of probable error attaching to a result and expressed in terms of numerical magnitude, or expressed in numerical terms of probability.

To gain a hearing, the doctor who introduces a new antitoxin must present data upon the probability of efficacy - the percentage of immunity, or the proportion of subjects treated who have been demonstrably benefited. The figures given by the doctor are a statement of what has just been found to hold in the case of a certain sample, but they are also a promise of what may be expected in the future. This concept of future probability is intimately connected with the experimental procedure. Sometimes the probability is so high as to amount to practical certainty, as, for example, that water at sea-level will boil at a temperature between $99.5^{\circ}$ and $100.5^{\circ} \mathrm{C}$. Thus, if we are boiling eggs scientifically, we take the temperature of the boiling water as $100^{\circ}$ and do not concern ourselves with the possibility of its varying from this. But scientifically we should only show this lack of concern as a result of having earlier established the high probability that the boiling point is between these narrow temperature limits. Professor A. A. Michelson secured a measure of the velocity of light to a large number of figures, but it took him more than another year of arduous work to establish that his earlier answer was correct to within narrow limits. It must not be forgotten that this second year's work was as integral a part of the 
scientific method as the first. It is not sufficient to "know" a result; it is necessary to know that we know it.

The experimental is the only scientific method that yields this knowledge with any degree of certainty that one demands and is willing to pay for in time and effort. If nothing is known about a certain individual except that he wrote a book, now lost, in 1640, then his date of birth is known within limits. In other words, an appreciable probable error is to be attached to any date of birth given, and it may very well be that no amount of historical research can change this. The certainty of this fact cannot be improved by the utilization of the historical or any other method. If a physicist wishes to know the rate of transmission of sound through a certain medium he can find it once, twice, or any number of times, and secure an answer with the degree of accuracy that he may set and be willing to devote the time to secure.

In Professor John Dewey's analysis of a complete act of thought there is, first, a felt difficulty; second, a definition or specific location of the issue; third, a tentative mental solution; fourth, a mental elaboration of this tentative solution to see if it is thoroughly sound, resulting perhaps in its discardance and the adoption of a second tentative solutionthe process is continued until a solution is obtained which mentally seems adequate; and fifth, this is then tried out in actuality and, if it succeeds, it is accepted as the solution to the problem. If it does not succeed, it results in a new or broader felt difficulty, and the process is repeated until a solution is reached mentally which is adequate when tried out. This results in a sense of conviction, and the problem is solved. I would add one final step. It is not empha- 
sized by Dr. Dewey in his book How We Think. After the solution has been found to work there is a mental looking forward, the general purpose of which is to appraise this new solution in the light of possible future needs. I do not think the act of thought is complete without this forward look. If we consider all these steps, we see that there is one step, that of trying out or, as Dr. Dewey expresses it, that of experimental verification, which is possible only in the experimental method. In short, the experimental method is the only one that can parallel in its entirety what we, with Dewey, may call a complete act of thought. Where this is possible, it is the ultimate method. Were one to determine accurately the straight-line distance from Chicago to New York, and ascertain that the probable error of this measurement was one inch, would he then ask travelers what they considered the distance to be, or would he use the historical method and find and trust what earlier people had said the distance was? No, within the limits of his error his determination is ultimate. It is to be replaced only by a determination yielding a still smaller probable error. If a topic can be investigated by the experimental method there is no excuse except that of less effort and expense for using another method. The field for experimental research is as broad as it can operate in, and just as soon as it enters a field it drives out the historical and questionnaire methods, except as preliminary methods. There is no possibility that these will be driven from the face of the earth, but they have been driven from much of physics, chemistry, astronomy, and engineering, from considerable of geology, botany, zoology, psychology, and medicine, from a little of education, economics, sociology, 
and business, and from practically none of law, literature, and religion.

It has been implied that the experimental method applies to that field of life, past, present, and future, represented by the present-time chart. The present time must be interpreted as including more than the present instant. We happily are endowed with memories. If it were not so the experimental technique would not be possible. When one lays down his experimental conditions, conducts the successive steps, and notes the outcome, he has at the end the entire experiment before him. If he has forgotten any of it he can do it over and refresh his memory. Memory is a sine qua non of research. It can be subdivided into memory for the relevant items, for the possibly relevant, and for the irrelevant. The redintegrative mind, that remembers everything irrespective of its value, is charming as a drawing-room phenomenon, but not of much use in the research laboratory.

In certain fields of investigation the particular items that need to be remembered are so well defined that there is little likelihood of forgetting them. Also in such cases there is usually little tax upon the memory. In another type of investigation the relevancy of certain items does not appear at the time the item is first met, but much later. If, at this later time, the item has been forgotten, the investigator is seriously the loser. Darwin studying seashells and body structures was called upon to remember a tremendous number of characteristics of each of the various species he examined, and hold these facts in mind for years-some of them quite clearly for not less than twenty years. With all these in his mind's eye, he gradually came to see that certain fea- 
tures were significant in relating species with species. At the end of his investigation, he could drop from memory those items which were not relevant; but through the long years of study up to this point he did not dare forget any item which might sometime prove relevant. In a study such as his it required genius to select well the possibly relevant items and native capacity together with serious effort to remember them. The systematic and classificatory sciencesbotany, zoology, geology-impose a tax upon the memory not second even to that of history. A study of the type in question has much in common with an historical study, since the relationships develop and come to light after the evidence is in. If pertinent evidence has been forgotten, the final relationship deduced is but partial, or it is not as well established as might be. This experimental type of study differs from that of history in that the basic items of information are not unique. This was strikingly called to my attention by Dr. Calvin B. Bridges, the geneticist, in connection with the study of the fruit fly. As I watched him at work he noted an odd fly in a certain colony. $\mathrm{He}$ said it was a mutation, and brushed it aside without prolonged study. In response to my expression of surprise, he informed me that it would arise again, probably within the next ten thousand flies studied, as mutations always recur.

The process of forgetting non-relevant facts of a plant, an animal, or a geological formation, is always an intrinsic part of the activity of a scientist. The mind, merely as a receptor of sensory impressions, is as prone to remember the irrelevant as the relevant. The geologist viewing a stratified formation on a near mountain, partly in the shadow of a cloud, is rather more impressed merely as a sensory 
experience with the outlines of the shadow than with the evidence of differences in stratification. He should remember the latter, while he should forget the shadow. It is within his power to choose what should be remembered and what should not. As soon as we pass beyond the field of such immediate memory as is affected by positive and negative afterimages, those things are remembered, as so clearly shown by Professor R. S. Woodworth, that have been mentally traced in the mind. The shadow and the less pronounced lines of cleavage are within the field of vision of the geologist, and he by an act upon his part mentally traces the stratifications. Very shortly they alone are in the storehouse of memory. The shadow has gone forever. This act of tracing a relevant aspect of an experience is in the experienced scientist habitual, but the building up of the habit has taken time and has been the result of a conscious process. The essence of the process lies in that step of the complete act of thought described as the forward look. The first time the novitiate in geology remembered a stratification, it was because in thinking of his future needs in the light of his geological interest he decided that it was a fact that he would probably, or at least might, need.

Surely there are individual differences in native mental capacity, but when one analyzes the steps of memory inrolved in a complete scientific type of investigation, he sees that they are largely subject to conscious control. First there is the location of an interest-I am a geologist, not a botanist; second, there is the becoming familiar with the field-the study of geology, not botany; third, my future needs, my looks ahead, involve rocks and fossils, not trees and leaves-so that, fourth, from the total of my sensory 
experiences I will select and trace in the mind only those of geological import. Surely, step by step, these are matters subject to conscious control. Now, if this is so, it establishes the distinction between two sciences such as botany and geology as a phenomenon of nurture, not of human nature. It is in differences existing in the outer world that we seek to differentiate between botany and zoology, not in innate differences in the human mind. These differences which the world about us imposes are basic in our lives, and not to be swept aside. They probably make or modify a majority of the differences we are aware of.

However, they do not make them all. Within our own structure there are physical and mental differences which result in the same external experiences being different to different individuals. We may say that the difference in a mountain slope seen by a botanist and a geologist is due to an acquired difference between the two, but the difference in the mountain seen by the man of normal vision and one color-blind is not. It is even probable that the difference seen by a natural scientist and an artist is not. A little study shows that many of the important differences between the various fields of life can be associated with differences which are innate in the mental structures of the participants in these different fields. The severity of the memory tax placed upon the geologist by the study of geology is perhaps quite comparable to that placed upon the botanist by the study of botany, while the difference in the two demands is a consequence of training. On the other hand, a different type of memory demand and a greatly different severity in demand is made by history on the one hand and, let us say, mathematics on the other. A man endowed by original 
nature with a poor memory would find it hard to succeed as a systematic botanist or geologist, but he might do well as a mathematician.

Of all the possible distinctions that can be drawn between different fields of human activity, those connected with differences in the original natures of successful participants are probably the most vital to the student while in the process of choosing a vocation. We have already considered certain of the special demands upon the historian. Though in each of the activities represented by the present-time chart before us every part of a man's nature is called into exercise, there is a great difference in the insistence of the call. The demands upon verbal facility, word knowledge, and fluency are much less in the physical and biological than in the social sciences. The demands upon mathematical ability are much greater in the physical sciences than in art, religion, and literature. The demands upon keen observation and accurate mental manipulation of spatial relationships is very great in the biological and other experimental sciences. The emotional tone that attaches to experience must be high in art, music, and religion. A sense of satisfaction in social contacts eases the activities of the teacher, salesman, preacher, and social worker. We unhappily have no final criterion for determining if the mental differences just mentioned are in large part due to differences in original nature or not. Evidence can be cited which is highly indicative that each is deeply rooted in genetic structure.

This lecture has been concerned with delimiting the fields of science, and has dealt in some detail with historical research. My next lecture will deal with the future and the field wherein human opinion is dominant. 


\section{LECTURE II}

\section{THE ROLE OF JUDGMENT IN "OBJECTIVE MEASUREMENT"}

$A^{\text {NTICIPATION is a characteristic of youth, retro- }}$ 1 spection of age. Forecasting is the youngest activity we are aiming to develop with scientific precision, and history is perhaps the oldest. We should make no invidious comparisons between these two, for each supplements the other, and each fills a very real human need. The anticipation of youth is chimerical unless moderated with the judgment that a study of history can give, and a sojourn in the past is a fantasy, and, however delightful, practically quite futile unless directed to the need of the future. If the past bordered upon the future the only approach to the future would be through a study of the past. We have, however, interposed between the two the present; and, as mentioned in my earlier lecture, due to the happy faculty of memory the present should be thought of as more than a point in time, as an actual expanse wherein resides the experimental method. Our study of the future should therefore draw heavily upon history for background, for perspective, for knowledge of tendencies to date; and it should draw upon the experimental method for the establishment of relationships and sequences of cause and effect where earlier historical and experimental study indicate the probability of the same relationship or sequence holding in the future.

It must devolve upon the judgment to say that the conditions leading to the as yet unknown future outcome are 
similar to those of some historical situation or some just terminated experimental situation. This act of human judgment can no more be avoided than the act of judgment in the so-called exact sciences which concludes that two present things are samples of the same thing, or that an experimental situation is so similar to an earlier one as to permit its being used for verification of the finding of the earlier one. The experimentalist unconsciously affected by the outcome of his experiment does not ordinarily feel that a very heavy tax has been made upon his judgment when he pronounces two experimental situations as similar.

Let us say that a chemist is investigating the flashing point, under certain defined conditions, of a particular oil. He performs the experiment once with a certain outcome, which I will designate by the letter A. He performs it a second time, keeping some five conditions, which are known to be important, the same as before-there being, of course, an untold number of other presumably trivial things which are not the same-and these five are of course not absolutely the same. The outcome of the second experiment is $A^{\prime}$, and $A$ and $A^{\prime}$ are the same within very narrow limits. The chemist's report is that the experimental conditions of the second experiment were the same as in the first, and this report presumably is entirely independent of the similarity of outcomes. After the experiment is over he is willing to stake his reputation upon the proposition that the experimental conditions were similar. Would he do so, had the final reading of the experiment, giving the outcome $A^{\prime}$, been made by a second person, and the result sealed for much later publication? Perhaps he would have done so under these conditions, but the point is that these 
are now the conditions of the prophet and not those of the mere experimentalist. They are conditions which throw into high light the responsibility imposed upon the judgment of the investigator of the future.

Whereas the ordinary experimenter can perform and reperform an experiment, including the initial set-up, the subsequent steps, and the discovered outcome, the person who investigates the future cannot. $\mathrm{He}$ is dealing with unique material, just as is the historian. This particular set-up, no matter how many details seem similar to earlier situations, is the only one that is available with which to estimate the particular bit of the future just ahead. Since no experimental verification of similarity of conditions is possible, an act of judgment of the prophet is the only means of meeting the issue. No rational scheme for estimating the course of the stock market, the success of political parties, or the future happiness of married couples can be devised which is independent of an act of judgment. Even where a thorough historical survey and an extensive antecedent experiment have been made, the question always arises: Are the conditions of the future essentially the same as those the outcome of which is known as a result of the historical and experimental study? Clearly, if this question is answered in the affirmative, there must always remain some probability that the answer is in error. In the case of most astronomical forecasts, this probability is surely very small. However, even here, if newspaper reports are to be trusted, twentiethcentury eclipses do occur at times measurably different from those predicted. It has come to my attention that seismologists make errors in their weather forecasts, and I have been told that prognostications of adult mental level from 
the test performances of childhood have been astray by one hundred per cent, and I can assure you of the sincerity of my informant. Though I grant the existence of an error, I do not trust my informant's estimate of its size. It is in fact something of a mental tax to think of intelligence quotients having one hundred per cent error.

Since there is never an exception to this fact of error of estimate, or, since there is always a probability of mistake when surmising future events, I could continue giving illustrations indefinitely. I merely wish to show that in the estimation of future facts there is always an act of judgment and always a probability of error.

In addition to the estimation of events, much of life is spent in determining, or, if you will, estimating, mental values. These always have a future reference, so they belong to the field under discussion. I know of no phase of human life of greater import and of greater dependence upon a sound determination of future values than that of curriculum construction. The inclusion of any item in a certain curriculum is a result of the estimate of some person or some group that knowledge of it will have a value in the later lives of the pursuers of the curriculum. When we consider the importance in our lives and in those of our children of elementary, high-school and college curricula, we cannot in sense and reason turn away from this problem of future values with a sneer that it is outside of the realm of science. It certainly is not outside the realm, but if it were, it would be so much the worse for science. Light may be thrown upon it by the best exercise of historical investigation, by innumerable facts revealed by experimental method, and by checks upon the outcomes of the soundest 
forecasts, put into practice, of earlier years. There is no step in the complete act of thought, including that of experimental verification, that should not be involved in the attack upon this problem.

The fact that many of the values that lie in a curriculum are values because fellow-citizens so consider them increases the difficulty of the problem, making it necessary to judge the outcomes by agreement with human judgments of values rather than by agreement with external objective facts, but it does not otherwise change the technique of investigation. If $100,000,000$ people in the United States think it valuable to know that Columbus discovered America in 1492, then to a prospective citizen of the United States, one who is to live and talk the same language with such people and their children, it is valuable to know this fact. In a case like this, the scientific builder of a curriculum is called upon to ascertain what "the people" think about the importance of Columbus and 1492, just as the physicist is called upon to ascertain what God thinks about gravity. God thinks that under certain conditions the rate of acceleration should be constant, and I believe $\mathrm{He}$ does not change His mind. What God thinks is the physicist's standard.

Though "the people" do, over long periods of time, change their minds, no more ultimate standard, failing experimental evidence not now available, is at hand, so that the builder of a curriculum is obligated to know this social standard. Some things are matters of evidence, and no social judgment to the contrary is entitled to any weight - the rate of acceleration of a falling body is of this sort. Some things are matters of human belief, and no experimental evidence affects them-such is the meaning of 
words. Surely in a world wherein words play the part they do with us, there must be rules of procedure for an investigation connected with them. There are, but the rules are not as incisive as those of physical science.

Because the serious investigator of human values has a more difficult task than the natural scientist, he is not outside of the pale of science. Rather he is more deeply involved in it. The intelligent putting of the question "What is the rate, or rate of change, of acceleration of falling bodies?" finds an invariable response. The best conceivable way of ascertaining the meaning of a word, of, let us say, the word "virtue," will yield a variable response, and a mean properly weighted tendency of responses must be found. This second problem is intrinsically more difficult than the first. We cannot say that because of the greater difficulty workers with this second problem are better scientists than workers with the first; for the excellence of scientific activity is to be judged by the rigor with which the scientific method has been adapted to the problem in hand, but we certainly can say that there is nothing in the problems which makes one a more scientific problem than the other.

The meaning of a word is its significance when found in future situations: thus determining its meaning is a problem in forecasting. We have in this field of meaning all the difficulties piled up together. Forecasting clearly has greater hazards than historical or experimental investigation. As a standard, the consensus of human opinion is clearly more variable and difficult to ascertain exactly than a standard which is a law of inanimate nature. The intrinsic complexity of the concept of a word like "virtue," even 
in the best consensus of opinion sense is great compared with the complexity of most of the terms distinctive of physical phenomena. Truly all the hard problems have been thrown together in this field of value-the future meaning of human expressions.

The instrument for attacking this problem is the questionnaire. Is this not a superb anticlimax? Here I have described the most difficult field of research, and that possibly the most pregnant for human welfare, and propose for its handling the weakest device that has ever obtruded its prying and at times discourteous self into the respectable field of science. Though I must admit all of this, I would ask how in the realm of mental values is any approach conceivable except that which ascertains what the valuing agents assign to be the values?

Occasionally a field of human activity undergoes a transition, and changes from one in which the issues are purely mental to one in which they are objective in the scientific sense. Such was the case when cosmology ceased to be religion and became astronomy. When this took place an entire set of issues earlier to be answered by human judgment disappeared in thin air, and new issues, to be solved by scientific observation, took their place. No thinking person will deny that this was a great social advance. Medicine is undergoing the same transition, business is influenced, and education is touched. We should encourage the movement, but meanwhile it would be foolish to deny that there are wide, important, intimate, and enjoyable phases of our lives in which mental appraisals rule. Does one listen to "Lead Kindly Light" because of considerations of candlepower? Are teachers hired because they have been found 
to stand high on a yardstick of honesty, or at $100^{\circ}$ temperature in industry, or fill a scant peck of trouble? There is probably not a university professor in the country today who does not hold his position as the result of one or more human judgments or misjudgments, as the case may be.

This matter of misjudgment is important. All that we mean by it is that more and better judgments disagree with it. A first university professor is a better one than a second if in the long run those, especially in responsible positions, appraising university professors so think. When there is disagreement, the minority, again giving proper weight to the various judgments concerned, is in error. In this field of human values there is no more ultimate definition of error. Excellence in the matter of professors is that which in the long run is believed to be excellence. Belief changes with change in era, but excellence for any given era is to be judged by the belief of that time. Obviously it cannot be judged by the standards of an era not yet in existence. An Einstein, if guilty of the same extremities of thought as today, would probably lose his position to a Euclid in early Grecian days, and rightly so: he would have been a poorer professor at that time.

It has been intimated that judgments of human values should be weighted in accordance with the importance for the matter in hand of the one judging. The one judging gains his importance because of the judgments of still others judging him, and the process continues ad infinitum. In judging the excellence of university professors, every Tom, Dick, and Harry should not have equal weight with, say, university presidents, colleagues, and national associates in the same field. Tom, Dick, and Harry would not them- 
selves wish that their judgments be given equal weight with experts in the field in question.

Let us suppose that we ask one hundred persons, chosen at random throughout the United States, for advice as to the best entomologist. Each of the hundred may say, "I am poorly informed upon the matter of entomologists. Ask So-and-So." The one hundred people to whom they have delegated the task will probably be office superiors: gang bosses, occasionally teachers, preachers, doctors, and locally known men of affairs. Ask these one hundred, and they will delegate the task to college graduates, scientists, teachers, etc. You may continue the process as long as you wish, being confident that upon every step you are getting more and more intelligent and trustworthy judgments. The final group is representative of individuals whose judgments should be heavily weighted as compared with those of the first group, and it is to be noted that this heavy weighting has come out of the judgments of the first group itself. Without further qualification, I wish the expression "consensus of opinion" to be understood to be some weighted consensus as just indicated.

A weighting somewhat of this general character was in the minds of the framers of the Constitution of these United States in connection with the election of the President. A return to a weighted judgment in selecting experts even for the highest federal administrative office would be in harmony with other social practice; scientific associates are more potent in establishing the merit of scientists than people in general; literary producers are more potent in establishing the excellence of literary production than readers of literature, and they in turn more potent than non-read- 
ers. And so it goes throughout the entire field of human thought.

An idea as to what is the consensus of opinion may be gotten in many ways, but some systematic procedure is highly desirable if a scientific issue hinges upon the outcome. A carefully worded questionnaire given verbally to a goodly sample of competent judges by friends in such a manner that serious answers are given just as a matter of courtesy, would probably yield as nearly fair results as could be expected. These conditions are seldom if ever obtainable; and, still more serious, it is generally not known how fair are the conditions which are obtained. The various issues affecting questionnaires in general can well be discussed in connection with a particular questionnaire, of which I am guilty.

The purpose of this questionnaire was to determine what scientists consider the place of questionnaires and also what is appropriate conduct in the matter of giving credit for aid received in research work. Upon several occasions in connection with my own writing I have been uncertain whether recognition for something should or should not be given, and upon more than one occasion I have felt that colleagues have erred in this matter in giving me credit. I can recall situations wherein my name has not been mentioned where I think it should, and situations where it has been mentioned where I think it was uncalled for. Finally the matter reached such importance in courses upon research taken by students writing theses, that I felt justified in imposing upon my colleagues at Stanford University for their opinions. Before presenting certain results of this questionnaire, I wish to emphasize that what constitutes appropriate ac- 
knowledgment of aid received is what fellow scientists so think. No set of instruments, no well-fed rats, no armchair speculation, can give us the final answer to this question. It is a question of human appraisal, and whatever is the consensus of opinion is the ultimate answer. I did not therefore use a questionnaire where some other method was possible. The questionnaire is as follows:

\section{ACKNOWLEDGMENT OF AID IN RESEARCH WORK}

\section{Dear Sir:}

Stanford University, May 25, 1928

This is a questionnaire dealing with the granting of recognition for help received. I am sending it to professors at Stanford in the various fields of science. Even though you consider all questionnaires unmitigated nuisances, or are especially busy, I still hope you may see fit to answer Question (a).

If you think that beginning research workers might profit by evidence as to what scientists consider appropriate acts of courtesy in giving recognition to colleagues and to others, kindly run through the questionnaire rapidly. I shall send a summary of the findings to all who reply, but I shall not quote specific individuals.

\section{Very sincerely yours,}

(a) In your opinion is a questionnaire ever an appropriate instrument for use in the conduct of serious research in any scientific field?

In the following paragraphs, $A$ is the author of a research and $\mathrm{C}$ is a person who may or may not be entitled to credit for some phase of it. In each instance the question raised is whether $\mathrm{A}$ should give credit (in preface, text, or footnote) to C. One of the following answers written in the right margin is desired: Yes; No; Optional (i. e. no ethical issue is involved, so the matter should be entirely at A's option); ? (i. e., the appropriate 
practice would vary and would depend upon conditions not mentioned in the paragraph. It is to be assumed that all conditions not mentioned are quite typical or normal).

1. C is A's paid draftsman and does high-grade work. (In questions 1, 2, and 3 the pay comes from A.)

2. $C$ is A's paid mathematical assistant and in the pursuit of A's problem develops formulas and provides mathematical proofs of which A, only an average mathematician, is incapable.

3. C is A's paid assistant and in the pursuit of A's problem hits upon a novel technique (one unknown to $A$ and not in general use) which A forthwith adopts in his future work.

4. How would you answer Questions 1 to 3 if the pay accruing to $C$ comes not from $A$, but from institution funds allocated upon the recommendation of $A$ ? $1 \ldots \ldots \ldots$ $2 \ldots \ldots \ldots . \ldots \ldots$

5. How would you answer the same questions if $C$ is $A$ 's wife receiving no "salary" from $A$ ? $1 \ldots \ldots \ldots$ $3 \ldots \ldots \ldots$. . . .

6. C is a colleague of A's in a university or research institution and has independent duties. Incidentally, in a shop talk, A gets a novel idea from $\mathrm{C}$ which he proceeds to utilize.

7. $C$ and $A$ as in 6 . In a conference called by $A$, who is a poor mathematician, A gets and proceeds to utilize mathematical aid such as might be given by any one having had a first-year college course in algebra. ${ }^{1}$

8. Same as in 7, substituting "calculus" for "algebra."

9. Same as in 7, substituting "advanced differential equations" for "algebra."

10. Student A gets an idea from a lecture given by Professor $\mathrm{C}$ to an elementary college class and elaborates and incorporates it in a published study.

11. Same as 10 , changing "elementary" to "advanced."

1 The word "year" should have been omitted from this question on account of its connection with 8 and 9 . 
12. $\mathrm{A}$ is writing a dissertation under the direction of C. Certain techniques given in the literature are called to $A$ 's attention by $C$. These are adopted by $A$, but the problem and all novel techniques have originated with $A$.

13. A as in 12. A feels "stimulated and inspired" by C, but cannot point to important specific techniques for which $\mathrm{C}$ is responsible.

14. Professor A gets an idea from a class paper written by student $C$, and elaborates and incorporates it in a published study. (Any comment you care to make on Item 14 will be appreciated.)

Now some of you know and I will inform the rest that the receipt of a questionnaire causes the body temperature of certain people to rise. I jeopardized my good, or at least uncolored, standing in more than one instance, in sending out this questionnaire, but $I$ do not regret it, and believe I can show the results are of definite value to writers, especially young writers of scientific articles.

Question (a) quite unmistakably has the word "ever" in it. I will read it again:

(a) In your opinion is a questionnaire ever an appropriate instrument for use in the conduct of serious research in any scientific field?

Now the high-temperatured recipients of the questionnaire seemed to think that I took an unfair advantage of them by putting in the word "ever." They wanted to answer this question with the word "no." In fact, some of them did so answer it, and then qualified their answers in such a manner as to mean "yes." For example, a biologist writes, "No, with possible exception of psychology"; a social scientist writes, "Answer depends upon the nature of research: decidedly no, in the work I am doing"; a medical man writes, "Rarely"; and another states, "Usually not 
satisfactory, but sometimes the only possible method"; and another, "Not as a rule"; and another, "No, except as a method of determining average opinion, interpretation, point of view"; another, "It usually is not, but it might be. It depends upon what information you ask, and whom you solicit"; a psychologist, "Not in general. It is, in rare instances"; another, "Very infrequently."

Of course, if there is any exception, the answer to the question as put is not "no," but "yes." I have no desire to take an unfair advantage of a person who writes "yes" to this question. In this case, all that $I$ infer is that he thinks there are one or more conceivable situations in which a questionnaire is appropriate in a serious research. I certainly do not infer that the respondent is a general believer in questionnaires.

With all due deference to my Stanford colleagues just quoted, I submit that these are illogical answers to the question, which was, "Is a questionnaire ever an appropriate instrument."

The questionnaire was sent to 204 scientists at Stanford, and 155 replied. Three of these replies, however, contain practically no information, so that 152 usable replies were received. I feel very grateful to my Stanford colleagues for their courtesy in answering, for I know that many of them quite resent receiving a questionnaire. Of the usable replies no less than 20 were "no," qualified in such a manner that they were logically answers of "yes" to the question as put; and no less than 30 answered "yes" with elaboration so that I would very clearly understand that they had serious misgivings as to the value of the questionnaire. If I quote some of these elaborated "yes" 
answers you will see a very characteristic feeling running through them. A biologist says, "Yes, but rarely"; a social scientist, "Very rarely"; an engineer, "In some cases"; another, "It may be appropriate, depending upon the type of research. This most certainly is, since it is a question of "opinion" "; another, "In rare instances"; another, "Yes, seldom"; an historian writes, "Yes, but rather rarely, where attitudes or opinions as such are valid data"; a worker in the field of medicine writes, "Yes, but damn seldom." I also found the comment, "Questionnaires are as a rule not viewed with enthusiasm by the recipient, and the casual way in which they are of ten treated is the greatest practical drawback to their utility." Need I add that the last two quotations are not from the same author, however similar their views?

Another in the medical field prints "No" with an exclamation point of sufficient size to be read across the room. This was not the only evidence of feeling that a sensitive soul could infer from the questionnaires returned. Another writes, "Yes, but with marked limitations. If used to obtain facts"; another, "To be used with caution"; three others, "Yes, sometimes"; another, "Yes, but it is overdone sometimes"; a physical scientist writes, "It might be in psychological research"; another, "Yes, if used with discretion." I have given you only a few of the qualified statements. One-third of the replies were qualified in some manner. I believe the reason is that those replying felt that in justice to the logic of the situation, they had to reply "yes," but that in justice to their past experience with questionnaires, they needed to assert that ordinarily they did not deem them satisfactory instruments. Some of these qualifications may 
have been due to the feeling that the interpreter of the results would misinterpret the respondent's views unless the respondent himself provided the cue. One social scientist replied to the question, "Yes and no. I give this answer because I could not leave it to anyone else to interpret my 'yes.' " Unfortunately the fear of misinterpretation here expressed is justified by certain unhappy experiences which are the rather common lot of those who reply to questionnaires. I sincerely hope that my interpretation of this present questionnaire will do no injustice to anyone's view.

Seventy-three, or about 50 per cent of those replying, gave the single word "Yes," but we must not conclude that they were not equally skeptical with the 33 per cent of the practical value of questionnaires.

Fifteen, or 10 per cent, replied with the word "No" unqualified in any manner, and another 10 per cent gave no answer, or answers of uncertain meaning. We thus find that between 80 and 90 per cent of those replying can conceive of some situation in which a questionnaire is an appropriate instrument for use in the conduct of serious research in a scientific field. A very substantial number of these doubt its general utility. Two views as to the field in which it is useful were expressed in the quotations read. Let me read them again. One correspondent writes, "Yes, but with marked limitations. If used to obtain facts"; and another, "Yes, but rather rarely, where attitudes or opinions as such are valid data."

These are very different views, but I believe they are both correct. If facts of a unique nature known only to specific individuals are desired, then an oral or written questionnaire addressed to the one person knowing these 
facts or to one of a few who know them, is surely the only method of approach. It is in fact an historical method. Let me mention the report of a questionnaire of this sort that runs into a couple of thousand pages, and that is used by the leading men in our universities as well as by many others. I refer to Who's Who in America, or to any similar reference book. This is merely a report of a questionnaire. If we had an authentic Who's Who in Rome in the year 100 B.c. would it not be held as the most authoritative of original historical documents? Surely this type of questionnaire is justified.

Now let me mention a questionnaire of the other typeone that merely aims to secure a consensus of opinion. We had such a one in these United States of America upon November 6, 1928, and as a result of it Herbert Hoover was elected President of the United States. It was a situation in which we wished to know the consensus of opinion as to the fitness of certain men for office, and we used the Australian ballot, which is simply a secret questionnaire.

In these two fields the questionnaire operates and it alone does operate. We cannot investigate unique facts by the experimental method. No man born on the Fourth of July is born again on that same date, thus permitting a verification of the fact that the Fourth of July is his birthday. To establish this fact, we have to ask someone who knows.

Also, we cannot secure a consensus of opinion upon some issue of meaning or value except by questioning all or a sample of those the consensus of whose opinions we desire. Therefore just as long as these consensuses of opinion are important to know, a questionnaire is the only appropriate 
instrument for their discovery. As one prone to trust objective measurement, it is with regret that I find no other instrument for studying this phase of human life.

Some answers to question (a) were neither "yes" nor "no" as requested, but "uncertain." If we call an answer with the word "uncertain" one-half "no" and one-half "yes" we can determine the average number of "no" answers by various scientific groups. Upon this basis there were, from the entire group, 18 "no" answers, to this first question, which is 13 per cent. These were drawn in quite different proportions from the various sciences. Ranked in order of decreasing percentage of "noes," we have ${ }^{2}$ onefourth of those in the physical sciences-physics, chemistry, and geology-expressing an unqualified disbelief in questionnaires, one-sixth of those in mathematics and in medical science so doing, one-eighth of those in history and engineering, one-twentieth of those in the biological sciences, and none at all in the psychology group-represented by education, philosophy, and psychology-or in the economic

Summary of Answers Given to Question A

\begin{tabular}{|c|c|c|c|}
\hline & Yes & No & $\begin{array}{l}\text { Percent } \\
\text { of Noes }\end{array}$ \\
\hline 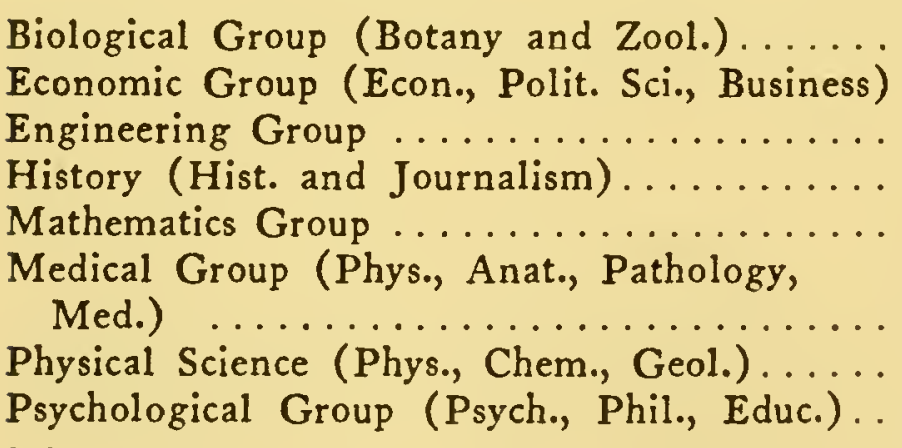 & $\begin{array}{r}21 \\
20 \\
26 \\
13 \\
5 \\
\\
28 \\
14 \\
17\end{array}$ & $\begin{array}{l}1 \\
0 \\
3 \mathrm{I} / 2 \\
2 \\
1 \\
\\
6 \\
41 / 2 \\
0\end{array}$ & $\begin{array}{r}5 \\
0 \\
12 \\
13 \\
17 \\
\\
18 \\
24 \\
0\end{array}$ \\
\hline Total $\ldots \ldots \ldots \ldots \ldots \ldots$ & 144 & 18 & 11 \\
\hline
\end{tabular}


group represented by business, economics, and political science. Clearly, answers have been colored by the specific vocation in which the person answering is engaged. Thus the physical scientist, who in his scientific work is never interested in a unique fact or in a consensus of opinion, is quite prone to consider that the questionnaire is entirely indefensible, while the social scientist, forced to deal with these things, shows the most confidence in it. I would not, however, give the impression that the 37 people in the social sciences replying were uncritical of the questionnaire. The arraignments of many of them are severe.

Let me now turn to the later questions. No matter whether the scientific investigator is in the physical or the social science field, when it comes to writing a report for the reading public, there is a single standard of courtesy which should be known, and it is that given by the consensus of opinion of scientific people. It is true that some who replied to my questionnaire expressed annoyance saying that any honorable man would have right standards of his own, and be fully competent to answer all questions pertaining to crediting colleagues and assistants. However, the judgment whether this is so lies with fellow-scientists. Certain it is that my respondents have radically different standards, as I can show by quotation; and I feel no warrant for attributing these to differences in honor-rather, these men have had different experiences, have been bitten in different places, have made different acts of mental transfer, this one adopting his policy from the courtesies of society, this one from the practice of business, etc. Judged by the consensus of opinion, and I reaffirm that that is the appropriate standard, many of the views expressed are erroneous, but 
from the internal evidence I do not think any of them are insincere. The consensus that I can report is that of some 150 people constituting a sample of just such as establish the standard in this matter. If it is in error it is only to be so established by a wider consensus. Before discussing the specific questions I must explain in a few words the steps followed in summarizing the replies. In tabulating the answers I have taken certain liberties as follows: Credit for the reply, "uncertain" is equally divided between "yes" and "no." Credit for the answer "yes-optional" is likewise split between "yes" and "optional." Credit for the answer "yes-?" is split between "yes" and "?," but as the "?" was used only four times in some two thousand replies, whatever is done with it is quite immaterial. In some 5 per cent of the replies the meaning was a trifle ambiguous. In case the ambiguity was pronounced, the reply has not been used in the tabulation; but in general the meaning seemed to be quite clear, and tabulation made according to the judgment of the tabulator. One reply which was ambiguous so far as the specific question, "Should the author give credit to the contributor in the preface, text, or footnote?" was repeated several times. It was, "The author should make the contributor a joint author." This view is well represented by the following quotation. "I think that one of the best ways of meeting such situations as these is that of joint authorship. That was the method of the greatest, most inspiring teacher and research man I ever knew, David Starr Jordan, who nearly always made his co-workers junior authors with himself." The question of joint authorship undoubtedly might arise in connection with many of these issues; but, on the other 
hand, every hypothetical case described in the questionnaire might be such that joint authorship would be highly misleading, for the author's contribution might be one hundred times, or more, that of the contributor. Those proposing joint authorship seem to do so in a generous mood, but it may be questioned whether an author, no matter how truly generous and desirous of helping a colleague or assistant, is treating his public fairly if he puts over a joint authorship work which is almost entirely his own. Generosity may cease to be a virtue when this is done.

I have here a table giving a summary of the replies to the various questions, and I would note some of the important tendencies shown.

SumMary of Answers to Questions 1-3, 6-14

\begin{tabular}{l|c|c|c|c|c|c|c|c|c|c|c|c}
\hline \hline & 1 & 2 & 3 & 6 & 7 & 8 & 9 & 10 & 11 & 12 & 13 & 14 \\
\hline Yes. & 42 & 116.5 & 133.5 & 106 & 31.5 & 44 & 69 & 64 & 75.5 & 51 & 41 & 95.5 \\
Opt. & 53.5 & 16.5 & 7 & 15.5 & 35.5 & 36 & 24 & 26 & 24.5 & 33.5 & 66.5 & 12 \\
No & 48.5 & 10 & 2.5 & 13.5 & 67 & 50.5 & 38 & 44 & 33.5 & 49.5 & 24.5 & 26 \\
$?$ & & & & & 1 & .5 & & & .5 & & & .5 \\
\hline Total & 144 & 143 & 143 & 135 & 135 & 131 & 131 & 134 & 134 & 134 & 132 & 134 \\
\hline
\end{tabular}

Changes in Answers to Questions 4 and 5 From the Answers To Questions 1, 2, 3

\begin{tabular}{|c|c|c|c|c|c|c|}
\hline & \multicolumn{3}{|c|}{4} & \multicolumn{3}{|c|}{5} \\
\hline & (Q1) & (QQ2) & (Q3) & $(\mathrm{Q} 1)$ & I(Q2) & (Q3) \\
\hline Greater obligation to credit & 12 & 8 & 5 & 37 & 13 & 6 \\
\hline Less obligation to credit... & 2 & 2 & 0 & 4 & 9 & 7 \\
\hline
\end{tabular}

Questions 1, 2, and 3 were drawn up with the intention of providing a series of situations wherein the amount of the contribution differed, with the hope of developing some principle which would be a function of amount. In question 1 the wording is intended to imply that the contributor, a draftsman, gives of his best trained services; in ques- 
tion 2 that a mathematical assistant, trained in a more intellectual calling, gives of his best; and in question 3 that an assistant gives of his best, and in doing so provides a technique that the author could not well have had in mind when hiring him.

The first question is:

$\mathrm{C}$ is A's paid draftsman and does high grade work. (In questions 1, 2, and 3 the pay comes from A.)

The median reply to this is that it is optional with the author whether credit be given or not. In sentiment those replying with the word "optional" certainly lie in an intermediate position between those replying with "no" or with "yes." Thirty-three per cent stated that no credit should be given, 37 per cent that it was optional with the author, and 30 per cent stated that it should be given. A not uncommon comment in connection with question 1 was that it would not hurt the author any to give the draftsman credit. This is perhaps a selfish point of view, but that hardly lessens its importance.

There are three parties to the transaction we are discussing-the author, the contributor, and the scientific public, and it is important that no unfairness to any one of the three result. It would be an unsound standard to judge of the fitness of the procedure by its effect on the author only. In fact, if any "rights" are to be neglected, it is only his own that the author has the right to neglect. The view just mentioned was frequently voiced, as witness these statements: "I have answered (the question) generally in what may be termed the larger courtesy. It does no harm to be generous in such matters, and one can well afford to do the graceful and generous thing in matters 
of this sort." A second quotation: "This is a matter of courtesy rather than a matter of ethics, if one can separate the two. C has been paid for his work in cash, but if his work is unusually good, the courteous thing is to acknowledge it in the preface." Here is a different view. "No credit need be given to any assistant whether common laborer or Ph. D., chemist, or other, for applying any methods known to his craft." Common observation shows us that stenographers, typists, draftsmen, printers, and proofreaders do not ordinarily receive published credit for their parts in a published work. The following view, voiced by a chemist, is not uncommon, though probably not quite a median opinion. "If the paid assistant did only what he was told to do, however well, but made no independent contribution to it, there should be no occasion for mentioning him. ...... There would be an endless list to recognize if one went beyond the bounds of contributions which are notable, specific, and original." Occasionally a technical or clerical worker does receive recognition. When Professor Karl Pearson acknowledged in print the excellent typography of an involved statistical article, we felt-that is, if we tried to read the article-that the acknowledgment was well merited. The workman here who set up the involved mathematical text did not do a routine job-not a set-up in a score would be as well done. The workman had gone beyond what is reasonably expected of typesetters, not in originality, but in skill. In granting this recognition, one need not believe that Professor Pearson was making a special effort to be kind and generous, rather that he felt as a matter of ethics that recognition of this superior piece of artisanship should 
be given. The less the granting of recognition is in response to the whim of the author, and the less it is influenced by personal feelings, of friendship, of inferiority, or superiority, the better. The author who goes out of his way to give credit to eminent men and to his superiors in rank, and who never, judged by any statements of his, gets help from contemporaries of equal or inferior rank is not unknown. Though he may not be respected in his own community, he not infrequently does make quite a showing in distant parts.

Endeavor as one might to make a general practice known and thus introduce some sort of standard into the giving of credit, there will always remain a field wherein the judgment-not the friendship-of the author should operate. It seems that the granting of recognition to the draftsman is in this field.

Questions 2 and 3 are:

2. $C$ is A's paid mathematical assistant and in the pursuit of A's problem develops formulas and provides mathematical proofs of which $\mathrm{A}$, only an average mathematician, is incapable.

3. $C$ is A's paid assistant and in the pursuit of A's problem hits upon a novel technique (one unknown to $A$ and not in general use) which A forthwith adopts in his future work.

The median judgment upon these questions was that recognition should be given: 81 per cent so affirming in connection with question 2 , and 93 per cent in the case of question 3. The contributor referred to in question 2 is not a mechanician, but one who possesses a mental capacity and information commonly gotten by more or less advanced study. He uses this whole-heartedly in the cause of the author. He is, if you will, a high-grade mental artisan. 
It seemed to be quite generally the feeling that he should be credited. The occasional observations written in would seem to warrant the belief that those who answered question 1 in the negative and questions 2 and 3 affirmatively were generally of the same opinion as was the professor who wrote: "Originality is the first test in these cases. Information that anyone in his position would be expected to give needs no mention." A certain few answered question 1 "No" and questions 2 and 3 "Yes," who held different views. One advised giving credit in the situation of question 2 "unless $A$ is so poor in mathematics that the work was simply like looking up a reference." Thus pronounced non-mathematical ability upon A's part is given as an argument for not giving credit. Another advised giving credit and commented as follows: "This questionnaire fails to recognize the fact that credit cannot be divorced from responsibility, and that he who takes credit beyond his understanding rides for a fall." Thus pronounced non-mathematical ability on A's part is here given as an argument for giving credit. Can both of these views be right? Possibly they are. If $\mathrm{A}$ does not now remember the binomial theorem, and asks his mathematical assistant to state it for him, surely no acknowledgment is needed. But if A does not know that such a theorem exists, or its function, but his mathematical assistant does properly use it for him, then even though meanwhile as a result of his assistant's tutelage he has learned the appropriate use of the theorem, it may well be that acknowledgment to his assistant should be given. Still another view, though one that hardly seems tenable in university fields, whatever the practice in industry, is that the author need give credit for nothing that his paid assistant 
does, provided he himself can understand and master it. The quotation given mentioning the sad plight of the fellow who comes a cropper when he fails to give credit for matter beyond his understanding pictures but one aspect of the threefold view already mentioned. For one's best selfish interest he should not claim too much, but long before a check because of fear of getting caught is operative, there should be another check to conduct, in a desire to be fair to one's helpers and one's public. One should not claim matter as his own upon which is the stamp of discovery of another, whether minor assistant, casual acquaintance, or eminent colleague. The unanimity of opinion in the case of question 3 that credit should be given to the contributor is not due to a similar unanimity in reason. Some of the best reasons given draw a distinction between the situations in questions 1 and 3 , or 2 and 3. A person earlier quoted states: "Credit must be given to any student, whether common laborer or Ph. D. chemist, who has invented or discovered either previously or for the occasion, a method reçuired as a link in the boss's chain." As pertaining to questions 1,2, and 3, and others, one writes: "The crucial point is whether the assistance is an intellectual contribution or a merely mechanical contribution..... I maintain that such assistance is as definitely mechanical in differential equations as in draftsmanship. To acknowledge it should be optional. When the assistance involves a novel suggestion, however, it becomes necessary for the man who receives it to acknowledge his indebtedness scrupulously, whether to a famous colleague, a paid assistant, or a patient relative." The patient relative aspect is considered in question 5 , and source of pay is considered in question 4. 
Question 4 is:

How would you answer Questions 1, 2, and 3 if the pay accruing to $\mathrm{C}$ comes not from $\mathrm{A}$, but from institution funds allocated upon the recommendation of $A$ ?

Of those who replied to questions 1,2 , and 3 that no credit should be given or that it was optional, some 10 per cent in the case of question 1,24 per cent in the case of question 2, and 50 per cent in the case of question 3 considered that there was a greater obligation that the author give credit if the author is not the source of pay than if he is. The rest expressed no change in obligation with a change in source of pay. Something of the standards of business do seem to apply. These standards would proclaim that if the services of a helper are paid for by the author they belong to him. The opposing view seems to be a majority opinion, though we may doubt if the majority view would go as far as one person who stated: "It does not make a particle of difference as to where the pay comes from." The majority view is better represented by the following: "[Give] credit where credit is due. The question of pay, salary, etc., does not enter in most cases. Even though the pay comes from $A$ in each case, seldom does A personally support the research. If $A$ is in business, the funds come from the business, or A is merely the custodian of funds set aside for some particular use; seldom if ever does A represent the actual source of the funds, hence the matter of pay does not to my mind enter the problem." This writer seems to hold that though theoretically the source of pay is an issue, practically in such situations as ordinarily arise, it is an immaterial point. I do not believe from any evidence at hand that it would still be considered immaterial if 
the decision were between recognition for work done for pay and for work done out of kindness, by some willing-to-be-imposed-upon acquaintance. Probably under such a condition the percentage who would consider there was greater obligation to give recognition when the assistance rendered was not paid for than when it was would increase considerably over the 10 per cent, 24 per cent, and 50 per cent found when the pay was shifted from the author himself to an employing institution. Perhaps source of pay has very little to do with the matter, but pay or lack of it is quite certainly a factor. One respondent to the questionnaire certainly does not consider it minor. He writes: "Originality is the first test .... The question of pay is the second test. If the assistant is paid he obtains that in place of credit except. ..... in exceptional cases. If in doubt, give credit." It is regretted that more direct evidence is not available, but it seems quite certain that the last view given is not representative of the median view. Considering the answers to question 4 together with those to later questions, it seems reasonable to believe that the median view holds that pay, as contrasted with lack of pay and possibly even source of pay, is a factor. Several respondents expressed the opinion that in the case of paid workers the practice of recognition should be a matter of contract or mutual agreement entered into at the time of employment. This does not seem to be a practical solution, for though it settles all issues as between author and contributor, it does not settle them as between the author and the public. Professionally it would be very unfortunate if a man of wealth could, by agreement with employees, foist himself upon the public as a great research worker, if, in fact, the brains 
back of his publications were those of his paid assistants. It would be better that there be no contract upon this matter than that there be one neglecting the rights of the public.

Question 5 is:

How would you answer questions 1, 2, and 3 if the contributor is the author's wife receiving no "salary" from her husband?

This question treads upon delicate ground, and the varied response indicates that little can be told as to just what part a wife has played in a research, by the author's published acknowledgment. We may, however, get a rough idea as to what is the central tendency of opinion. In the matter of crediting assistance of the grade of draftsman, there is a tendency voiced by some 36 per cent of those not stating in answering question 1 that it was obligatory that the draftsman be recognized, that there was an increased obligation that the wife be given credit. This 36 per cent represents persons who said the draftsman should not be given credit, but that it was optional or obligatory that the wife-draftsman should be, plus those who said it was optional in the case of the draftsman but obligatory that credit be given in the case of the wife-draftsman. Some 10 per cent took an exactly opposite view-that there was less obligation to credit the non-paid wife than the paid draftsman. This issue is truly not a simple one; to credit a wife for draftsmanship when the husband is getting renown for, let us say, proving that the earth goes around, may be the occasion of very invidious comparison. The possibility of this may not have occurred to the 36 per cent who would credit the wife, but not the draftsman. One would be loath to conclude that the husbands would wittingly place their wives in a position permitting unfavorable comparison; rather, one 
would believe that the 36 per cent held that there is a greater cobligation to spouse than to paid draftsmen, and aspired to express such added obligation by giving recognition. This seems to be correct, for in connection with the higher talent considered in questions 2 and 3 we find even greater percentages-50 and 60 -believing that there is greater obligation that the wife be credited than that the paid mathematician or research assistant be. In these two cases no individious comparison results when activity of wife is compared to that of husband. There is a small minority who take just the opposite view. Approximately 8 per cent maintain in the case of question 2 , and 5 per cent in the case of question 3, that there is less obligation to credit the wife than the paid worker. No written comments throw light upon the viewpoint of this small minority, unless the observation of the professor who wrote, "Do anything you ran get away with," is pertinent. I do not hazard to pick one reason for the tendencies shown out of the multitude that any normal married couple could propose. Rather let șome of the husbands speak for themselves. This may not be entirely fair to women, for most of my respondents are men. It will not, however, be unfair from the standpoint of a consensus of opinion of scientists, for most scientists are men. So far as the median view is determinable, we can say that there is slightly added obligation to give credit to a wife than to a paid worker, though a goodly number maintain that there is no difference in obligation due to the marital relation. A biologist states, "Credit obligatory if no salary. Wife relationship not the issue." A social scientist expresses the opinion that "the factor of family relationship does not alter in the slightest the ethical question." Just the opposite 
view is voiced by another social scientist, who writes, "This is a question of family relations on which I hesitate to enter." It seems to be viewed as a matter of family relations by the person who wrote "I would not dare give other than full credit to my wife." Still another, "... would mention [his] wife, an act of courtesy only." A small group proposed that the author at least give the wife the opportunity to be mentioned or not as she may desire. As the rights of the public are generally minor in this matter, this has much to commend it.

I personally wish at this point to take the liberty of advising the young candidate for the doctorate who is publishing his first research to think very consciously of this matter from the standpoint of his young wife, and of the outsider observing them both through the medium of the preface. I shall not be so unkind as to quote from the prefaces of certain doctors' dissertations, but one finds in many of them acknowledgment of the major professor for his vision, continual inspiration, and guidance through the intricate mazes of the research, and to the wife for self-sacrificing aid in computation, typing, and in the taxing job of proof reading. Not occasionally, but almost universally, the young married candidate for the doctorate is obligated, deeply obligated, very, very deeply obligated, to his wife, but such recognition in the preface as $I$ have mentioned is a cheap coin in which to pay. I am sure it is ordinarily not so intended, and that it is merely an error of judgment which leads to acknowledgments of this sort. One would think, as he reads of computing, typing, and proofreading, that the wife's contribution could be represented by the money saved in not being called upon to pay a salary to certain none too 
intellectual clerical workers. As I have seen the sacrifices of wives "for the good of the cause" I know that typically this is not the case. The wife, unskilled in computation, spends more than mere hours of time when she struggles with the columns of figures which the husband gives to her. The hunt-and-peck typist or even the five-finger artist, does not, in the service of a husband, stop when the clock strikes 5. She works after the children are in bed until midnight, and so it goes. No acknowledgment in the preface can pay this debt, and usually the attempt is a sorry failure. As to how the husband shall meet the obligation is a family matter which I do not conceive to be my business to attempt to answer, but that a few kindly condescending words in the preface does not meet it is a public matter just as soon as the masterpiece is in print. Question 5, as put, stated that the husband was the author and the wife the contributor. To gain perspective I suggest that when writing the preface the husband imagine that the situation is reversed, and write as though the wife were the author, and the husband the contributor. I dare say it will be quite an illuminating experience.

Let us now consider issues arising between university and research institution colleagues.

Question 6 is:

$C$ is a colleague of A's in a university or research institution and has independent duties. Incidentally, in a shop talk, A gets a novel idea from $\mathrm{C}$ which he proceeds to utilize.

Ten per cent of the respondents stated that no credit should be given, 11 per cent that it was optional, and 79 per cent that credit should be given. There were a number of qualified answers. Typical of one wing is the pro- 
fessor who said, "Yes, [A] should credit C, and should ask permission of $\mathrm{C}$ to use [the idea]," and also the one who wrote ". . . . . if two scientists talked together about their plans for future research, and number two proceeds to utilize one of number one's ideas and gets a piece of research done on it (this has happened to me two or three times) then I consider that number two's behavior is absolutely unethical, and no amount of public acknowledgment can make up for his behavior." It seems that to these men quoted the "idea" remains the sole property of the originator, even when he has not ear-marked it and staked out future rights in it, as of course he would not, if it occurred incidentally in a shop talk. Of quite a different view is the pessimist who writes, "Just getting an idea involves no obligation. Conversation is supposed to be (occasionally) stimulating." Also quite different is the following view:

As related to this subject, I want to say that I believe in the most complete freedom in the commerce of ideas. In other words, I believe in a man airing his ideas and letting the consequences fall where they may, not troubling himself to inquire whether he gets credit for them or not, no matter how original and valuable they may be. Likewise, I believe in a teacher giving help, regardless of whether the student or other person ever gives him recognition or not. In other words, regardless of the manner in which these questions are answered, I should not change my position on this fundamental proposition.

In other words I don't believe in one man saying "dibs" over an idea, or in his acting in any dog-in-the-manger manner about it. However, I appreciate, from the other point of view, the fact that any courteous and considerate person will give all the recognition he can to those working with him and associated with him, perhaps even giving credit for good intentions when no 
service of any real value was rendered. Usually the man who can give credit occupies the more strategic position and a little notice of a poor devil farther down on the ladder makes the latter struggle harder-assuming this is desirable.

It is the teacher's lot not to get much credit no matter how far his students progress nor how much he has done to help them along the road. This makes no difference, however. His reward is in their success, not in his being acclaimed for it.

I can nearly think of a Bible reference that makes my whole position clear: "Cast your ideas upon the waters, and two will grow where only one grew before." That doesn't sound quite scriptural after all, but the essence of good doctrine is there.

Truly, this man who almost quotes Scripture has a kindly and generous point of view, but it quite certainly is not the median view. The great majority of opinions lay between these two classes quoted. I quote the following as more or less typical of the median view. "[It] depends upon whether [the] idea is a mere germ, or has been partly incubated, or is practically hatched .. . If partly incubated, he has no right to use it without . . . express permission, and certainly [he] should make proper acknowledgment."

We may conclude that recognition is obligatory if the idea gotten is important as it stands, and not only as later elaborated by $\mathrm{A}$ and if $\mathrm{C}$ himself recognizes it as an important original idea. If the idea is claimed and justly claimed by $\mathrm{C}$ as his property because he is the originator, it would seem that $A$ is obligated to ask permission to use it with due recognition, while it would seem that $C$ is probably obligated to permit such use, for his original deliverance of the idea was not in confidence. If $A$ 's request to use the idea in further work is denied by $C$, it 
then seems that $A$ should only continue in case he makes a clean breast to the public of the situation, and, one would expect, only in case he considered the friendship of $\mathrm{C}$ of less importance than the work in question. If both parties take the "larger courtesy" view, the general progress of science is furthered. As repeatedly indicated in replies received to the questionnaire, this issue is not an academic one. There exist incompetent workers who seek to profit by the ideas of their colleagues. There exist competent egotists who revere their own ideas so highly that they see them expressed without credit in the works of their colleagues, when in fact the views are merely those that any reasonable man working on the same problems would develop of his own accord; and still more trying, there exist workers with poor memories, who feel that ideas in truth gotten by them from earlier sources are in fact their own, and that they should be given published credit for them. In this maze no course will please everyone, but a generous attitude, a strict sense of honesty, and a realization, as one respondent puts it, that "to fail to give credit consciously for work by another is the most contemptible form of theft" will smooth out many a difficulty.

Question 7 is:

$\mathrm{C}$ and $\mathrm{A}$ as in 6 . In a conference called by $\mathrm{A}$, who is a poor mathematician, $\mathrm{A}$ gets and proceeds to utilize mathematical aid such as might be given by anyone having had a first year college course in algebra.

The issue here is whether the call for assistance by the author places him under special obligation to give credit. Twenty-three per cent said the giving of credit was obligatory, 27 per cent that it was optional, and 50 per cent 
that it was not called for. A biologist says "Whether the aid be much or little, credit should be given to C." There is expressed the view that since no money wage was given, credit was obligatory. The opposing view is more generally held, not an inconsiderable number attaching little or no importance to the fact that A called for the assistance, and these respondents reacted solely upon the basis of the intrinsic importance of the contribution. One professor specifically states that if $\mathrm{C}$ simply saves $\mathrm{A}$ the trouble of looking in a reference book, no credit should be given. A mathematician considers that "A could probably find the necessary information by himself if he took the time," and that no credit is called for. It is this professor's view that "credit for new ideas or techniques should be acknowledged." Another professor states that in the case of question 7 he would feel "no more inclined to offer credit than he would to a stenographer who copied his manuscript." As an expression of the median view I quote an engineer as saying that "It depends upon the time expended, and the help given to A." Another professor states it thus: "Not worth bothering about," and another writes, "Credit would here be a doubtful compliment to C. A would better convey his gratitude to $\mathrm{C}$ in private."

Though 50 per cent said that no credit should be given in the preface, text, or footnote, it is not to be presumed that they would not express their gratitude. As in the last quotation "It would be a doubtful compliment" to acknowledge this work, because of its elementary nature. If, however, $\mathrm{C}$ should desire such acknowledgment, it ought to be obligatory upon $\mathrm{A}$ to give it. A is certainly indebted to $\mathrm{C}$ in some manner. A nice solution, as more than one 
suggested, would be "A says to C, 'T'd like to acknowledge your help.' C says to A, 'Don't mention it.' " As this issue little concerns the public, a private expression of gratitude, if deemed sufficient by $\mathrm{C}$, should be the best way to handle it.

Questions 8 and 9 change the issue in a sense, making it a public matter. Question 8 is the same as question 7, except that the aid given is in calculus, and not algebra, and question 9 is the same as 7 except that the aid given is in advanced differential equations, and not algebra. In question eight 39 per cent think that no credit should be given. Twenty-seven per cent consider it optional, and 34 per cent obligatory. In question 9 the percentages are 29,18 , and 53. There are two important changes between the situation numbered 9 and that numbered 7 . First, a higher grade of ability is called into play, and second, the scientific public is concerned, for it desires to know if the author himself is a master of calculus and of differential equations. The very fact that customarily the author's name is attached to an article is indicative that there is a personal interest in the author as well as in the subject matter of the article.

The consensus of opinion is that a much greater obligation to give public recognition exists in cases 8 and 9 than in case 7. This seems to be good practice, and quite irrespective of the wishes of $\mathrm{C}$, the author should set himself straight with his public, and in case the contribution of $\mathrm{C}$ does lie beyond his present training he should mention $\mathrm{C}$ by name or, if $\mathrm{C}$ should so prefer, refer to him as "a mathematician." It is, of course, little of a compliment to an advanced mathematician to say that he rendered help upon 
an elementary problem in calculus, so it may well be that $\mathrm{C}$ would not care to have his name mentioned. A rather striking and, I estimate, not typical reason for not crediting the contributor, given by a medical man in connection with questions 7, 8, and 9, is "Mathematics per se is a subsidiary method in biological science: merely a means toward an end. Once the phenomenon has been discovered, analyzed, and mechanism proven, mathematics may assist in making our knowledge orderly. Putting mathematics first, and thus crediting it with more than it can do is putting the cart before the horse." Instead of this view, should one not rather acknowledge merit wherever it may raise its head above the dull horizon of the prosaic? Does one hold a mighty general in low esteem because he is merely an agent in the cause of others? Is Robert $\mathrm{E}$. Lee in the cause of Jefferson Davis a negligible character?

Questions 10 and 11 deal with the rights of a professor in the material of his lectures. In this connection I will ask you to recall the generous view of the man who almost quoted Scripture. Do scientists generally consider that they have a personal right in the matter of their general public and classroom lectures? Question 10 is:

Student A gets an idea from a lecture given by Professor C to an elementary college class and elaborates and incorporates it in a published study.

and question 11 is the same except that the class in question is an advanced class instead of an elementary one. In the case of question 10, 48 per cent of the respondents consider that recognition is obligatory, 19 per cent optional, and 33 per cent that it is not called for. In the case of question 11 the percentages are 56,19, and 25. There is 
considerable qualification of answer. A few maintain without qualifications that the professor should be credited, but most of the comments received expressed the view that only under certain conditions was the student called upon to acknowledge the lecture contributions of the professor. In quite a real sense, the student may consider that his tuition pays for all the information he receives which is not original with the professor-in the capacity of teacher, the professor is hired to pass on the accumulated wisdom of the ages, and only in his capacity of research worker is he called upon to extend it. Accordingly, as one respondent writes, "Give no credit provided the idea is classic, already in the literature." Incidentally, scarcely any professor would want credit for an idea that was classic. Not infrequently one finds a professor credited with something of which he is not the author. He may himself be to blame for this in not having presented the matter to his classes in such a way that it was obvious he was not the originator.

From the standpoint of the public the more specific the credit given, the better. In giving credit a professor may adopt the "larger courtesy" and in asking for it, maintain the "bigger generosity," but the public does not desire either. It wants the unadulterated facts. In giving credit the student should first search for the truth-he ordinarily makes more errors due to ignorance than to intention-and second, he should realize that published acknowledgment is honey to the young professor, and not exactly vinegar to the older one. He should be scrupulous in giving it where it is due. It is to be noticed from the responses to questions 10 and 11 that little distinction is made in this matter between elementary and advanced lecture material. 
Questions 12 and 13 concern themselves with the rights for recognition of the professor supervising the work of a student. All degrees of intimacy of supervision exist. I have heard from a very creditable source of one case at a certain university in which the professor under whom, according to the records of the registrar's office, the student did his research work for the Ph.D. degree did not, at the time of the final examination, know the subject of the research, or that he was the student's adviser. I would call this minimal supervision. On the other hand, as stated by one of my respondents, there are cases "where most of the work [has been] done by us [major professors], thesis, method, evaluation of data, and finally grammar." Between these extremes lie the bulk of theses, all alike in that on the books of the registrar and in the minds of colleagues, one certain professor is in a sense sponsor for the work. Ordinarily the professor's part is so material that there is no issue as to whether credit should be given. Questions 12 and 13 present less certain cases. Question 12 is:

$\mathrm{A}$ is writing a dissertation under the direction of $\mathrm{C}$. Certain techniques given in the literature are called to A's attention by $\mathrm{C}$. These are adopted by $\mathrm{A}$, but the problem and all novel techniques have originated with $\mathrm{A}$.

'Thirty-eight per cent say that credit should be given, 35 per cent that it is optional, and 37 per cent that it should not be given. Thus the median reply is that it is optional. I wonder how the question would have been answered, had it read " $A$ is writing a dissertation under the direction of B. Certain techniques given in the literature are called to A's attention by a third party, C. These are adopted by A, but the problem and all novel techniques have originated 
with A." Surely the question as put indicates that the major professor has done just about as little, and that not original, as could well be, and still 38 per cent consider it obligatory that credit be given. Would these 38 per cent ask that recognition be made if the plain unvarnished truth constituted the recognition? The major professor himself could hardly desire that that be cited as his contribution. He would surely prefer that the matter be not mentioned. Let us see some of the reasons given for saying that credit should be given.

A social scientist answers question 12 with "No," but adds, "I think a student who has had the guidance of a professor in connection with a dissertation should always acknowledge (in the preface) the receipt of assistance from the professor." This view, in its demand for recognition of the major professor, is certainly not far from the median view. As a matter of ethics, it seems to me personally quite unjustifiable. Perhaps it is just a little white lie, such as is addressed to a very unpleasant acquaintance, "I am pleased to meet you," "Hope to see you again," etc. Explain it on some other basis if you can. Whether this explanation is correct or not, I accept the fact at its face value, and advise students under all conditions to acknowledge their major professors in their prefaces-failure to say something kind just is-not-done in polite society, no matter how little the professor has contributed. A second social scientist says that credit should be given, and writes "Owing to the peculiar duty of the professor toward his candidate, one would be prompted to say ' No' here, except that it is important to teach the student to lean over backwards in this matter of acknowledging credit." The particular 
professor just quoted did very consistently throughout the entire questionnaire, as judged by the median opinion, lean over backwards in calling for recognition of help received, but his argument should not justify the responses of others who do not so lean. Their most common observation was "[Giving credit] is a matter of courtesy."

Question 13 is:

$\mathrm{A}$ as in 12. A feels "stimulated and inspired" by C, but cannot point to important specific techniques for which $C$ is responsible.

Thirty-one per cent said that recognition was obligatory, 50 per cent that it was optional, and 19. per cent that it was not called for. The median judgment is that the matter is optional with the author, but the medial feeling as judged by comments, is that the author should exercise his option by giving credit to the major professor. The question as put is a poor one, being capable of considerable difference in interpretation as to the contribution of the professor, but all of the reasons applying to situation 12 for giving credit seem to be present here, plus certain very pertinent added reasons.

The last question reverses the issue, and raises the question as to when the professor should give credit to one of his students. The question is:

Professor A gets an idea from a class paper written by Student $\mathrm{C}$, and elaborates and incorporates it in a published study.

No less than 71 per cent said that credit should be given. Nine per cent said that it is optional, and 20 per cent that it should not be given.

No other question in the questionnaire seemed to suggest so many personal and generally unpleasant experiences as 
this one. We are certainly dealing with an issue which has been the occasion of much heartburn. A young professor writes "Rumor has reached me of numerous instances where students have worked hard at projects, only to have instructors 'cop' the major portion of their projects. It seems convenient for A to develop amnesia for sources." This is a very unkind remark. It has not emanated from a student who has failed to pass a professor's course, but comes from a professor, and it does not stand alone. Another professor of advanced years and long experience writes, "I have heard, however, of some flagrant cases where the 'prof' has pirated and published without acknowledgment mighty good stuff done by various students and assistants." A head of a department writes, "I know that students have not received appropriate credit for ideas presented by them." An economist writes, "American university professors have been guilty of grave injustice in my opinion in failing to recognize the moral responsibility they have to students in such cases as [questions] 2 and 3 . Not only this, but I have professional books on my shelf in which elaborate footnotes appear, taken almost wholly from theses by students, which theses were deliberately assigned by the professors to get the facts needed for such footnotes. There is one nationally known professor at- who, I have been informed more than once, practically requires in advance of his students, even $\mathrm{Ph}$. D. candidates, that any findings shall be his for his use in books. This, it seems to me, is an outrage, but the student is generally helpless in such cases." The average age, rank, experience, and salary of the professors just quoted is, I should judge, 55 years of age, head of a department, 25 years experience, 
and salary in the upper 5 per cent. No matter how one would react to these views if presented in the college daily, sponsored as they are, they must be treated seriously. A suggestion made by a young professor as to why $\mathrm{A}$ does not give credit to $\mathrm{C}$ is to be found in the following quotation: "Reluctance to credit $\mathrm{C}$ may be due, in some cases, to a correct suspicion (which crediting $\mathrm{C}$ might cause others to share) that $A$ might better have left the elaboration of the idea to $C$. If $A$ suggests this to $C$, and for various reasons $\mathrm{C}$ does not do so, or is not sufficiently able or experienced to do so, then it is proper for A to go ahead. In such a case he should gladly credit C." In the last five quotations the most unkind observations have been made by the two youngest professors, but the other three have been no less forceful in expressing the belief that due credit frequently has not been given to students. I have selected the quotations just given because of the type of view expressed.

I will now select just as strong statements of the opposing view as $I$ can find in my questionnaire answers. A social scientist considers that credit to the student need not be given, and says, "Have you read Kipling's poem 'Even As You and I'? In it he suggests whoever did anything worth-while got a great many of his ideas from others. I think a good conscience that is not psychopathic is about the best guide." A biologist says, "The students in the questions depend on the professor, either directly or indirectly, for the ideas they acquire, hence do not need specific acknowledgment. If the student shows promise, the professor would do well to encourage him to develop his ideas for himself. If he is not interested, the professor may take it over without violating professional cour- 
tesy or ethics." A medical man writes that the "chances [are that] C lacks originality. [The] professor only refreshes [his] memory, and elaborates on [his] pre-existing knowledge, belief, intuition, etc., just as from general reading. There must be a limit to giving credit to everyone who has written something which may be useful to a reader. .."3 An engineer considers the giving of credit optional and writes, "The original idea was probably presented by $A$ to the class. $C$ simply calls $A$ 's attention to the matter. In most cases, the elaboration and presentation are the major part of the work."

Many intermediate views could be cited. Here are a few of the most typical. A mathematician writes, "Perhaps [the] student should be taken into full confidence and given a chance to collaborate in the study and share the honor of joint publication. Discouraging otherwise." A physical scientist advises giving credit "if [the] student had [the] idea too." Another from the social science field says that credit is obligatory if the "student really consciously had an idea" but that it is not called for if "the professor and not the student got the idea. Except for human contacts, we would no doubt be relatively deficient in ideas, and if each were religiously traced to its source, a large part of scientific literature would be just that. I presume it has happened that one got a very fruitful idea

\footnotetext{
3 The rest of the quotation from this professor is, ".. . but in my opinion credit is due to those intimately or personally associated in the prosecution of problems of research, regardless of the nature of the assistance or cooperation - all this promotes an atmosphere of fairness and sincerity in the study of problems, useful criticism, and gives inspiration and zeal to younger men. This has been my experience with many associates and students. It places the responsibility where it belongs, also makes the professor less fallible and authoritative."
} 
by misunderstanding someone else." A biologist states that the answer to this question is "yes or no, depending on whether $\mathrm{C}$ recognized the value of the contribution." These quotations are only a few of the same general tenor.

Quite a number of quotations could be given, the tenor of which is that credit should be given, not so much as an ethical right, as a means of encouraging and stimulating $\mathrm{C}$ to further work. A historian writes, "If the policy of giving due credit to the students for any ideas their class papers may contain were generally followed, students might feel it more worth while to put real thought into their work." A biologist writes, "Credit of this sort will mean much more to the younger man in many ways, and may stimulate his interest to an unusual degree. This is a big part of the teacher's business."

In spite of wide diversity of view there is an undoubted central tendency shown. If a student present an idea that is new as judged by the wisdom of the professor, and if he sense something of the import of this idea, then before the professor uses it he should endeavor to get the student to develop it fully either independently or as part of a joint study. If the student does not care to do this, the professor is at liberty to use it himself, but only with due acknowledgment. In none of the replies was it considered that the student had an inalienable right to the idea to the point that the professor should not use it without the permission of the student after the student disclaimed any intention to develop it. Ideas gotten from papers written by students but not in the minds of the students writing the papers require no acknowledgment.

The question just discussed is the last one of the 
questionnaire. If we now try to formulate a general rule governing all cases, we shall find much need for qualifying and additional clauses. It, however, is worth the attempt. A few such generalizations are volunteered by the respondents. Here is one:

The responsibility of the senior toward the junior is much greater than vice versa. Obviously, the credit means more.

In general, credit and responsibility go together. The origin of an idea is a fact which should be recorded with scientific accuracy. It is good ethics (and also good policy) to make the record complete.

Here is another: "The man who acknowledges too much has lost nothing; the one who acknowledges too little may lose a friend." Another writes: "In general, I think it best to be generous in giving credit to others, especially to those not so far up the ladder." Another says: "Life is too short for any but an unselfish attitude on any of these problems." Another writes: "Giving credit is a simple courtesy which is so cheap that anyone can afford to be generous. Furthermore I believe that this acknowledgment enhances rather than detracts from the author's kudos. . . . A failure to do so indicates a lack of generosity, even a meanness that is most objectionable." Another says the "basis of ethical duty to give credit to another is 'a special indebtedness to another for an idea that has not been so published as to become common knowledge.' . . Giving credit upon other grounds is a matter of good manners, not of ethical duty." An unmarried man observes that "A little extra appreciation may win or hold the good will of employees, friends, wives, and other enemies." The shortest summary found is "Make acknowledgment in case significant help is rendered." This statement is rather too 
abridged to meet all the issues. A graduate student formulated the following: "Credit should be given in every case where the material cited would add to the prestige of its originator." This is an excellent formulation, but as it does not distinguish between pay and gratuitous help, and does not keep the public in mind as one party, it does not meet the median view. I would propose the following: "First, an author should give published credit whenever the contributor has stepped outside of his regular line of duty as it is related to the author, and when such recognition will add to the prestige of the contributor. Second: a student, when writing a thesis, should follow the usual courtesy of expressing appreciation for the help rendered by the major professor, whether he has gone beyond what would reasonably be expected of him or not. Third: an author should make such recognition that his readers will not credit him with phases of work appearing under his name beyond his present training or capacity to produce." I believe that this formulation includes all cases from the exceptionally able, paid clerk or technical assistant, to the patient relative or the thought-provoking colleague or student.

With this particular questionnaire in mind, let us attempt to make a few generalizations about questionnaires. It was mentioned that 204 scientists were solicited, and that 155 replied, though a few of the replies did not contain useful information. An examination of these, together with an examination of the names of those not replying, suggests that there is a greater likelihood of not getting a useful answer if (a) the recipient is sick, (b) on sabbatical leave, (c) not well known to the sender of the question- 
naire, (d) holds a minor position of one year tenure. No other tendencies were discernible. It does not seem that any one of these should select people prone to be non-typical in a certain given manner in their attitude upon the matter of granting credit. It is accordingly believed that the sampling is a fair sample of those polled, and it is also believed that those polled are a fair sampling of scientists in the United States. At best this important matter remains a matter of belief, as it cannot be proven without an investigation much more extensive than the questionnaire itself; and such is characteristically the case with polls by questionnaires, for 100 per cent, or even 75 per cent as here, of return is exceptional. This lack of demonstrable fairness in the sample is probably the greatest shortcoming of the questionnaire. The user of the questionnaire should never lose sight of it.

A second intrinsic difficulty not unrelated to this first is an ethical one. What right has the sender to ask for the time and honest reply of the recipient? And if he has no right, what reason is there to think that he will get an honest reply made after due reflection? One of the respondents to my questionnaire who sent in a non-useful paper wrote "[questionnaires] are sent to busy men who must either take time off to hunt up data or think it over or else answer superficially. This is so involved that $I$ find it necessary to go over it several times before getting the gist of it." Two or three others expressed similar sentiments. In these cases I wonder if the trouble was so much with the complexity of my questionnaire as it was that I had no claim upon the time and effort of the recipients, at least none that appealed to them. I would put this as the second great 
shortcoming of the questionnaire. To meet it, so far as possible, I think every questionnaire investigation should be so planned that a benefit will accrue to the parties answering; perhaps a promise of the results of the study is sufficient. Less than this can hardly be offered. One respondent wrote that duplicate copies of every questionnaire should be sent out, for if the matter is worth the time of the recipient, it would be of such value that he would like to keep a copy for his files. It should not be deemed sufficient to say to the recipient, "You will be helping the cause of science." As to that, each should be the judge for himself.

I lay it down as an axiom that every human being connected with a study should get some satisfaction from it. The recipient of a questionnaire is the intermediary between the author's hope and its realization. To constitute an organic work, the middle must be vitalized as well as the two extremes. The leaves of a tree bribe the trunk to send up water and food from the roots, by offering good fixed nitrogen in return. Under these conditions the trunk accepts the task and becomes an integral living part in harmony and in willing cooperation with the roots and with the leaves.

The third shortcoming of the questionnaire method lies in the difficulty of making from a priori considerations a fair selection of experts. As previously mentioned, this need not be an insurmountable difficulty, for lesser experts can be used to select greater ones.

The questionnaire is sometimes used in a field where the experimental method could be employed. In such a case it is clearly a makeshift, and indefensible except where time and cost necessitate it. Such was the case when the oral 
questionnaire method was used to draw up the manual of trade specifications used by the United States Army during the war. The judgments of a few officers stating the qualifications needed in, say, an airplane hangar attendant, could be quickly gotten, while an actual qualitative and quantitative survey of the duties of such attendants would have been a long undertaking.

Let me conclude this investigation of the value of the questionnaire by saying that unless and until experimental science relieves us of the need of human judgments, or removes from our minds an interest in unique events, this wayward child of science, feeble as it is, will remain an indispensable helper. It will thus be always needed, and we can but hope that it will curb its intrusive disposition and mend its unseemly ways. 


\section{LECTURE III}

\section{IN WHAT UNITS SHALL WE MEASURE INTELLIGENCE AND ACHIEVEMENT}

THE units in which natural phenomena have been 1 measured have been intimately connected with progress in science. It is not until we have units of measurement that we have definite measures of progress, but of course there must have been progress before this, or the units themselves would not have been derived. Undoubtedly units of weight, time, distance, temperature, volume, etc., grew out of felt social needs. The early developments of units in all of these fields antedates historical time, but we can imagine what might have taken place.

A Neanderthal man in hunting had wandered three sun-settings from home. With his mighty club he killed a wild boar, and gorged himself, but, even so, the major portion of the carcass was unconsumed. Fearing that he would be killed if he should fall asleep with all that wealth beside him, he shouldered it and set out and shortly came to a village of friendly tribesmen. Now property rights were well established in those days. It was agreed that if a stout tribesman entered a village with a dead boar over his left shoulder and a club in his right hand, the boar was his property. Our man was a cunning fellow. He thought, "This is a wonderful carcass, and I cannot take another bite, and I am sleepy and cannot stagger for another three days, so I cannot take it home now-and I remember having found that even a beautiful carcass loses its savor after 
three days' ripening in the sun; so I must negotiate a long-time contract." Seeing a wife and many children gathered about a tribesman who eyed his trophy hungrily, he said, "My compatriot, you and your family need sustenance, and need it now. I shall need it three sunrises hence. I give you this choice pork if you give me back the same amount of prime fat and protein in three days. How now, is it a bargain?" "It is." Our sleepy hunter has not lost his wit. He says, "Come, red-haired urchin, and lift this portion for me." The boy struggles and can barely budge it, so the thing is weighed. Our hero pulls off a lock of the urchin's red hair and ties it in his own as a means of identifying his weighing scale three days hence, when he hopes to get back an equally heavy portion of a newer kill. The headman of the clan bears witness to the transaction, and almost in a jiffy snores proclaim that no time is being lost in the enjoyment of the three-day period.

This contract in futures, in addition to principles of credit and underwriting, involves physical measures of time and weight. The time unit is fairly exact. Unless our man sleeps the sun around and fails to notice a sunrise, he can each day chew a mark on his club and have documentary record when the three days are up. His weighing scales lack something in precision. They are in fact not much better than our own scales of mental measurement today, but they are a beginning for the science of dynamics. Whence came the background that led our Neanderthal scientist to conceive of weighing an article? Did he know that two properties, mass and force of gravity, were involved in the weighing feature of his program? No, he simply knew that the thing done was beneficial to him. He 
was going to want, in the future, fresh meat and lots of it, and the urchin could lift. In other words, he has a measuring device of something, he cares not much what, but it is a something which it is to his advantage to measure.

How close the parallel to our mental measurements today! Our mental tests measure something, we may or may not much care what, but it is something which it is to our advantage to measure, for it augments our knowledge of what people can be counted upon to do in the future. The measuring device as a measure of something that it is desirable to measure comes first, and what it is a measure of comes second. The amount the red-haired urchin can lift depends upon the mass, the slipperiness of the hold he gets, his immediate effort and state of being, etc. In the first crude usage of this weighing scale, which of these are relevant and which are not is not thought of. All that is considered is that on the whole it is a pretty good scale. Homo-Neanderthal was as tickled with his weighing scale as are my colleagues when they devise a new psychological test. The use of the scale is the quickest means of discovering its shortcomings. Neanderthal's great-great-grandchild may stipulate that the lifting is to be by grasping the hind legs of the animal, and no slippery hold is to be permitted.

In the matter of mental measurements we are in that stage where we know that we are measuring something that it is valuable to measure. Our measures work in giving us information that is good to have. Those standing high on the Army Alpha do, on the whole, make better officers than those standing low. Those standing fairly low do make better clerks in positions involving monotony and light be- 
hind-the-counter chit-chat than those standing high. Those scoring high on a number of our school achievement tests do succeed better in the work of higher grades than those standing low, etc., almost without end.

My discussion therefore starts with measuring devices that are valuable, and it does not need to start with any hypothesis that we know just what the valuable thing is that we are measuring. I can now give an answer to the question which is the title to this lecture, "In what units shall we measure intelligence and achievement?" The answer is "In such units as will be of most value to us in doing the work of the world." This answer of course requires further elaboration. If some philosopher argues that intelligence is a mental trait that shows itself in some carefully defined manner, I shall not take his statement as evidence that I should measure this thing. Only in case his definition involves in it the idea of greater utility in practical problems than some other definition, would I feel inclined toward it, and then the test would be whether this greater utility was actually present or not. For the Neanderthal man to have a measure of weight that was independent of slipperiness would be an advance. It would better serve the needs of commerce of that day, just as an international standardized currency would better serve the needs of commerce today.

I am not arguing for a unit that serves a commercial need as opposed to one that serves a scientific one. I am merely advocating a unit that serves a need of some demonstrable sort as opposed to one that meets a hypothetical mental standard. The mathematician can propose and develop most beautifully innumerable different units of time, 
but probably one only of them will well meet the objective needs that the astronomer finds inherent in his data. As a problem in abstract thought the development of these different units of time is highly profitable; in fact, not uncommonly suggestive of issues to be experimentally investigated. But, so far as adoption is concerned, that one only is to be adopted that most completely meets the temporal conditions imposed by life. The time relationships of life are generally imposed by a power beyond ourselves, by God, by nature, by necessity, or by whatever name you choose. Now as indicated in my last lecture, some of the mental relationships of life are not imposed by so invariable and just a hand. They are, however, none the less imposed, though by society itself, and it is just as necessary that our mental scales meet the needs that society imposes as that our physical scales meet the needs given by the laws of the physical universe.

What are these needs imposed by society in the field of mental phenomena? Clearly, one need is that a term used be used with the meaning that society has already attached to it. If we define honesty in some manner, for example, as the ability measured by a certain specific test, not at all in keeping with the already existent consensus of opinion as to its meaning, then the units of the test are improperly called units of honesty. They may be valuable units of some mental capacity - that remains to be proven, but the value does not partake of the already existing value known to be attached to the concept honesty. Even if the order of individuals as given by the scores on the test called an honesty test agreed with the order of the same individuals judged for honesty by their acquaintances, still the test 
units might not be appropriate, for this would only affirm that the two rank orders were similar, and it would not state that the quantitative differences between scores were alike. Suppose the test places three individuals, $A, B$, and $C$, in this order, and such that the number of units from $B$ to $C$ is twice that from $A$ to $B$, and suppose the judgment of acquaintances places the individuals in the same order $A-B-C$, but such that the distance from $B$ to $C$ is the same as that from $A$ to $B$. Then, although the test preserves the rank order of the judgments, its units of measurement are inappropriate because they do not preserve the quantitative relationship of the criterion, which is honesty as sensed by competent acquaintances.

Another source of trouble may be mentioned. It is the location of the zero point of measurement. In some mental investigations estimates of ability from zero are frequently made, while in others they are seldom if ever employed. In the case of honesty we may judge of the distance between individuals without in any instance judging of an individual's honesty above zero. We can then lay down two important rules for a test measuring honesty. First, the function measured by the test should be the same as that judged to be honesty by competent people in general, and, second, the differences between test scores of individuals should be proportional to the differences in honesty of the same individuals as sensed by competent people. A third condition, that dealing with the zero point, may or may not be of great importance. I will call any scale meeting the first two conditions a sensed-difference scale.

Since people do talk about honesty, would it not be a fine thing if a reliable objective scale for the measurement 
of it existed, thus making if possible, by giving a test, to obtain fairly accurate information upon a trait which is now much less accurately revealed by such judgments of acquaintances as it is ordinarily possible to collect? The merit of such a measure would lie first in measuring just the same trait and in proportional units that judgments now evaluate under the same term, and, second, in doing it more accurately and expeditiously than is now possible by means of judgments. Such a scale would serve in the work of the world. It would simply make it possible to do better that which we would do anyway. We should not have to justify the objective of such a measure, for the objective is already socially sanctioned. A scale actually established to be of this sort needs no defense.

Of no other kind of scale can the same be said. No other kind of scale is, strictly speaking, entitled to be named by a word whose meaning is already established by social usage. Let us consider such a scale. We will call it a scale of "intellability." Intellability is not an English word already having a meaning, so I am treading upon no social preserves in using the term. I can define it as the ability measured by my test, and thus I have a very objective definition, though not a definition with meaning to my hearers as yet. In fact, the term is like any other technical term coined to describe a new phenomenon.

The word "chromosome" is such a term. Only those becoming acquainted with certain life phenomena, new as judged by older standards, understand it, and profit thereby in their understanding of life. An entire set of relationships and meanings have been built up around the word. The important thing to note is that all these elements of 
value have been built up. Not one, without demonstration, could be adopted from earlier social meanings or habits of mind. This is a scientific procedure, and I shall shortly speak more of mental units, which cut loose completely from social concepts as represented by existing meanings of words. I wish now to point out that intellability has not a leg to stand on except as it grows its own. This term and this concept require justification, whereas honesty, meaning thereby present social consensus of opinion, requires no defense.

The proof that intellability should have a place in the sun is no small undertaking. As a mental trait its meaning is to be related to existing concepts of other mental traits which are not defined in terms of test scores, and it must be shown to have some unique property which is important in the lives of men. From the date of its birth it is on the defensive just as were such terms as "chromosome," "gamete," "ion," "proton," etc. These words have survived, but recall how each describes a characteristic of nature not earlier described, how each is involved in and helps to explain relationships not earlier understood. The same rigorous test will determine if intellability is to live. Now I believe that such new mintings are going to take place, and that soon. They may even in time relegate to the scrap heap some of our fondest concepts such as intelligence, innate mental ability, and the still common terms of faculty psychology, just as "effluvium," "humour," and the "four elements, earth, air, fire and water" have been. These are no longer of social value, having been displaced not by new words meaning the same things, but by words descriptive of entirely new structures of thought. The periodic 
table of elements tells a story so much more interesting and forward-looking than any bounded by "earth, air, fire and water" that these latter words as boundaries of matter have been allowed to crumble.

At present I do not wish to defend intellability or other new mental unit. Rather I want to indicate the benefits of, and the method of deriving, mental units which take their cues from present concepts. I have made an attempt to do this with results that seem very promising. The function I have dealt with is achievement in the elementary school. The ultimate source of authority upon what constitutes achievement in the elementary school is the consensus of opinion of American school men and women.

It has been argued that each of the questions of an elementary school achievement test should be accepted by such a consensus as appropriate, and should be so weighted one to another in the aggregate test score that the relative importance of the various parts of the test is in harmony with the consensus, and finally, no material elements should be omitted that the consensus would include. Now this is not sound doctrine-the consensus passes judgment on the grand total outcome. It asserts that the distinctions drawn by the test scores between children are or are not sound. The consensus is ultimate in the judging of people, not of test items. The preliminary stages in the selection of items for a test may depend upon the judgment of the individual or group devising the test but no excellence in judgments at this stage is a proof of validity of the test. Ultimately and authoritatively, this depends upon the agreement between the measures of school achieve- 
ment of children as determined by the test scores and as determined by the consensus.

The detailed process connected with the preliminary and final validation of a test is too lengthy to expound here. As any careful test-maker will know, it is concerned with securing a test of high precision or reliability in addition to securing one that is valid in that it meets the views of the expert consensus.

In the devising and weighting of the parts of the original Stanford Achievement Test, of which I am one of the joint authors, the considerations just mentioned were clearly in mind. It was attempted to devise a test that would do, but more accurately, what teachers attempt to do anyway when they record school achievement marks, with one important exception.

The exception is that no attempt was made to make the units of the test proportional to the judgment units of teachers. If on the test three pupils, A, B, and C, had scores 40, 60 , and 70, not only is their order of achievement indicated, but it is also stated that Pupil B is twice as far. above Pupil A as Pupil $\mathrm{C}$ is above Pupil B. It is known that in general a consensus of opinion of teachers would give the same order of pupils but not the same quantitative relationships. In short, the scores upon the original Stanford Achievement Test give a rank order of pupils in substantial harmony with the consensus of opinion order, but they do not preserve the quantitative differences of the consensus of opinion standard. It should have done this latter, to be fully entitled to the name, "An Elementary School Achievement Test," for the meaning of elementary school achievement is already established by teachers' judgments. 
As an independent study not connected with the construction of the test, the quantitative aspects of the Stanford Achievement Test units and judgment units were investigated as follows: It was assumed that teachers of the elementary grades were equally competent in judging of the achievement of their pupils, and that the sensed difference from the grade mean of the third-grade pupil, who was not promoted or was doubly promoted, that is, who was allowed to skip a half-grade, was the same as the sensed difference from the fourth-grade mean of a pupil not promoted or doubly promoted, and similarly for each of the other grades. In short, if a third-grade pupil is sensed as so non-typical that he is put out of the group, he diverges by some number, let us say, $x$, of sensed differences from the group mean, and if a pupil of another grade is likewise so treated, he diverges by the same number, $x$, of sensed differences. The distance of these two pupils from their respective grade means is therefore the same in terms of sensed differences; that is, these distances are the same on the judgment or opinion scale which is our standard.

This method of securing measures of sensed differences seems to me reasonable, but it is only one of a number of possible methods. A variety should be employed, and the results compared. Though I can state numerical results for this one method only, they seem to me of themselves to be important. I can state the results in terms of the Stanford Achievement Test units. To make the test units proportional to sensed difference units it is necessary to multiply the units in the neighborhood of the mean score for eight-year-olds by one and one-half, as compared with 
units in the neighborhood of the twelve-year-old mean. I do not expect this statement to carry any particular meaning to any of you, but from it can be derived another. It is: If the sensed difference between the mean scores of third- and fourth-grade pupils is called 1, that between second and third grade pupils is 2 , and that between seventhand eighth-grade pupils is $2 / 3 .^{1}$

In short, teachers do sense the achievement differences between grades as progressively less as we ascend the grade ladder. This is not at all surprising. These lesser differences in the upper grades that are sensed are due to demotions and double promotions, so that in the later grades groups are more homogeneous, and closer together in the teachers' judgments. I mention this fact to make clear my point that the units of a true achievement scale-one that means by achievement what is already meant in the experience of school people-should be such as to yield differences between grade means proportional to these sensed differences. For example: If a certain general school achievement test yields third- and fourth-grade norms that are 30 units apart, this same test should yield seventh- and eighth-grade norms that are 20 units apart. I should say that I am arguing for a principle, not for this exact numerical relationship, for the data from which it was determined are not as extensive as they should be to decide so important a matter.

I trust that I have shown that units proportional to sensed difference units have a peculiar claim to validity in

${ }^{1}$ These facts may be deduced from Table $\mathrm{E}$ of Kelley, Truman L. The Influence of Nurture Upon Native Differences, 1926, together with the published norms on the original Stanford Achievement Test, 1926. 
connection with achievement. They certainly have no less a claim in connection with honesty, originality, or other mental function.

What are appropriate units in which to measure native intelligence? I speak of native intelligence, and not intelligence, for this latter term means to some intelligence as determined by original nature, and to others the outcome of nurture, achievement, and original nature. I do not know what the consensus of opinion is as to the meaning of intelligence, but if I speak of native intelligence, I feel fairly sure that that fraction of later life acumen is implied that has not been determined by the specific nurture of the individual. This very statement supposes that there is such a fraction. We cannot tell until we attempt to measure it.

Now if one portion of later life capacity is due to one cause, say, original nature, then the rest must be due to some other, single or complex. Thus if we have a scale of native mental ability, we should also have a scale of something else. I believe it will be in harmony with general opinion to call this something else a nurture scale. Let us then first consider the determination of this second scale. If such a scale can be built up it will have value, very great value, upon its own account, and it will also have great value in showing what is not to be included in the native intelligence scale.

One aspect of the concept, native intelligence, is that it comes increasingly into manifestation with growth. Though present in germ at birth, it is not then full-fledged. Just as the physical changes that occur at puberty are considered matters of original nature, and not of nurture, even 
though they take place fourteen years after the gametic union, so mental phenomena may and probably do occur at late as well as early periods in life, which are in fact but the flowering of original nature. Thus one of the important characteristics of native intelligence is this phenomenon of delayed expression, or, if you will, is the phenomenon of growth.

On the other hand, nurture is timeless in the sense that the opportunity to learn a certain thing and the effort to teach it may occur at any age; that reading is not taught with equal emphasis from birth to adulthood is surely due to limitations as to feasibility imposed by original nature, not due to lack of environmental agencies willing to teach it at any age. If, therefore, we desire to build a nurture scale, we must rule out of it all of those things that are highly correlated with chronological age from birth to adulthood. To select the elements which will enter into our measure of nurture we must find elements which do not correlate with chronological age, or, if there are none such, we must consider that a test element is partly nurture and partly nature in proportion to its tendency not to correlate with chronological age to its tendency to so correlate.

I can make my meaning clear by an illustration. I give as a completion exercise the following: "Little Miss Muffet sat on a tuffet, eating ..." In giving this exercise to groups of one-year-olds, two-year-olds, etc., up to adults, we should find varying numbers of correct responses. None of the one-year-olds will get it, some of the two-year-olds, etc., but at no age shall we get 100 per cent correct response. Immediately we see that the Little Miss Muffet growth curve is not like the sexual maturity growth curve. A certain 
percentage of boys are sexually mature at 12 , a larger percentage at 13 , etc., until all are mature at 20 . The ability to say the words, "Little Miss Muffet sat on a tuffet" is conditioned upon the maturity of vocal organs and cerebral connections which are innate and which develop in an orderly manner with increase in age, but the proper completion of this exercise with the words "curds and whey" depends upon something not so conditioned, and not in all cases happening in an orderly manner with increase in age. I doubt not that there are people in this audience who did not know of Miss Muffet's fondness for curds and whey. Because of people such as these, the correlation of ability to complete the exercise and age will drop down below what it would be if the completion were merely a matter of native intelligence. This shortening or dropping down of the correlation is a measure of the extent to which the exercise is a function of nurture.

It only remains to find just the proper procedure to utilize this fact in determining just what portion of an outcome is due to nurture and what portion to nature. Such information can be utilized in selecting items as nearly 100 per cent nurture as possible to build up a nurture scale. If we have such a scale then we shall be able to clearly see what nurture does. It is manifestly unfair to judge of its role by our present scales of intelligence, because one and all have been built up with the idea of securing as high correlation with chronological age as possible, and not with the idea of securing as low correlation as possible.

Compare if you will nature to height, and nurture to breadth. Suppose that I have a more or less effective set of measures of height-sticks gathered at the seaside, of dif- 
ferent lengths. I gather them because they are of different lengths, paying no attention to other features. Now of course it will happen that they will also be of different widths, but they may be totally unordered for width, and totally inadequate as a width scale. If I persist in using my set of sticks to measure all new phenomena, I will get the impression that the only essential characteristic of such phenomena is height, and come to believe that there is no other dimension. Has not something of this sort happened in the case of those who attribute most of mental difference to difference in native intelligence? These people have had at their hand a measuring device, a Binet test or any other mental test that you wish to name, the very elements of which were chosen because of high, not low, correlation with chronological age.

The nurture advocates are largely to blame for this situation. They have not developed a nurture scale. They cannot effectively combat positions based upon measured individual differences by beating the air with verbal observations that there are other differences. They must demonstrate that there are, by measures based upon objective tests, or upon demonstrable and verifiable consensus of opinion. Generally speaking, they have done neither, and in their criticism and ridicule of the advocates of the all importance of original nature, they have not uncommonly included all psychological measurement itself as an object for their attack. But intelligence and achievement measurement seems to have survived these valorous assaults, and I. now fear that unless the nurture proponents hurry up, the measurement people will seize their Holy of Holies and measure nurture itself for them. 
I have said that the devisers of mental tests have chosen test items on the basis of their correlation with chronological age. Cannot an even more accurate method be followed to build up a native intelligence scale? What are the properties of such a scale? It would correlate with chronological age to a certain high amount, and any inclusion of an item largely nurture would lower the correlation. Second, and this is the new criterion that I propose: The correlation between an individual's score at one age and the same individual's score at a later age should be perfect, or as nearly perfect as the chance factors in the test permit. Clearly, this would be so if the test is a native intelligence test, for one's native intelligence is given at birth, only requiring growth for it to blossom forth in its different aspects. Now growth results in a difference in age means, and the correlation method in which deviations of individuals are measured from their own age means would completely allow for this phenomenon of growth. Therefore the deviation from an age mean at one age and that at another are merely due to innate individual differences, provided of course the scale is, as supposed, a scale of innate mental ability.

I have used this second principle, not, as I here advocate, in the selection of items of a native intelligence test, but in testing units of measurement of one, probably the best, intelligence test-the Stanford Binet. I am convinced, and I am sure the author of the test is also, that the items of the Stanford Binet fall considerably short of being 100 per cent native intelligence items, uncontaminated by nurture. Nevertheless, it has seemed worth while to assume that they were such items, and then to see if the units of meas- 
urement were as good as they could be. Discarding now the consensus of opinion standard as to what is meant by native intelligence, and by units of it-in other words, by equal differences in native intelligence- let us adopt a criterion independent of human judgment. As there is no clear consensus of opinion as to the meaning of native intelligence, we are not taking any violent liberties with usage if we ascribe to it the following properties.

(1) Except for growth, it does not change in the individual as age changes. (2) Natural or correct units for its measurement are those which reveal this fact. As a corollary to this second statement, we can say that if the units of measurement are not these natural units, then the correlation when differences are taken from age means of an individual at one age and the same individual at a later age will be less than if measurements are in these natural units.

This immediately suggests the experimental device of finding the natural units of measurement by so determining test units that the correlation between early and late scores is a maximum. This has been done with an outcome that I will shortly mention. Also the correlation between sibs has been investigated. As there is an innate correlation dating back to the germ cells, between children of the same parents, we can use the same argument and say that the natural unit of measurement will be that which will make this correlation a maximum.

In passing, let us note that one characteristic of the natural unit of measurement in the case of a nurture scale would be that which would make these same correlations minimal. The argument is straightforward, but the application of it meets difficulties because, as mentioned, our 
scales do not come to us, probably cannot come to us as pure nature and pure nurture scales.

The first population upon which I can report experimental findings consists of 521 pairs of sibs, tested with the Stanford Binet. Of these 262 were California children, for whom data were kindly supplied by Dr. Lewis M. Terman. The data for the remaining 259 were given me by the late Dr. Bird T. Baldwin, from Iowa Child Welfare Station files. All of the children were considered normal. An examination of both of these groups suggests that the populations were not quite typical, as there is an excess number, perhaps 5 per cent, of both low- and high-grade cases. It was ascertained after considerable labor that the effect of these cases upon the issue involved was small, so all cases have been included in the results that I shall report.

The correlation between sibs for this population of 521 , taking as the raw scores deviations from smoothed age means determined from these same data, and then using the Pearson product moment formula, was .62. Of course, in getting this a year's mental growth, whether from 4 to 5 , from 5 to 6 , or from any other age to the year above, is in every case called one. Now it is known that at the upper end of the scale, say from mental age 15 to mental age 16, a greater mental difference is indicated by the difference of one mental year than actually takes place in median children as they develop from median 15-year-olds to median 16-year-olds. This is a disconcerting element for our present purpose. Though I have not attempted to allow for it, I would say that as the bulk of my data involved mental ages below 14 years, this factor cannot be expected to seriously cloud the general relationship for ages up to 15 . 
The mental span from 0 to 4 years was given the literal symbol " $a$ "; that from 4-5 was called $b$, that from 5-6 was called $c$, etc. Thus a child of mental age $51 / 2$ was given a score $a+b+.5 c$. A child of mental age 101/4 was given the score $a+b+c+d+e+f+g+.25 h$, and similarly for other mental ages. As all the children were above mental age 4 , and also above this chronological age, the first literal element, $a$, dropped out of the correlation computation. It was endeavored to ascertain the values that should be assigned to $b, c$, $d$, etc. that would make the correlation a maximum.

A further statistical condition was imposed to simplify the work and to prevent chance fluctuations from unduly affecting the values, as would obviously be the case were it to turn out, for example, that $b$, the mental year from 4 to 5 , should be called $2 ; c$, the mental year from 5 to 6 , should be called $.5 ; d$, the mental year from 6 to 7 , called 3 ; and so forth, in an irregular manner. This was the requirement that values of $b, c, d$, etc. should lie on a single curve capable of representation by a second-degree parabola. Even the requirement that they should lie on a straight line would have been sufficient to tell whether the early mental years were greater or less than the later, so the condition that these units lie on a second-degree parabola is quite general enough to yield as great refinement as our present state of knowledge can profit by.

Let me summarize the argument underlying this procedure. The correlation between sibs in the case of measures of ability not influenced by nurture is something that dates from the birth of the younger sib, and since it is given once and for all this correlation will not change 
throughout the life of the couple, if allowance is made for growth. The measure of this correlation will be weakened by any improper units of measurement. If therefore we start with units as given by a test, and alter them so that a higher correlation between sibs is obtained, we shall be altering them in the direction of natural units of native ability in the function tested. The same argument holds so far as direction of change of unit, if the measure worked with is in part a measure of something other than native ability, something such as nurture, not having a high invariable correlation as between sib and sib. ${ }^{2}$

Since brothers and sisters 3 to 4 years apart in age have different school teachers, a common nurture influence between sib and sib showing high correlation can hardly exist in the matter of school subjects. In other fields not limited to family things (thus perhaps religion is excluded), there is still less reason to believe that sibs have a common nurture. The Stanford Binet is considered to be a test largely inHuenced by native ability and, to a lesser extent, by nurture. Then we investigate the Stanford Binet units and so alter them that the correlation between sibs is a maximum. In the particular sample worked with, this treatment raised the correlation from .62 to .72 . I will express the results as they bear upon units in the same terms as I did those dealing with sensed differences. We will remember that we found that if the difference between the third-and fourth-grade means in general scholastic achievement is called 1 , that the difference of seventh- and eighth-grade means is then to be called .67 , in order that equal numerical differences be

\footnotetext{
2 See Appendix A.
} 
sensed as equal. Here in the case of the Stanford Binet it is found that if the distance between the mean Stanford Binet scores of third- and fourth-grade children is called 1, the distance between the mean Stanford Binet scores of seventhand eighth-grade children is to be called .50 , in order that the correlation between sibs shall be maximum. These two results are not indentical, but they are of the same general urder. There is no logical reason why they should bear any resemblance to each other, as the tests are different, the subjects tested are different, and, most important, the purpose of the investigations are absolutely different. The one investigation aimed to secure units equal in the sensed difference meaning, and the other to secure units which would not weaken any intrinsic correlation which might exist between sibs. That the outcomes are similar is both surprising and gratifying. The prospect is that here in the mental field there is no great discrepancy between sensed and natural units of measurement. We know, according to Weber's law, that equal sensed differences in height are not equal differences as the physicist or the man with the measuring stick counts them. For such judgments of difference as one commonly needs to make, the physical measure of difference is not a bad unit to employ. It is with little difficulty incorporated into our scale of meanings, and no separate sensed difference scale of length is found in common usage. The prospects are that the same thing will be found to hold in the mental field. Though the sensed difference scale is in terms of meaning, it may yield to another, but slightly different one, in terms of which the phenomena of mental life can be more accurately and invariably expressed.

Now the fact that the Stanford Binet is called an in- 
telligence test, and the Stanford Achievement Test is called an achievement test does not settle the question as to whether they are or are not measures of the same thing.

Further, excellent as human judgments may be, and ultimate as they are in determining questions of meaning, they do not serve to determine a question of meaning here. The natural field in which human judgment finds expression is in the appraisal of fellowmen, not of test items. If a reliable consensus of opinion-and we can determine the reliability of a consensus-asserts that John is as intelligent as Joe, no test result can impugn the statement, but if a consensus of perfect reliability asserts that test item No. 1 will be found upon trial to measure the same function as test item No. 2, the issue is not closed. If the members of a group differ in their relative success with the two items in a manner not attributable to chance-and this can be measured-then the items are different, no matter how certain the judgments had been to the contrary. Judgment has overstepped its proper limits in claiming authority in this matter. True, when experimental evidence is not at hand, judgment of such a matter as this may be of much assistance, but it is not the ultimate court of appeal. Accordingly, though judgment should proclaim the Stanford Binet and the Stanford Achievement Tests to be different, we are not called upon to accept this assertion in the face of experimental facts, and we are not expected to forego getting such facts because of the assertion. I have investigated the units of the Stanford Achievement Test, just as I have those of the Stanford Binet, with results that are most interesting, both on their own account, and because of their relationship to the Stanford Binet results just given. 
Through the kindness of Mr. W. E. Wiley I was able to study the Stanford Achievement scores of some 230 pairs of sibs attending the elementary grades of the Lodi, California public schools. In the case of the Stanford Achievement Reading Test, I found that if the difference between the third- and fourth-grade means was called 1, then the difference of seventh- and eighth-grade means should be called .43 , in order to yield the maximum correlation between sibs. The result is quite in harmony with the .50 found for the Stanford Binet. This similarity may indicate that the assumptions made are about equally valid whether the Stanford Binet or the Stanford Achievement Reading Test is involved. In these same subjects it was found that for the Stanford Arithmetic Reasoning Test if the third to fourth grade difference is called 1, the seventh to eighth grade difference should be called .83 for the correlation between sibs to be a maximum. This result is a little farther away from the Stanford Binet result, and on the opposite side of it from that for Reading. Possibly the Stanford Arithmetic Reasoning Test is even more a native mental capacity test than is the more comprehensive Stanford Binet. Finally, for the same pupils it was found for the Stanford Computation Test that if the third to fourth grade difference is called 1, the seventh to eighth grade difference should be called .44 to yield the highest sib correlation. It has not teen possible to calculate the probable errors of these results, so we must judge of their reliability by comparison one with another. They certainly do not wander over the conceivable range, which is from plus infinity to minus infinity. The smallest value we have is .43 , and the largest .83 , with values of .44 and $.50 \mathrm{in}$ between. 
One further approach, again entirely independent as to population, though somewhat similar as to hypothesis has been made. Assuming that the correlation between sibs measured for a native ability is some intrinsic amount greater than 0 and less than 1, and remaining constant for life, we have the argument already given. Now let us assume that the correlation between an individual measured for a native ability at one age and the same individual measured for the same ability at another age is perfect, no matter, of course, what the two ages, when natural units are employed and deviations of scores are taken from age means. This is an even more usable hypothesis than the former because the trustworthiness of our quantitative results are in large part dependent upon two things, one of which, nature, is the cause of high correlation, and the other, nurture, of low correlation. Surely one's original nature is perfectly correlated with his own original nature at a later age, so we clearly have one factor which leads to high correlation. The other factor, nurture, is probably not the cause of high correlation from age to age, for teachers change, and the incidents of child life are not strung upon a purposive chain-most children at the age of 14 do not know what vocation they will follow. An exception to this statement may be necessary in the case of religion and politics, for they may be the outcome of highly correlated elements of nurture.

Through the kindness of $\mathrm{Mr}$. Cecil R. Brolyer I have been able to study the Stanford Achievement total scores of 348 California school children tested with one of the forms of the Stanford Achievement Test in elementary school grades above the third, and retested three years later with 
the other form. At this later time quite a number of the children were in high school, and the test may not have been quite hard enough to have adequately tested them, though the test is known to be a serviceable measure in the ninth grade. It was found that if the third to fourth grade difference is called 1, the seventh to eighth grade difference should be called .45 , in order to yield the maximum correlation between the individual's first score and his second. This is in remarkable agreement with the earlier findings reported. The function tested is a composite including reading, arithmetic, language usage, spelling, history and literature information, and science information.

A similar investigation was made of a younger population-224 children in the second and third grades at the time of the first testing. The Stanford Achievement Test is comprised of nine tests when given to grades 4-8, and of 6 tests, 3 reading, 2 arithmetic, and one spelling, when given to grades 2 and 3 . Utilizing the results of these six tests only provides a means for studying the relationship of units at the second grade level to those at higher levels. It was found that if the third to fourth grade difference is called 1, the second to third grade difference should be called 1.66 in order that the correlation between the child's score at the first testing and that at the second, three years later, should be a maximum. The comparable value in the sensed difference study was 2.00 , so in these results again we see much similarity, considering that they are based on entirely different hypotheses.

The data that I have presented tend to show that units which make the product moment correlation between sib and sib or between individuals at one age and the same 
individuals at another age a maximum are closely similar to units which are sensed as equal by teachers, and they are such that approximately, if the third to fourth grade difference is called 1, the second to third grade difference should be called 1.75, and the seventh to eighth grade difference should be called $.55 .^{3}$

The agreement between the sensed difference and the maximum correlation units is an important point in their favor, but I do not at this stage of our knowledge assert that one of these or the average of these is indubitably the best unit to use for the scientific study of mental relationships. So far as present meaning of terms is concerned, a sensed difference unit certainly holds chief claim to consideration, but so far as new meanings, to be seen only when new units are employed, are involved, some other unit may be more serviceable.

Worthy of consideration in this connection is a unit based upon a Gompertz growth curve as S. A. Courtis has shown, and also the unit suggested by the studies of L. L. Thurstone. This unit is such that the mean score for an age group divided by the standard deviation for a random population of the same age is a constant. It is a device that would naturally lead to the use of quotients in the interpretation of scores, whereas the sensed difference unit naturally leads to an interpretation by means of differences in scores. It may be that we shall need both units. Consider the temperature scale. At the present time two very distinct types of interpretation are present, the one involving straight differences in temperature-practically all of our

\footnotetext{
See Appendix B.
} 
common usages of the scale are of this sort-and the other involving the so-called absolute temperature scale, in which temperature is measured on the Centigrade scale from $-273^{\circ}$. On this scale, when other things are equal, the pressure of a gas is proportional to its temperature, just as on Thurstone's scale group variability is proportional to group mean. In the case of temperature, the statement as to proportionality of pressure and temperature does not hold throughout the entire temperature range, but that does not prevent it from being a very useful relationship throughout much of the range. So with Thurstone's scale, though the relationship he pictures as being a possible picture for the hoi polloi may not hold for imbeciles or geniuses, infants or octogenarians, it may, however, be a very useful relationship for the description of the rest of us.

One further basis for the determination of units of mental measurements has very great scientific possibility. If we have a number of mental traits-to make it specific, let us think of musical ability, mathematical ability, and memory ability - that, when measured in a certain manner, are completely independent of each other, then this manner of so measuring them has peculiar value. If the traits are not, intrinsically, in the mental structure of mankind, independent, no units can be devised which would make them appear so, except perhaps discontinuous units or those all of the values of which are zero. Therefore if we can find any traits and units in which to measure them in terms of which independence is manifest, these will be the natural units, these will be the units in which all relationships will be evaluated in their true light.

The first steps in the building of a scale of measurement 
in which variability is proportional to mean, in the building of a scale in which the correlation of sibs or of early and late performances of the same individuals is a maximum, and the building of a scale in which the units are proportional to sensed differences, have all been taken with great promise. The first steps even have been taken in the determination of scales revealing independent mental traits, but here the task is much more difficult, though the benefits to be derived are correspondingly greater. When this latter is done-I do not say, if it is done, for it simply must be done, the needs of society and our demands for knowledge. will not be satisfied until it is done-we shall have a tool so powerful for the understanding of individual differences and of native possibilities and of nurture needs that we shall wonder how we staggered along in our social adjustments and our uncertain educational efforts without it. To any of you who are just entering the field of psychological research, we can say that the best problems await you. You can be happy that you are not restricted by Wundtian boundaries. 


\section{LECTURE IV}

\section{THE BEARING OF RECENT SCIENTIFIC DEVELOPMENT UPON PROBLEMS OF EDUCATION AND INHERITANCE}

QUCH experimentalists in curriculum construction as OW.W. Charters and H. O. Rugg are yet only few in number, so it is only a very slight exaggeration to say that from the dawn of history to the present day curricula have been constructed solely upon the basis of the opinions of individuals or of groups in authority unsupported by experimental evidence. During the World War an army school for mechanics was established in Brooklyn. A person connected with the instruction in mathematics informed me that 90 per cent of the mathematical content listed as necessary was, upon investigation of the activities of mechanics actually successfully at work, found not to be essential. The curriculum was radically modified, with the result that many more men were quickly made effective fighting units. Seldom do we have such an urge as a great war to stir our self-complacency with our current educational practices.

Some one may say the 90 per cent not needed for the immediate activities of wartime mechanics would be valuable for the activities and cultural life of similar people in times of peace. As to this I shall remain skeptical until proof is forthcoming. I cite this army school situation not to argue for more or for less theoretical mathematics in school work, but to illustrate two types of processes which may be employed in the building up of curricula. A certain content 
may be included because knowledge of it is demonstrably needed, or because it presumably will be needed, in the planned-for future activity.

It is surely true that intelligent and experienced adults can judge more wisely than children of what knowledge will be needed in later life. In granting this, does one grant the correctness of a curriculum drawn up upon the basis of the opinions of experienced adults? It is to be noted that this has been the method since the dawn of history. Has nothing happened meanwhile enabling an improvement in it? Is it to be the method for eternity? In other fields of life, history records an expropriation from judgment and an appropriation by science of one domain after another. Medicine has changed from an exhortation of evil spirits to an experimental science, astronomy from the interpreting of horoscopes to celestial physics, psychology from philosophy and belief in obsession to a laboratory science and an experimental study of individual differences. At every step an earlier prerogative of speculation has been reluctantly given up to observation and experiment.

Carefully note if you will that this yielding of ground by speculation has not narrowed the field in which to speculate, for at every step new and greater vistas have been opened up. The reluctance to yield ground has been due to the fact that generally the particular individuals who have had their speculative wilderness expropriated have been different individuals from those who have appropriated it, charted it, and in penetrating it have found a deeper, darker, and altogether fascinating wilderness beyond. We need not fear when we turn a domain over to measurement and statistics that we have lessened the opportunity for the 
mind to reason and to ramble. Does anyone believe that ten thousand, one thousand, or one hundred years ago there was greater opportunity for these things than there is today? Why, it is but a few years that we have had that limitless domain of non-Euclidian geometry in which to roam.

Let us then fearlessly approach the issues of curriculum construction and, though we rob some educational patriarch of the speculative activity that is closest to his heart, we should note at the same moment that we are simply clearing away detritus and exposing an underlying vein offering more profitable and more extensive fields for development.

If you are familiar with certain recent enumerations of geographical and historical allusions found in current educational literature, you will surely know of the invective directed against the use of such information for purposes of determining the proper content of the elementary school curriculum. Typical arguments are that such data would give Dayton, Tennessee, great geographical importance and Tom Heflin a great political personality, etc. This would be true if there is abrogation of the judgment, when one becomes aware of facts in a situation earlier devoid of them, but no such abrogation is called for. If one author, in writing a political history, believes that Elihu Root should receive more attention than Tom Heflin, does the fact, say, that Tom Heflin's name appears ten times as often in certain newspapers as that of Elihu Root, annul this judgment?

The issue connected with knowledge as to frequency in current usage of historical and geographic facts is the same as that connected with knowledge of word frequency. 
Thorndike's Word Book gives the one hundred, two hundred, five hundred, one thousand, two thousand, etc., up to ten thousand most frequent words in current English usage, as determined from a very comprehensive investigation. There are also several other word counts which can be used. Does this information do away with the exercise of judgment upon the part of the author of the elementary school reader? It certainly does with reference to certain features of the elementary text. Without the Word Book the author would have to use his judgment as to whether a certain word was, without specific instruction, within the range of comprehension of the pupils of a given school grade. With word counts at his hand this question is answered approximately by simply turning to the word in question and noting its frequency value. Thus one task of the elementary textbook writer has been taken away from him by the word count. This simply means that he can turn his attention to issues that are more worthy of his mental effort.

The old textbook not utilizing the word count is at a disadvantage in competition with the new one, and the author of the old book may perhaps ridicule the utilizing of word counts in constructing a reader. If this selfsame author would add to his present talents the knowledge provided by the word count he would be a still better authorwisdom will not hurt him-and he would maintain a place in the elementary reading textbook field; but as he seldom will do this a struggle ensues between the new and the old.

What has been said about word knowledge and reading is but illustrative of what is now taking place in every field of instruction from the kindergarten through the university. 
Though the outcome of the struggle is, I judge, certain, it may be long and bitter, and consume much of life's valuable time which should be devoted to more important matters. If we look at the matter from the viewpoint of earlier practice, the three following stages might be suggested: (1) All issues connected with the writing of an elementary school reader are settled by the judgment of the author. (2) An ever-increasing number are settled by scientific investigation, thus removing them from the province in which the author's judgment alone operates. (3) Finally a stage is reached in which nothing is left to the judgment of the author. These three steps would occur only to a man of narrow vision, but in such case it is no wonder that he will tenaciously cling to the first stage, fearing that any admission of experimental evidence is but an entering wedge which, if permitted, would finally demolish the ancient and venerable method that he stands for. Though I hold no brief for a method because of its antiquity, I should only be content to see such a method discarded in case a better arose in its stead. In this old method are to be found such good things as delightful fairy tales and classical stories, good English, good morals, and so forth. Would one substitute a word count for any of these, taking out, let us say, the infrequent but shivery word "ogre" and putting in the frequent good Republican word "prosperity?" Without answering yes or no, I will maintain that a better answer can be made with the frequency values of "ogre" and "prosperity" in mind than in ignorance of them. Here, as everywhere, to be afraid of knowledge is a cardinal sin against progress. With a mind awake to evolution we can readily see that the stages are not as given, but these: 
(1) all issues settled by judgment; (2) an ever-increasing number settled by experimental evidence, and as they become settled, an ever-increasing number of new issues arising which must be settled by judgment; (3) no third stage which is different in nature from the second. The problem has changed. That which in the first instance merely called for an act of judgment is now seen to be an intricate problem in science as well as judgment. The net social result of this change is an improvement in elementary readers with the resulting more rapid learning of school children.

Word knowledge was taken merely as an illustration. A similar story could be told involving individual differences, laws of learning, nature of growth, transfer of training, and so forth. How long has this fight between opinion and experimental evidence been going on? In the matter of curriculum construction it has hardly started. The determination of what constitutes an appropriate curriculum is a problem of estimating the future-the issue being, what can be done now that will best serve the pupil in the future, immediate or remote.

In my second lecture I made the observation that if the past bordered upon the future the only way to solve problems having future reference was by a study of the past. I then argued that the past does not border on the future, for the present intervenes, and the present is more than a point in time. It is a definite expanse limited by memory, aided by recorded fact or not, as the case may be, and containing verifiable elements of knowledge. This expanse is the home of the experimental method. Having located the issue we immediately see why it has been with us for so 
short a time. In the history of the race the experimental method in any field has been with us but a few centuries, and in the social sciences it is still an infant in swaddling clothes.

The first great need in providing a scientific foundation for curriculum construction is that we expand present-time so that we may conduct experiments in learning, in individual differences, in continuity of interest, in transfer of training, and in the nature of pupil idiosyncrasies, over a long number of years. If our experiments of these sorts could be a generation in length, assuredly hundreds of educational problems now "solved" by judgment-it would be truer to say now embedded in ignorance and polished with opinion-would yield to objective treatment. In addition to lengthening the present-time span we should extend the range of issues attacked by experimental methods. As one example, consider the honor system, put in, modified, taken out of high schools and colleges, with never an attempt to determine in a demonstrable manner the effect upon the child, which is surely the most vital matter connected with the question. Our social heritage in this matter is voluminous, and it is of such long standing that we continue year after year to attack this problem with opinion, it not even occurring to us that a new technique is possibile and essential to intelligent progress.

The introduction of the experimental method into human thinking has as yet had a rather small effect upon the public school curriculum. What should be its effect may be properly considered under two headings: first, what should be its effect upon curriculum research, and second, what should be its effect upon the philosophy of the curriculum. The 
first has been briefly considered. The second is a matter of opinion and in this connection I wish to quote certain eminent modern scientists.

In order that my present emphasis upon the experimental method may not destroy a total view of human development, I wish to quote first the very fine view of history given by Henry Osburn Taylor in the following words: ${ }^{1}$

Thus I have tried to set before you a layman's view, in which history shall not be mere narrative, nor merely the series of events forming the past; but shall incorporate and be the onwardstriding thought, the interwoven tissue of event itself, the element of continuity without which nothing is or can ever have been. Every object in nature, every bit of science, every philosophic theory, every phase and kind of religion, and every constructive or destructive act of life, possesses the constituent of being and becoming which is time.

As elements in the "onward-striding thought" of man, history and experiment are united. Though judgment as the basis of values leans heavily upon a record of the past, it should not be thought of as synonymous with history, being rather in the mental field what custom is in the field of conduct. Just as custom is measurably less than past practice, so opinion may be a very inadequate reflection of the history of thought. Such contrasts as have been drawn between judgment and experiment as bases of curriculum construction are not contrasts between history at its best and science. They are rather contrasts between general impressions of what the past has bequeathed, and experimental observation.

Perhaps an illustration will assist in making this point

1 "A Layman's View of History," Science, Vol. 67, No. 1731, March $2,1928$. 
clear. A consensus of opinion of people who have thought about capital punishment would yield an average result with wide variability from this average. Probably somewhere, not at the median of this distribution of opinions, will be found a view actually best interpreting the forward-striding of mankind - this is the interpretation, at its best, of history. Ordinarily we cannot pick this one view out from the many others, and are compelled to use a median view as the best available standard, though it depart quite radically from the best interpretation. Expressed in another way this is equivalent to saying that the standard (the median view) for this epoch is difficult to ascertain because of the variability in view, and when ascertained is of transient value because of the rapidity of social growth. In the case of the objective experiment, the variability of the results is ordinarily small, so that the use of the mean result will be a close approximation to the true result.

Still another distinction between judgment based upon history and current impression and experimental observation is important. The two things serve different purposes. For example, let us gather a consensus of opinion as to the status of transfer of training between certain school subjects, and second, let us conduct an experiment upon this. The specific thought of the past upon this subject, leading both to the present consensus of opinion and to the recorded history of it are probably so different in their general scope from the issue attacked experimentally that comparison is difficult. The experimental investigation, by its change in emphasis, may actually change the problem, undermining the historical and the judgment values just as was done when alchemy was superseded by chemistry. In addition 
therefore to the hazard in utilizing opinion, due to the variability of judgment, there is also a hazard due to uncertainty as to the relevance of the issues as determined by judgment. No comparable hazard as to relevance is present in the experimental method, which involves a testing-out step so that the experimental issue is supported or not supported by the experimental findings.

At its best judgment, unsupported by experimental evidence, is the future reference aspect of history. The connection between issues suggested by judgment and those arising from experiment is intimate and mutual. One important aspect of experimentation is a verification of the deductions of judgment, and as such it bears much the same relationship to judgment that experimental does to mathematical physics. Let me quote Dr. Edwin B. Wilson upon this point: ${ }^{2}$

Let us for a moment consider what is the function of mathematical physics. In a certain sense we get out of mathematical physics only what we put in. This is a purely mathematical implication and means merely that if our mathematics is watertight every conclusion must follow deductively from the premises. But in another and more physical sense we may and we ordinarily do hold that when we interpret our mathematical conclusion as a fact of nature we get new physics. In this way Hamilton got conical refraction........ Many other instances of obtaining from mathematics new physics could be adduced, and also many, perhaps more, instances of obtaining too much or too little. It is the interpretations that determine the value of mathematical physics and that make it as Darwin pointed out in 1912 a more exacting science than pure mathematics.

The relationship here pictured between mathematical

${ }^{2}$ "Some Recent Speculations on the Nature of Light." Science, Vol 65, No. 1681, March 18, 1927. 
physics and experimental physics is the ideal relationship to be brought about between judgment and experimentation. Mathematical physics becomes established after its deductions have been verified by experiment, and judgment as to appropriate processes, methods, and values should likewise become established only after experimental verification.

Until such time, judgment may determine conduct because no better method of determining it is available, but it should be realized that it does so on sufferance only. Just as mathematical physics is a more exacting science than mathematics, so judgment that stands up under the scrutiny of experiment is a more exacting type than judgment not called upon to do so, which latter is ordinarily understood by the term judgment, or opinion.

It has been mentioned that one important aspect of experiment is the inferences to which it leads. Of the innumerable illustrations of this, few are more striking than the discovery of $\mathrm{X}$-rays by Roentgen. I quote from Lafayette B. Mendel: ${ }^{3}$

[Roentgen] was not searching for a method of penetrating the interior of the body with light; rather following the studies of Lenard and Herz he was engaged in consideration of radiation from the seat of electric discharge.

Before the discovery of $X$-rays, it is inconceivable that any scientist, though fully informed of antecedent history, should set itself the problem of discovering $X$-rays. History, though complete, and judgment, though excellent, would have been inadequate for the attack upon this prob. lem. The inferences that gave us this wonderful new tool

3 "Some Tendencies in the Promotion of Chemical Research." Science, Vol. 65, No. 1693, June 10, 1927. 
in physical and medical science came directly from experiment and observation. Its discovery is not just a piece of good luck. It is characteristic of the outcome of experiment by one who observes carefully and infers with sagacity. It requires a special ability and outlook to see the significant aspects of an experiment. As Lafayette Mendel has said:4

Without a background of facts thinking becomes a difficult, if not a futile task. A rich store of fundamental facts is the indispensable equipment of what Pasteur so expressively termed the "prepared mind." Many persons are privileged to make chance observations: only the prepared mind profits by them.

When we attempt to incorporate scientific method as a subject matter into a curriculum, it is plain that facts, many and well ordered, must continue to constitute an appropriate content; but the handling of them, the reasoning with them, the drawing of inferences from them, and the devising of experimental tests of inferences is something new in the curriculum, something which cannot possibly in the world's history antedate the development of the scientific method. Is it not safe to say that whatever the value of a technique of instruction prior to the time of society's becoming selfconscious in the matter of scientific method-and we may ask if that time has yet come-the value is not that it develops a scientific type of thinking?

As an illustration of the inability of average or above average students to observe, infer, and make a few simple generalizations about phenomena, I wish to report an exercise in concept formation given to a university psychology class. The subjects were not inferior college students, but

\section{${ }^{4}$ Ibid.}


the process was so foreign to their mental habits that they were quite lost. Four shorthand symbols called "ray," "hay," "kay," and "lay" were presented, one at a time, on flash cards in figures or outlines with added circles, loops, and lines. As each card was presented for a few seconds, it was named by the experimenter "ray," "hay," "kay," or "lay," depending upon which of these four shorthand symbols was present somewhere in the simple figure. The only instruction given to the students was that they were to observe carefully so that they themselves would shortly be able to name the outlines. Every little while in the process of experiment the opportunity was given for them to attempt to do so. Just as rapidly as a student abstracted from the figures shown the four essential features that led to the naming of them, he was dismissed from the class, having solved the problem. The essential lines were not deeply buried in a complex figure. Most of the outlines were the essential elements themselves, plus a single added figure, such as a preceding circle or a following loop. For example, "kay" was a straight horizontal line. Outlines called "kay" were this horizontal line with a circle on the end, or with a circle in front, or with a loop on the end. Just as soon as this one feature, a horizontal line, was abstracted out of the situation presented, and all outlines containing this feature called "kay," the problem was solved. It seems simple enough for the kindergarten. Perhaps it is. Perhaps, as John Dewey implies, we should get greater success before the child's natural reasoning tendencies have been blunted by school discipline. However, for this group of average or above average college students the problem was too difficult. It had been 
intended to finish the experiment and its discussion in a two-hour laboratory period. At the end of four such periods three-fourths of the class were still unable to name the outlines. If this seems unbelievable to you, I ask you to repeat the experiment and satisfy yourself. ${ }^{5}$

The conclusion I draw is that the students in question had never had even the simplest training in careful observation, in the drawing of inferences, and in the verification of hypotheses; in fact, that they had probably had training antagonistic to these things. I judge, therefore, that they were as ignorant of the scientific method as though their pre-college training had been directed toward the trivium and the quadrivium.

In view of the present state of the curriculum and the techniques employed in such slight modifications of it as occasionally take place, does it not seem that there has been a pitifully slight transfer from racial knowledge of the scientific method to elementary school practice? I have not intended to picture tuition in the scientific method as a simple matter. We shall not know how difficult it is until we try, and when we do try we shall have an entirely new set of standards whereby to judge youth and wherewith to pick our future men of science. It is just about as reasonable to think that training in music will pick good mathematicians as that training in book knowledge, dependence upon authority, and rule of thumb, will select observers of natural phenomena, ingenious devisers of hypotheses, and severe critics of what constitutes proof.

Some progress has been made. John Dewey's philosophy,

${ }^{5}$ Considerable care must be taken to insure that those who have solved the problem do not inform the others. 
as so ably interpreted and extended by B. H. Bode and W. H. Kilpatrick, though placing a different emphasis upon many matters, does support a training in scientific method as does no other current philosophy. However, in considering the bearing of science upon education, the as yet unrealized benefits of a common knowledge of scientific method should be placed well in the foreground. A vigorous adaptation of the curricula of certain experimental schools to this end, followed by a thorough investigation of the results thereby attained, might revolutionize our teaching process in a generation or two.

Probably one result of a standard of measuring pupils which involved their level of attainment in the scientific method would be a realization, only dimly sensed at present, that different pupils should be differently trained. Were it established, as I believe it will be some day, that native capacity and appropriate training for the man of science are radically different from those for the man of letters, society might adopt dual or multiple standards of excellence in adults and types of training for youth. True, such an outcome would complicate our philosophy of life, but let it, if it leads to a truer picture. There is no virtue in preserving a simple philosophy at variance with the facts. The facts that bear upon this fundamental issue suggest that there are several different kinds of mental capacity, several different achievement growths, and an equal number of appropriate types of training, and even an equal number of psychologies of learning. To create a great mathematician and a great musician, we should probably start with two individuals of very different native talents. We should give each a training having, in addition to many 
common elements, a very considerable number of different elements, and the psychology of instruction of these different elements should probably be very different. The common elements in the two training processes are such things as reading, United States history, honesty, courtesy, and so forth. The different elements are ear training, vocal and manual production of music, musical appreciation and especially musical composition, and on the other hand, a training in the scientific method, in mental manipulation of spatial relationships and of quantitative concepts, in sustained attention, symbolic thinking, and logic. There is no a priori or experimental foundation for thinking that a single set of laws of learning would apply to these disparate activities, so that we should anticipate that different psychological principles, at least a radically different stressing of the factors conditioning learning, should be employed in the different educative processes.

On the basis of earlier work already reported in print, ${ }^{8}$ I venture to assert that a half dozen or more fields of life are as discrete in their mental demands as music and mathematics. Although we need much more experimental evidence as to independent mental traits, it is now time that we construct a philosophy of education permitting of them. The religion and philosophy of India are cordial to the idea of different goals for different people, but, generally speaking, Western philosophy and religion are not. Too many centuries have been devoted to teaching that all men are or are not directed toward one single goal, and further,

${ }^{\circ}$ Kelly, T. L. The Influence of Nurture Upon Native Differences, 1926. The Interpretation of Educational Measurements, 1927. Cross-Roads in the Mind of Man-A Study of Differentiable Mental Abilities, 1928. 
this goal has been so remote-the Day of Judgment, or thereabouts - that it has been impossible to devise any experimental check to see if the doctrine is sound. It likewise is impossible to determine that it is not sound. There is no harm in believing in a single goal, providing it does not, as it has in the past, lead to a withdrawal of men's interests in the immediate issues of a present lifetime, and in the existing social structure.

It has always seemed strange to me that modern philosophers familiar with the doctrine of evolution, aware of biological evidence that innumerable species that have lived in the past are now gone forever, and that the universal story of life is that of branching, growth, and then more branching, and so on and on, with no evidence of termination, should, in the case of man, reverse the process, and picture development as toward a single goal-perfection of some single sort. The idea that human perfection is a single thing exists only in the mind of man, for no experimental evidence supports it. Experimental and observational evidence can give no light upon an ultimate placed in the remote future, but it does give us much light as to a past and present tendency. It would seem wise to heed it in building up an outlook for the present, and the immediate future.

The complexity of modern life and the specialization required of leaders in most fields of activity are such that present society could not exist if the doctrine of uniform development were strictly adhered to. Require a child to develop equally in the various fields of science, in engineering, in social and cultural activity, and what should we have in the end? Though he were one in a thousand in ability and versatility, we should merely have a delightful jack-of- 
all-trades, who would make a fine patriarch for some lost and retarded tribe on a distant island, but he would be of little use in the work of a big city or in the defense of a nation in time of war. His chemical warfare, his prophylaxes, his art of communication, his military strategy, and so forth, almost without end, would be so inadequate that his quick annihilation would be certain, and a nation composed of such as he would promptly vanish from the face of the earth. The doctrine of uniform development is untenable, for the race that would adopt it would be no match in peace or war for one which developed specialists.

Generally speaking, the practice of the nations of the western world is to reward specialists; and their philosophy, as reflected in their public school curricula, is to develop paragons of uniformity. It is time that the right hand knew what the left was doing. There is no need to believe that, once the philosophy of uniform development concedes a step, that there will be no stopping point short of the other extreme, complete specialization of training. The hazard of this for social stability is evident. It lies in the difficulty of securing unity of action from a heterogeneous group.

Let us, for argument's sake, suppose that the goal of human life is single, and that of the many mutations as represented by specialization, one only is fit ultimately to survive, the rest being destined to die. Would it not be a calamity if in our endeavor to select the perfect man we chose the wrong mutation, eliminating the rest, including the one that in truth was the only one fit to survive? Shortly the one mutation that we fostered would die, for it intrinsically is not stable, and the human species as a 
whole would become as extinct as the dodo. The disappearance of a species in the past has been sufficiently frequent to suggest such a possibility for mankind. Mankind, however, has one great advantage over those forms of life that now no longer flourish. Man has a mind with which he can partially foresee the consequences of proposed conduct, and in the light of such pre-vision alter conduct before it is too late. Is not foresight his greatest blessing and promise of racial survival?

I have drawn certain implications for education from our knowledge of science, particularly such as pertain to individual differences. What are some of the implications to be drawn from it for racial betterment by eugenic breeding?

We should first recall some of the momentous items of racial knowledge bearing upon human generation, heredity, and improvement of racial stock. The first item and, I should judge, the most momentous of them all to human thinking, is the knowledge that sexual intercourse is the cause of offspring. When this idea first took form in the mind of primitive man, there must have been a feeling of kinship with God, of potency, of mastery over the very sources of life, that consciously put him above the brute. Some such kinship with the Lord of Creation must have welled up in the mind of man when he first controlled fire and became master of the living flame; such kinship as, in historic times, in the case of Newton, who was nearly overwhelmed with the idea that one law, and that within his ken, linked the motion of the heavenly bodies with that of objects upon the earth about him. Truly the knowledge of conception and the part that man and woman play in it is a mighty story that every child should be told reverentially 
at his mother's knee that its initial coloring be not that of the lurid light of the alley.

Perhaps primitive man was disappointed in that he could not use this great knowledge for the immediate control of generation, but instinctive passions, long antedating his intellectual knowledge, continued their rule. Probably in his attempt to give the mind a better chance to be master of passion he put on clothes, and now, after an interval of untold thousands of years, he has learned that by judicious continence or the use of other contraceptive devices the old rule need no longer operate, and the clothes are coming off again, at least so it seems. At any rate the knowledge of contraception profoundly affects man's outlook. It gives him a sense of mastery, of ability to cope with human generation not possessed before in historical times. Coupled with this knowledge of contraception is further knowledge in part ominous, and in part reassuring. It bodes ill for mankind to be assured, as much evidence indicates, that thus far contraceptive practices have been more extensively employed by that stratum of society that we might well most wish to increase-by college graduates, by the well-to-do, and by men and women in professional walks of life. Let us hope that some day, not too late, this nation will awake to the seriousness of this situation, and take the steps well within its power to change it.

The reassuring information is found in the very substantial body of knowledge explaining the mechanism of heredity. If the rules of breeding are known, then it only requires the will to do in order to progress in the direction the mind may dictate. In my next lecture I shall discuss the use of analogy in scientific work. In the matter of the 
mechanics of heredity we can say "as in the animal kingdom, so in the human." There are now too many specific verifications of this view to make it reasonable to longer doubt it. Of course we shall wish to test it upon every important issue, but meanwhile the presumption with reference to an as yet not tested point is altogether in favor of the view that the same mechanism maintains in mankind as in the lower animals.

Francis Galton was the great leader in showing the application of the principles of heredity to mankind. He demonstrated the principles of regression and variability as characterizing heredity in the human species, and he found a regression coefficient between offspring and parents of about .5. Let me illustrate this in the case of height, and to make the illustration simple, let us suppose that the average height of men and women is the same, and is 5 feet 8 inches. Then Galton showed that the average height of offspring of parents 4 inches above the racial average is 2 inches above the racial average, or the average height of offspring of six-foot parents is 5 feet 10 inches. However, these offspring will vary considerably about their own average. Similarly the average height of offspring of five-footfour parents is 5 feet 6 inches, and these vary considerably about their own average. Let us merely for the sake of illustration suppose that height is a desirable trait, that the more of it the better, and let us proceed to breed with the purpose of augmenting this feature. To start with we will say that the party platforms of the Republican and Democratic parties each affirm that the parents of the next generation shall be 6 feet tall, and even the Socialists agree, so it is law, lived up to and enforced. If you can imagine 
all of this you see that in a single generation, the mean height of the citizens of the United States is raised 2 inches - probably a greater change than has taken place in the race in historical time. There is no more reason to doubt that this would be the outcome than to doubt that dogs give birth to puppies, and cats to kittens. Further, this increase in height is permanent. If, after the first generation, all bars to mating are removed, and random mating takes place, the mean height of succeeding generations will remain 5 feet 10 inches.

No one familiar with genetics will doubt this statement, but some opponent to eugenics may say "All well and true, but you cannot continue the process indefinitely, raising the mean height of the race every generation by 2 inches, and thus obtaining in five hundred years a race of 8 or 9-foot giants." For reasons too intricate to explain here, this criticism may be taken as based on a sound conception of inheritance in a stable population. I would, however, give three reasons why it should not lessen one's trust in the possibility of eugenic breeding.

First: to take the first step, that represented by raising the mean height 2 inches, has been, according to our hypothetical illustration, an unmitigated good, whether anything further is done or not. There are hundreds of such first steps that society now would endorse; for example, people are agreed that a physique able to resist tuberculosis, as contrasted with one not so able, is good; to have keen vision rather than faulty is good; to have a capable mind rather than a feeble one is good; to have a sound body rather than a deformed one is good; and so on. Such first steps as these, if realized, are sufficient in number to remake society. 
There would be a greater difference between this new society and the society we now have than between the Greeks in their glory and the Eskimos in their squalor. Thus the first step alone is worth the taking, though it should lead to nothing further, but this is not to be expected.

Second: after the first step has been taken, society can re-appraise itself and consider of the next step. After the height of the race has been raised from 5 feet 8 inches to 5 feet 10 inches, it may decide that the 8 -foot ideal is not a worthy aim after all. The next generation is more competent to decide than the present, so leave it to them.

Third: if they decide that continued increase in height is desirable, they can look for it in two ways. In the first place, by the further application of the selective processes, which produced the first increase. This would tend to raise the mean, but not beyond a certain upper limit, if simple Mendelian principles, as they affect regression and variability, hold in the matter of height. In the second place, they could raise the mean by seizing fortuitous mutations and by breeding future generations from them. Now we do not know very much about the rules governing mutation, but is it not axiomatic that a mutation from a 6foot race is more likely to yield genes that produce a 6 -foot six race than that a mutation from a 5 -foot race will do so? In short, whether from the viewpoint of immediate benefit or of progress toward a remote goal, the taking of the first step is justified.

I have used height in my illustration because it lends itself readily to quantitative discussion, and not because I think it is an important eugenic feature. I believe that one ground for criticism of eugenics is the fear that the 
criteria used in the selection of parents will operate against certain genuinely meritorious types - a belief, perhaps, that the movement would be administered by "mental testers," and that a high I. Q. as determined by the Binet test would be essential to selection. If one holds that many harebrained freaks score high on the Binet test, and many gifted in one way or another score low, then the matter looks serious. I shall shortly give reasons for not thinking the I. Q. a very good measure to use as one of the measures in the selection of the eugenically fit. But let us now ask if any real danger lurks therein. For someone to show that a few "odd ducks" score high on a test is not sufficient to prove that the device is poor. To establish this, it is necessary to show that the proportion of such among those scoring high is greater than the proportion in the breeding population at large. In short, it becomes an experimental and statistical matter. Investigations of this sort will surely be made just as soon as eugenics attains such a status that devices for use in selecting parents are actually considered.

How about the geniuses of one sort or another that score low on the Binet test? Here again it is an experimental matter to determine if the type of genius in question constitutes a larger proportion of those scoring low on the test than of those scoring high. If it should be found on thorough investigation that selection of people with high Binet scores tended, let us say, to eliminate musicians (such partial data as are at hand indicate the opposite), then I venture to assert that present test users themselves would practically unanimously consider it an improper device to use for the selection of the eugenically fit. If, as is more likely, it is found that high Binet standing has little effect 
one way or the other in selecting musicians, it would be considered inadequate upon this issue, and a supplementary measure covering musical ability should be employed, if it is desired to breed musicians. In short, knowledge about the instrument employed, readily though not inexpensively obtained, can sustain or disperse all fears as to disgenic tendencies of a technique.

Though I know a mathematician of high order in a crippled body, should I conclude that we should not eliminate if possible crippled bodies, for fear that we should thereby eliminate mathematicians? I should come to this conclusion only in case it is shown that mathematical capacity of high order is relatively more often found in crippled bodies than in sound bodies. The issues involved are statistical matters in just the same sense as are those in life insurance experience tables. Some progress has been made in the building up of tables giving the probability of death at various ages of people having different traits, a sound heart, tubercular ancestry, etc. Similarly we can build up tables giving the probability of certain traits in offspring born of people showing different conditions. Though time of death does follow certain rules as expressed in the lifeinsurance table, there is a large chance element in it, represented by exposure or lack of exposure to contagious diseases and to accidents. Probably no similarly large chance factors operate between the mental and physical status of parents at the prime of life and that of offspring at prime of life. We may accordingly expect a more accurate forecasting of mental and physical equipment of offspring, knowing that of the parents, than is now the case in forecasting time of death from data contained in the physical 
examination blank filled out at the time the insurance policy is applied for.

When the time does come that fertility of the able is encouraged, and sterility of the incompetent rewarded, what may we expect to be some of the bases of selection of the eugenically fit? We may be sure that there will be many bases, and not one, for we know that different genes or genetic elements mediate different traits. We cannot influence eye-color by selecting the genetic element that has to do with the number and perfection of the digits of the hand. Many physical traits should be attended to, those having to do with the soundness of the sensory, motor, and visceral organs coming first. The independence of genetic elements is such that, generally speaking, selection of a cenetic unit because of its known good effect in some regard carries with it no detrimental effect in another regard, nor for that matter, any beneficial effect, either. Though we select so as to improve some physical organ, say the quality of the lungs, we shall not thereby run a risk in some other respect, say, the condition of the eyes. This statement may need some slight qualification as more knowledge is obtained, because single genetic units do affect more than single organs; still, it surely is not far from the literal truth. We therefore see that improvement of one feature by breeding is altogether to the good, and is not the occasion of any alarm with reference to other features about which little is known. This permits a piecemeal attack of the problem and a continual increase in effectiveness as knowledge grows. The very extensive body of knowledge now extant covering animal breeding serves in the development of desirable physical features in the human species. 
Undoubtedly much the same situation will maintain in connection with mental traits. Here the difficulties of ascertaining independent mental organs and still greater difficulties of tying them to genetic structure warrant a less specific approach. Without knowing what genes condition musical ability, we can, nevertheless, improve it in offspring by breeding from musicians. This method can be effective, demonstrably so, though the genetic mechanism is unknown.

Our first need is to determine what are the independent mental traits. We should not think of a single I. Q. or a single intelligence score, but of ability scores, as many in number as we can experimentally justify by showing the existence of an equal number of independent mental traits. High standing in each of these is what society judges to be high standing, and it is a good thing to have, for it means expert ability such as high musical talent, high mathematical talent, high manipulative talent, high literary talent, and so forth. If we breed for these separately we shall in each case confer a good upon society, and perhaps in the distant future some superman can be bred combining all of these talents to a high degree. It is beyond our present knowledge to even surmise whether this is possible, for the genetic relationships involved are quite beyond our grasp to picture, and we have no experimental evidence bearing directly upon this issue. Whether a single type superman or several types of supermen or even an indefinitely large number of types are the goals of mankind and thus of scientific breeding is a question that we may well let the greater wisdom of the future with its more perfect knowledge of evolution ascertain. In any instance, the first steps are clear and only await the social will to be put into operation. 
The plain truth of the matter is that the racial knowledge about inheritance and about how to produce healthy, capable offspring has already outstripped the racial spirit of self-sacrifice, cooperation, and tolerance that is necessary to make the knowledge effective. In mentioning tolerance, I do not so much mean willingness to permit the dissemination of knowledge and views of minority groups, though that is of great importance, as I do willingness to tolerate, even to aid, those differently endowed. The odd child, though something of a genius in one line, is suppressed in the elementary school and made to conform. The university professor of law has, and that not infrequently, belittled and ridiculed the talents of the engineer, and so it goes. Feeling somewhat ill at ease in the presence of the differently endowed seems to be followed by dislike for and antagonism to him and finally by an effort to make him conform. Intolerance is confined to no stratum of society, and wherever found it is a potential stumbling-block to genetic advance.

An unselfish devotion to the nation is called for. Many a married couple today, knowing themselves to be above the average in physical and mental equipment, are childless by preference, because they love their freedom and their pleasures, or because they are ambitious for advancement in their chosen line of work, which is not that of rearing children, and because they feel no sense of responsibility for the genetic structure of the coming generation of the nation to which they generally are proud to belong. Many men and women today are not fit to be parents, and know it, but they do have children because of incontinence or of sheer indolence in securing knowledge of and in the use of 
contraceptives, which practice they perhaps defend by hiding behind the cloak of religion; or they have children because their passion to have them leads them to suppress their better judgment. Such passion may pass under the guise of parental love. It is a veritable Judas kiss implanted indelibly upon the brow of the defenseless child.

Though no religion will openly defend the propagation of the feeble-minded or the congenitally diseased or insane, many do actually support these by the sin of silence, and by placing their taboo upon the discussion of the matter. We need a militant religion that will arouse mankind to as great sacrifices for the welfare of the coming generation as they have made for themselves. Of course the selfishness that leads a man to circumscribe his life by the hope of personal salvation has no place in this new religion. Selfsacrifice, planning, preparing, and, above all, using God's greatest gift, one's scientific knowledge, in behalf of those to come, is the way the spirit of Christ can be expressed in the evolving world wherein we live.

Much of intolerance is just narrowness of intellectual vision. It is to be combated by disseminating knowledge. As an aid in doing this I bespeak your support of the American Association for the Advancement of Science, and of its temperate and persistent effort to extend scientific knowledge. If you are not already a member, I am sure it would be a benefit to you personally to be one. It would put you in touch with the living men who are almost daily expanding our concept of the world we live in. If there is a Galileo over the age of 21 in the United States today, I venture to prophesy that he is now one of the 17,000 members of the American Association for the Advancement of 
Science. Membership is open to all who apply and pay the nominal entrance fee and dues.

When the membership grows from its present 17,000 to 100,000 or to 500,000 , its organized cry for tolerance and light will ring as loud in the press and perhaps in the pulpit as at present do certain organized cries for bigotry. There is no reason why its membership should not thus expand, for science does or should play an essential part in the conscious life of everyone. Whatever phase of science is your hobby or specialty, the American Association for the Advancement of Science bids you welcome. Its sections and affiliated societies extend from Agriculture and Astronomy down through the alphabet to Zoology. I particularly urge the taking out of membership by those in the borderline fields, economics, political science, education, history, and philology, for the broader the front that science can present to its misguided but active enemies, the better.

In conclusion let me say, if a curriculum, adapted to individual differences, committed to the development of the world's new tool-the scientific method-and dedicated to the nurturing of original talents, seems remote, recall the growth of the last three centuries and be optimistic. If the possibility of racial betterment by the conscious breeding of a nation's citizens seems fantastic, recall that less vital issues than this have been the bases of epochal religions; and recall also that disgenic tendencies less potent than the selfimposed sterility of a nation's leaders have undoubtedly led to the decay of nations. Darwin tells us little of the speed of evolution, but of its certainty he leaves no room for doubt. 


\section{LECTURE $V$}

\section{MENTAL TRAITS OF MEN OF SCIENCE}

$\mathrm{O}$

$\mathrm{NE}$ who approaches research with a desire to follow wherever the spirit moves, with a willingness to use a new mechanism and master a new technique, even if need be to discard an old problem for a broader underlying one, will find that a study of what research has meant in the world and some acquaintance with its process and with the characters of the men who have made it mean what it does, gives not only vision but also specific suggestion. In such a study we must distinguish between prime movers in scientific research, and hangers-on. These latter are not only the great popularizers of science; they may be great philosophers as well, who incorporate new knowledge along with old into a comprehensive system. A very energetic group of such philosophers is now engaged in incorporating the concepts of Einstein into the earlier world of Newton.

Not being great investigators themselves, these men may fail to see something in the heart of the process, and they may overemphasize and oversimplify some aspect, to the obfuscation of some other more recondite essential. Two of the greatest men of this class of all time were Herbert Spencer and Francis Bacon. The benefit to society of their endeavors may well be great, but this benefit lay in arousing confidence and a will to do scientific work and to trust its findings, not in technique for its actual accomplishment.

What discoveries do we owe to Bacon, the modern sponsor for the inductive method? Not only did he give the 
world no great discovery, but further, his writings did not reveal a sympathy with the great work of Copernicus, or familiarity with the great discoveries of Kepler. We must consider his method in the light of his own slight accomplishment with it.

Though Herbert Spencer was better informed about the scientific accomplishment of his time than was Bacon about that of his time, and though Spencer did draw upon a wider knowledge both of the limitations and of the accomplishments of science, still he was withal a philosopher, a man who told what science could do for the world rather than just how it was to do it. Spencer has given us no noteworthy experimental contribution.

Shall we look to Francis Bacon for the key to scientific genius such as welled within Galileo, Pasteur, and Newton? Listen to some of his words. He criticizes Aristotle in the following manner: ${ }^{1}$

.. having first determined the question according to his will, he then resorts to experience, and bending her into conformity with his placets leads her about like a captive . .

The correctness of this judgment is open to much doubt, for Aristotle states:2

Let us first understand the facts, and then we may seek for their causes.

And again, in speaking of the parthenogenesis of bees, he says: ${ }^{3}$

${ }^{1}$ Spedding, James, and Ellis, R. L., eds. Works of Francis Bacon, 1889. Vol. IV, 1 st book of Aphorisms. Aph. 63, p. 65.

${ }^{2}$ Lewes, G. H. Aristolle, a Chapter from the History of Science. 1864 , p. 110.

${ }^{3}$ Ibid. p. 110. 
There are not facts enough involved to warrant a conclusion and more dependence must be placed on facts than on reasoning, which must agree with the facts.

And still again:4

We must not accept a general principle from logic only, but must prove its application to each fact, for it is in facts that we must seek general principles, and these must always accord with the facts.

Aristotle was quite clearly aware of the primal and compelling nature of facts, but he made few observations himself, and his followers of the Middle Ages forgot this part of his teaching, so that in Bacon's time it was customary to "expect general principles from logic only," and fact and the experiment as the basis of knowledge was to be found in no circulating philosophy. Preceding Bacon's time many true scientists did return to these first principles. About 100 years earlier Leonardo da Vinci had said: ${ }^{5}$

The interpreter of the artifices of Nature is Experience, who is never deceived. We must begin from experiment and try to discover the reason.

Though not the originator of the idea, Bacon emphasized the basic nature of the fact and the power lying at the individual's command in the control of experiment as none other had done. Bacon would have one observe, make inferences, and on the basis of these plan experiments, observe further, make further inferences, guarding every step of the process, and proceed from minor generalizations to those of greater and greater generality, building the structure of scientific knowledge as it were brick by brick, by the inductive method.

Ibid. p. 112.

- Abbott, Edwin A. Francis Bacon, 1885. p. 335. 
History has no place in the process. He says: ${ }^{6}$

. . . we should at once and with one blow set aside all sciences and all authors; and that too without calling in any of the ancients to our aid and support, but relying on our own strength. Again, ${ }^{7}$

It is idle to expect any great advancement in science from the superinducing and engrafting of new things upon old. We must begin anew from the very foundations unless we would revolve forever in a circle...

There is no great subtlety in Bacon's method. According to his statement he has just happened to discover a rule of thinking whereby all knowledge may be attained:8

. . . my way of discovering sciences goes far to level men's wits and leaves but little to individual excellence; because it performs everything by the surest rules and demonstrations.

Of course some mills operate more smoothly than others, and Bacon considered his own mind quite definitely disposed to know the truth. As I read his own words describing his talents, do not let his complacency turn your attention from the fine list of qualities which he mentions as conducive to knowledge. He wrote: ${ }^{9}$

I found my own nature a special adaptation for the contemplation of truth. I had a mind at once versatile enough for that most important object, I mean the recognition of similitudes ... I possess a passion for research, a power of suspending judgment with patience, of meditating with pleasure, of assenting with caution, of correcting false impressions with readiness, and of arranging my thoughts with scrupulous pains. I had no hankering after novelty, no blind admiration for antiquity

${ }^{6}$ Spedding and Ellis. Op cit. Novum Organum, Vol. IV, 1st book of Aphorisms. Aph. 122, p. 108.

Ibid. Aph. 31, p. 52.

Ibid. Aph. 122, p. 109.

9 Abbott. Op. cit. p. 27. 
. . . For these reasons I considered that my nature and disposition had, as it were, a kind of kinship and connection with truth.

A man with the wit of Bacon cannot write on a subject without illuminating it. Certainly many of his observations are true and fine, but his own attempt to demonstrate his method by analysis of heat was rather futile. He missed a connection somewhere-I believe it was in his failure to build on the past, in his belief that research is a mechanical process, and in his lack of sufficient definition of the scientific issue. Bacon then lies a little outside the field of most promising investigation. Let us turn to men who did greatly extend our knowledge of the world, to find, if we can, the nature of the actual steps employed.

Of these none is more satisfying to study than Charles Darwin. Men like Pasteur, Newton, Willard Gibbs are so brilliant, so in tune with nature's mysteries, that they leap to conclusions across gaps that we cannot follow, but Darwin, as great a benefactor to the world, as true a scientist as history tells us of, does not seem to sense nature's mysteries, and then gather confirmatory information, but by the very rigor of his research he compels her to reveal them. Darwin walks in no seven-league boots. Each step is foreshadowed by the one before. Upon closer examination we may find that this distinction between a Pasteur and a Darwin is not a real one, but in the process of comparison the life of Darwin provides a better key to that of Pasteur than does that of Pasteur to Darwin.

Darwin was not a brilliant youth, and seemed to delight in boyish pastimes in the open air. In this he did not differ from half the other boys of his or any other generation. His passion for collecting was revealed very early in life, 
and it is somewhat exceptional. It found expression in gathering beetles, shells, coins, minerals, and other things. The collecting tendency, or, as others would say, instinct, though common, is very unequally developed in different individuals, and Darwin may well have had it to so pronounced a degree that not more than five in a hundred would equal him. This interest must, of course, be taken into account in the attempt to understand his life, but of itself it is insufficient to account for his success, else we should have had thousands of Darwins whereas we have had but one. Darwin loved the out-of-doors, was a keen observer and collector, and readily turned toward science.

Speaking of his scientific endeavors, he said:10

I worked on true Baconian principles, and without any theory collected facts on a wholesale scale.

Are we then to cite Darwin as an exponent of the Baconian method? We are not, and because of what seems to be just a chance incident in his life. Darwin found in the middle of England what he thought was a tropical shell, and was greatly moved when Sedgwick was not pleased. What was the tropical shell doing in England? Well, whatever it was doing, it aroused no resentment in Darwin, but it had no place in Sedgwick's scheme of things. Darwin wrote as follows in his old age, though that need not lead us to distrust the reality of the youthful experience:11

.. I was then truly astonished at Sedgwick not being delighted at so wonderful a fact as a tropical shell being found near the surface in the middle of England. Nothing before had ever made me thoroughly realize, though I had read various scientific I, p. 68 .

${ }^{10}$ Darwin, Francis. Life and Letters of Charles Darwin, 1891. Vol.

${ }^{11}$ Ibid. Vol. I, p. 48. 
books, that science consists in grouping facts so that general laws or conclusions may be drawn from them.

Here, then, is where Darwin broke with Bacon. This incident in Darwin's life marks an epoch. Was it essential to his scientific development, or lacking it would some other incident have arisen leading to the same deepening of his view? Certain it is that such an incident in the lives of most men would not disturb the even tenor of their ways. Whether necessary or not, it did happen most opportunely, for it was essential that Darwin work to a purpose, and discard pure induction as the key to scientific work.

Pure induction would lead a man upon the seashore to observe indiscriminately skies, water, sea-life, land-life, human life, color, temperature, odors, physical phenomena, intellectual phenomena, and perchance moral phenomena. In short, all of life would be his field, and from its richness he is to induce principles. The task is impossible, and Bacon's comments give only such comfort as a man drowning in Lake Michigan could get by thinking of his plight if in the ocean. Bacon wrote:12

- . let no man be alarmed at the multitude of particulars ... For the particular phenomena of art and nature are but a handful to the inventions of the wit.

We must be concerned with the multitude of particulars, and we must seek a method that is discriminating, that is a guide in this wilderness of facts.

When Darwin ceased to be interested in collections of all sorts he became a more effective collector and interpreter of certain things. This limiting of field of effort is necessary, but it also has its dangers. If we take history as a

${ }^{12}$ Spedding and Ellis. Op. cit. Aph. 112, p. 101. 
guide and limit our effort to fields described in the past, new fields are not investigated. Also if we take $a$ priori hypotheses as guides, there is no progress if our hypotheses are incorrect. Darwin's position seems to be that of the perfect scientist, having in it little lost effort and effective in finding and establishing truth.

The idea in connection with which Darwin is most frequently mentioned was well phrased by Herbert Spencer, who coined the expression "the survival of the fittest," and it was suggested to Darwin through an earlier thinker. ${ }^{13}$ Writing of his work in 1838 he said:

... fifteen months after I had begun my systematic enquiry, I happened to read for amusement Malthus on Population, and being well prepared to appreciate the struggle for existence which everywhere goes on from long continued observation of the habits of animals and plants, it at once struck me that under these circumstances favourable variations would tend to be preserved, and unfavourable ones to be destroyed. The result of this would be the formation of a new species. Here then I had at last got a theory by which to work; but I was so anxious to avoid prejudice that I determined not for some time to write even the briefest sketch of it. In June, 1842, I first allowed myself the satisfaction of writing a very brief abstract of my theory.

He spent four years mulling it over before he would permit himself to become sufficiently attached to it to write it down!

Clearly realizing that an hypothesis might become a prison, Darwin immediately provided a way of escape. In his biography he wrote: ${ }^{14}$

I had, also, during many years followed a golden rule, namely, that whenever a published fact, a new observation or thought

\footnotetext{
${ }^{13}$ Darwin, Francis. Op. cit. Vol. I, p. 68.

${ }^{14}$ Darwin, Francis. Op. cit. p. 71.
} 
came across me, which was opposed to my general results, to make a memorandum of it without fail and at once . . .

Writing in his old age of his early life and, we must believe, of a period following his experience with Sedgwick, he said:15

From my early youth I have had the strongest desire... to group all facts under some general laws. These causes combined have given me the patience to reflect or ponder for any number of years over any unexplained problem ... I have steadily endeavored to keep my mind free so as to give up any hypothesis, however much beloved (and I cannot resist forming one on every subject), as soon as the facts are shown to be opposed to it ... I cannot remember a single first-formed hypothesis which had not after a time to be given up or greatly modified. This has naturally led me to distrust greatly deductive reasoning in the mixed sciences.

Darwin's mind was master. Though he gave himself loose rein to form hypotheses, once formed they did not control, but became subject to rigid tests of adequacy.

The reading of Malthus was fortunate in his life, but of course we cannot say indispensable, for his mind was ripe for the idea of variation, and survival of the fittest. If Malthus had not provided the cue to a valuable hypothesis, something else most surely would have. Darwin himself clearly recognized that it is no more in the hypothesis than it is in its modification, elaboration, and verification or rejection, that the scientist makes his contribution. Scientific method as exemplified by Darwin seems to possess the following attributes:

(a) Delimitation of field upon the basis of antecedent endeavor, whether of oneself or of others.

${ }^{15}$ Ibid. p. 83 . 
(b) A wide acquaintance with as many facts in this field as possible.

(c) The tentative construction of a hypothesis by the inductive method to account for these facts, and

(d) The elaboration of the hypothesis and a collecting of additional facts bearing upon it, leading generally again by the inductive method to a modification or rejection of the hypothesis. These additional facts are collected in a systematic manner by observation of selected features of nature or by carefully controlled experimentation.

'This last step (d) is repeated as many times as may be necessary to reach the degree of agreement between facts and hypothesis called for by the investigator himself.

Darwin could not say of this process as Bacon had said of his, that it tended to make all men equal. Too much of breadth of view, too much of originality, too much of rigor, persistence, and utter honesty with oneself are required to lead one to think that this process can be standardized and will lead to a "levelling of men's wits."

Darwin has been most kind to the world in his biography in permitting us to see him unadorned. The candor with which he describes himself is on a par with that with which he notes difficulties arising in connection with his own hypotheses. Seldom does a man appraise himself so dispassionately that one feels no necessity of modifying his verdict. Darwin was one of these rare self-appraisers. I wish to quote him, but will take the time to do so only upon those traits of character that seem to be an intimate part of his scientific life. He said: ${ }^{16}$

The passion for collecting which leads a man to be a systematic naturalist ... was very strong in me, and was clearly innate ...

${ }^{10}$ Darwin, Francis. Op. cit. p. 26. 
Of his school work in mathematics, he said $:^{17}$

[It] was repugnant to me, chiefly from my not being able to see any meaning in the early steps in algebra. This impatience was very foolish, and in after years I have deeply regretted that I did not proceed far enough at least to understand something of the great leading principles of mathematics, for men thus endowed seem to have an extra sense. But I do not believe that I should ever have succeeded beyond a very low grade.

Darwin had the good fortune to get an assignment as naturalist on board the Beagle, upon its extended trip in southern waters. This was without pay, but he also had the good fortune to have independent means. His greatest work of collection and observation was done on this trip. Of it he says: ${ }^{18}$

The voyage on the Beagle has been by far the most important event in my life ...

Of his native talents he writes: ${ }^{19}$

I have no great quickness of apprehension or wit which is so remarkable in some clever men, for instance, Huxley ... My power to follow a long and purely abstract train of thought is very limited; and therefore I could never have succeeded with metaphysics or mathematics. My memory is extensive, yet hazy. It suffices to make me cautious by vaguely telling me that I have observed or read something opposed to the conclusion which I am drawing, or on the other hand, in favour of it; and after a time I can generally recollect where to search for my authority. So poor in one sense is my memory, that I have never been able to remember for more than a few days a single date or a line of poetry.

\section{Again he said: $:^{20}$}

... I think that I am superior to the common run of men
${ }^{17}$ Ibid. p. 40.
10 Ibid. p. 82.
${ }^{18}$ Ibid. p. 51.
${ }^{20}$ Ibid. p. 83. 
in noticing things which easily escape attention and in observing them carefully. My industry has been nearly as great as it could have been in the observation and collection of facts ... My love of natural science has been steady and ardent.

He writes of his success in a very modest and probably in a truer tone than did Bacon write of his: ${ }^{21}$

Therefore my success as a man of science, whatever this may have amounted to, has been determined, as far as I can judge, by complex and diversified mental qualities and conditions. Of these, the most important have been-the love of science-unbounded patience and long reflecting over any subject-industry in observing and collecting facts-and a fair share of invention as well as of common sense.

Let us take Darwin at his own valuation, which gives us a good, wholesome statement of his talents and of his weaknesses.

His good friend Huxley referred to him as 22

. . something bigger than ordinary humanity-an unequalled simplicity and directness of purpose-a sublime unselfishness.

And George J. Romanes writes: ${ }^{23}$

No one in this generation is able to imitate Darwin, either as an observer or a generalizer.

Darwin would not countenance such claims, and we need not believe him unequaled in any talents, sublime in any virtues, or bigger than humanity. He was one with us, and what he did is within our ken. At least let us believe so, so that we may endeavor to follow in his footsteps.

Of the superhuman virtues that Huxley cites, that of unselfishness comes as near to being justified as any. Think if you will of a young man of today, of independent means,

\footnotetext{
${ }^{21}$ Ibid. pp. 85-6.

22 Darwin, Francis. More Letters of Charles Darwin, p. 71, footnote (3).

23 Romanes, George J. Darwin and After Darwin, 1896. p. 8.
} 
giving up his country club and an easy pleasant social life and burying himself upon a tedious ocean trip in a small boat, wherein every wind that blew, or perhaps every meal that the cook brought forth, caused sickness, because he had an idea and wished to find if it were true. Let this same young man feel ahead of time that he may be chasing a will-of-the-wisp, but let him carry on withal. Finally, when the trip is over, the data in hand, and the sick body attempting to recuperate on terra firma, the man, now nearly thirty years of age, suspends his judgment for another twenty years, and devotes his time to penetrating scrutiny and to verification before he reports in print the outcome of his labors. Here is an unselfish devotion which of itself explains why every age and every land has not a Darwin.

A particular combination of talents, of virtues, and of circumstances made the man. Many of these circumstances were favorable, but one at least, his health, quite otherwise. Some of the world's great men of science have risen through circumstances of life that have seemed almost uniformly unfavorable. Roger Bacon and Galileo Galilei were such. Religious leaders have commonly thrived under adversity. So we must not attach too much importance to favorableness of environment. If there is a spirit of revolt abroad, a feeling that the arcana of life are being withheld by authority, there arise, singly and in small groups, those who dare greatly. The resulting stimulus to research may be even greater than is the case wherein full social approval accompanies an undertaking.

In the time line that is our history is the record of great courage, great ability, and great accomplishment. I wish to name just a few who have carried the torch of science 
down the ages. Other names could be mentioned who have had a greater effect on human life, great rulers of the bodies or of the hearts of men-Alexander called the Great, and Jesus called the Christ-but few, if any, who have kept more pure and undefiled the channels whereby men acquire new knowledge of the world they live in.

Pythagoras, Hippocrates, Euclid, Archimedes, Apollonius, Galen. Even among these in the dawn of science are to be found lines of demarcation. Pythagoras, Euclid, and Apollonius were masters in pure reasoning, in mathematics; Hippocrates and Galen in living matter, in medicine; and Archimedes in physics, tied then as now to mathematics. Galen, who flourished in the second century A. D., was the latest of these. He was an experimentalist, and a keen observer of human phenomena, but at about this time in the world's history something seemed to happen. For the next thousand years thinkers turned their thoughts inward to philosophy and religion.

Logically, pure mathematics requires no physical phenomena to operate upon, but actually it has been inspired to new advances by every physical discovery, and as these were few in the Dark Ages, mathematics also languished, though it did not attain quite the depravity of the physical and biological sciences. When the light began to break again, it was, of course, feeble. Seen in this dimness is Roger Bacon, who flourished in the Thirteenth Century, a great man who dared to look about him for truth, who dared to observe the life immediately before his eyes and within his touch, and whose simple honest utterances caused him great physical distress. The feeble flame nursed by Roger Bacon was held aloft by Leonardo da Vinci, 
Nicolaus Copernicus, and Galileo Galilei, and by an everincreasing number. Of this increasing number there are a few who have fanned the flame to so white a heat that we may believe it will never die again. First in this list is Isaac Newton, who tied physics so close to mathematics that none has tried to extricate it since, though Michael Faraday did show with a brilliance that probably can never be equaled again what the mind of man, little tutored in mathematics, can grasp of nature's hidden physical processes. Of Faraday's great contemporaries, I will mention only Charles Lyell in geology, and Charles Darwin; a generation later are Louis Pasteur and Willard Gibbs. There may be one or two men living and in their prime today in a class with these that have been mentioned. It would be no kindness to any living man to have the world say to him while his labors are still in process, "We expect as much from you as we got from Newton or Darwin."

I have mentioned several mathematicians, physicists, and astronomers, several medical men and biologists, one geologist, and one chemist. There is no clear reason for stopping the list here. Though these men whom I have named are in the front rank of men of science for all time, they do not stand alone, and others of their level or very nearly of it could be mentioned. None, however, of equal rank will be found in the field of social science, none who have given new foundations to human thought upon demonstrable and verifiable bases. The Ptolemaic system of social science has yet to be shaken by some economic Copernicus. So much of myth, so little of fact, so much relatively of outcome and so little of method, have come down to us from the early Greeks that it is difficult to investigate 
the issues connected with scientific outlook and procedure. We do, however, in the case of both Greek scientists and philosophers, find a spontaneity and an independence not characteristic of later workers who have a genuinely valuable history upon which to lean. Even Galen, who flourished in the Second Century A. D., drew heavily from Hippocrates. He did, however, much that was original, and he has told us all about it in his writings.

He was the son of a well-to-do architect, who saw to it that his son had a liberal education, and he lived in Pergamos, which had an excellent library. He started the study of medicine when seventeen, and continued it during his travels, which included such centers of learning as Smyrna and Alexandria. The controversial nature of medicine at his time probably meant much in his development. We may illustrate this by a modern instance. Mendel, who developed laws of heredity, had nothing to combat, and his work was lost for twenty-five years, and he himself dropped it and turned his energies to administering a monastery. When Lamarck and Weismann and others take opposing sides on the question of heredity, Mendel's work becomes vital, is found, and takes its place as a masterpiece. Another instance is illustrated by the life of $\mathrm{Da}$ Vinci. His very original work in mechanics aroused little comment in his day. He himself devoted his time to painting and to other things, and his physics was almost lost to mankind for three hundred years, the great scientists of the Fifteenth and Sixteenth Centuries being apparently unfamiliar with. it and not profiting by it.

To be ahead of one's time means more than anything else that the points one makes are not appreciated, and 
thus are not doubted by others. New knowledge is the spark that springs to life between the flint and the stone of claim and counter-claim. Most of the medical practitioners of Galen's day diagnosed and treated on the basis of logical deduction, operating upon specific evidences of disease. They might be called part-treaters-separatistsbecause of the specificity of their point of view. Galen, taking his cue from Hippocrates, thought of the whole organism as a unit, and based his arguments upon this concept. He might be called a unitarian. Both the separatists, and Galen the unitarian, were great dialecticians.

In the wordy conflict that was carried on between him and his opponents, Galen appealed to a more ultimate authority than deduction-namely, experience and experiment -controlled experiment. He used a genuine experimental method as a shield and buckler in his fight. However, it is doubtful if we should credit him with realizing the true dignity of the method as a guide in the building up of a philosophy. He did not quite use the method as did Galileo, or in fact Archimedes, as a great beacon light to knowledge, as a thing more ultimate than doctrine. Galen was no such anatomist as Vesalius, the next great light in medicine, who flourished fourteen hundred years later. With his philosophy of unity of the human organism, he could not be, for the anatomist turns his attention successively to very limited portions of the whole. Galen's point of view was a great advance in his day, but it became a heavy drag in the centuries that followed. The reason for this is not far to seek. Galen was a ready writer, and an expert in argument. He did not change the method of investigation from that of mere logic to that of experiment, and observation. His 
arguments, more than his facts, upheld the banner of Hippocrates, and they were forceful arguments, as are generally those that subsume much of life under a single principle. Further, this practice in thought was current for at least fifteen centuries, so that Galen quite naturally belonged to the followers of Aristotle and the church.

Let me give one sample of Galen's success in making generalizations, such generalizations as for centuries preceding the Renaissance filled the churches and the halls of learning, and darkened the windows to the life about. He adopted the principle that there is a specific attraction between the tissues and the things that give them life. He proceeds then to show that this principle explains why the lodestone attracts iron, why the stomach receives food, why the kidneys receive urine, and why the uterus receives semen. Now is not this fine-one principle accounts for all of these things, and for many more, and having once noted this principle one need look no farther, for his knowledge is complete.

This principle just cited was and still is descriptive of something that takes place between every body tissue and the food that nourishes it. It is a brilliant generalization characteristic of a great thinker. That Galen extended it beyond its useful field does not detract from his keenness in appreciating its importance in the living organism. Galen's experiments were very numerous and remarkably sound in the sense that conditions were controlled, and his observation of what happened most excellent. He almost discovered the circulation of the blood. I quote from Brock's translation of his treatise on the natural faculties. ${ }^{24}$

${ }^{24}$ Brock, A. J. Galen on the Natural Faculties, 1916. p. 321. 
Now . . the following is sufficient proof that something is taken over from the veins . . . to the arteries. If you will kill an animal by cutting through a number of his large arteries, you will find the veins becoming empty along with the arteries; now, this could never occur if there were not anastomoses between them.

Galen's hypotheses were superior, his experimentation thorough, and his presentation precise, argumentative, and jogical. Had his immediate followers accepted his hypothcses as hypotheses, and had they continued and trusted experimentation instead of being content with his logic, the gap between Galen and Harvey might have been one generation instead of fifty.

Some of Galen's personal traits may be inferred from his writings. He had a high sense of personal responsibility. He exercised great self-control, and forswore sensual pleasures. He had a strong sense of what might be called righteous indignation, and he was a man of great energy and industry. From what he does not write, we must conclude that he was unconcerned with the suffering caused by vivisection. It is in fact quite impossible to conceive how he could have been concerned, and observe phenomena that he did observe, and have the thoughts while doing so that he has recorded. As the geologist must trace in his mind the fault line, and forget the cloud upon the mountain, so vivisectionists before the days of anesthetics had to attend to physiological processes and not to psychological. After Galen, no really great figure in the history of science occurs until we come to Roger Bacon, who flourished in the Thirteenth Century-seven hundred years ago - seven hundred years, the span of life of modern science. Because of the fragmentary and at times contradictory 
evidence, one today can scarcely fully understand Bacon. The authority and hold of the Church upon all channels of learning and upon rules of thought was such that only a peculiar combination of devotion to the Church, of belief in the evidence of the senses, and of skill in relating the two, could gain a hearing. Today a scientist can ignore any organization, if he so chooses, and continue his way not seriously hampered. In the Thirteenth Century intellectual development simply did not take place in the sense that it affected history, except under the aegis of the Church. Unless this is borne in mind, we can scarcely understand an Abelard, a Roger Bacon, a Galileo, or a Voltaire.

Voltaire's protestations of religious faith do indeed seem insincere and those of a man who played upon the stupidity of his spiritual superiors. How about Roger Bacon? Could he believe, as he affirmed, that the Scriptures contain all true wisdom, and at the same time argue that experience is the true way to knowledge? In his third work he maintains that experimental science holds a pre-eminent position because conclusions are verified by direct experiment, and accordingly truths and secrets of nature are discovered such as no other method would permit of. Whether sincere in his dual affirmation or not, is it not true that any other position on his part would have made him either just another schoolman of the Middle Ages, or an unknown shortlived scientist, neither of which outcomes would have stirred the slumbering world as did the life he led?

If he knew that supreme trust both in the divine authority of the Church and in experiment were incompatible, but professed belief in both, we can honor him for the courage he displayed in tempting a fire that could extinguish him 
in a moment; and if he truly thought them compatible, we can thank him for his dullness in not seeing the danger that he ran. Though Roger Bacon defended the divine authority of the Church, he also investigated the magnifying lens, gunpowder, and particularly the possibility of defining phenomena in exact mathematical terms. His name means nothing to us because of this first activity, but it is emblazoned in the halls of science because of the second. Some of his personal traits of character can be surmised. He was of good family, precocious, a scholar of high order, of tremendous energy - he practically touched as many sides of life as did Aristotle-an excellent arguer, a man of spirit, who, after the condemnation of his works and an imprisonment of fourteen years, soon died, an embittered broken man. With his own last days in mind, think of the truth, the terrible personal truth of his statement that the four great causes of error are (a) authority, (b) custom, (c) the opinion of the unskilled many, and (d) concealment of real ignorance with the pretense of knowledge. As Bacon proclaimed and could bear personal witness to, the last of these was the most vicious. It is fitting that the awakening of science should be ushered in by so great a martyr. Others followed in his footsteps.

We can mention three great astronomers: Copernicus, perhaps saved from the fate of Roger Bacon by death just as the first printed copy of his revolutionary work appeared; Kepler, harried by the high priests of the Reformation; and finally, Galileo, whose life was a hard struggle against poverty, a bitter fight with authority, and an irrepressible urge to know nature at first hand.

Up to the time of Galileo's invention of the telescope 
he was an original thinker who greatly furthered the development of physical science by his experiments and demonstrations, but whose influence did not, at least in the minds of the people of his day, greatly disturb the cosmography of Aristotle as sponsored by the Church. He believed in the Copernican theory, but was willing to hold this view as an hypothesis against which there was no interdiction. $\mathrm{He}$ wrote to Kepler in $1597:^{25}$

... many years ago I became a convert to the opinions of Copernicus, and by his theory have succeeded in explaining many phenomena which on the contrary hypothesis are altogether inexplicable. I have arranged many arguments and confutations of the opposite opinions, which, however, I have not yet dared to publish, fearing the fate of our master, Copernicus, who, although he has earned immortal fame among a few, yet by an infinite number (for so only can the number of fools be measured) is hissed and derided. If there were many such as you I would venture to publish my speculations, but since that is not so I shall take time to consider of it.

Here is an illustration of the necessity of an understanding audience. Do we not also see in the last sentence an awareness upon Galileo's part that he must soon enter the lists? His entrance came a decade later with his perfection of the telescope. He writes to a friend in $1610::^{26}$

I am ... staying in Venice for the purpose of getting printed some observations which I have made on the celestial bodies by means of my spyglass ... and which infinitely amaze me. Therefore do I give thanks to God, who has been pleased to make me the first observer of marvellous things unrevealed to bygone ages.

In particular Galileo saw the satellites of Jupiter making

${ }^{25}$ Fahie, J. J. Galileo, His Life and Work, 1903. p. 40.

${ }^{26}$ Ibid. p. 85. 
their orderly rounds, and he knew the full significance of this as the final incident in the proof of the Copernican theory, and as the evidence that would confound the followers of Aristotle and Ptolemy. Who has communed with God as did Galileo with his telescope pointed toward Jupiter, and to himself has later denied him? Certainly not anyone with Galileo's honest mind. The die was cast. Galileo was the knight errant of the worlds that rotate about the sun, but in the years to come it was a battle of wit to preserve his position, and at the same time his personal freedom from imprisonment and from the rack.

The trials he had to face in his struggle for a livelihood, in his later blindness, and in the opposition of the Church, were enough to tax the courage of any man, but there was another trial which must have been greater than all of these combined, the incompleteness of his knowledge upon certain crucial matters.

Galileo discovered and accurately described the four chief satellites of Jupiter. The rebuttal of the Aristotelians was ludicrous and vicious. They claimed the phenomena were visionary, due to aberrations of one sort or another and caused by the instrument of observation. Galileo's defense to these charges was adequate, except in one instance. He had observed Saturn and found three stars instead of one, having interpreted the ring about Saturn as constituting two added stars, one on either side. When these two, which were in fact but part of Saturn's ring, vanished entirely from the heavens, as the ring of Saturn does vanish when viewed through ordinary telescopes, twice every twenty-eight years because it is then seen edge-wise, Galileo was non-plussed. Nature was playing tricks upon 
him. She was giving aid and comfort to the enemy by her fickleness. Of course Galileo did not believe this of her, but how could he, who had asserted that Saturn was a triple planet, defend himself from his critics?

This was serious enough, but of course more serious was the fact that Galileo could not understand the situation. Seldom is scientific knowledge so necessary to a man's wellbeing. The following letter to a friend, written in $1612,{ }^{27}$ is the cry of distress of a strong man who has no sword to wield as his enemies draw near:

Looking at Saturn within these last few days, I found it solitary without its accustomed stars, and, in short, perfectly round and defined, like Jupiter, and such it still remains. Now what can be said of so strange a metamorphosis? Are, perhaps, the two smaller stars consumed like spots on the sun? Have they suddenly vanished and fled? Or has Saturn devoured his own children? Or was the appearance, indeed, fraud and illusion, with which the glasses have so long mocked me and many others who have observed with me? Now, perhaps, the time is come to revive the withering hopes of those who, guided by more profound contemplation, have fathomed all the fallacies of the new observations, and recognized their impossibility. I cannot resolve what to say in a change so strange, so new, so unexpected. The shortness of time, the unexampled occurrence, the weakness of my intellect, the terror of being mistaken, have greatly confounded me.

Galileo took hope, guided apparently by the disappearance of Jupiter's satellites behind Jupiter himself, and he prophesied that the two smaller stars would reappear. True, they did, but Galileo's telescopes were not powerful enough for him to resolve the difficulty, though he did record quite accurately the phases of Saturn as revealed by his instru-

${ }^{97}$ Ibid. p. 110. 
ment. Saturn's behavior must have been a veritable sword of Damocles in the days that followed. Fortunately, his enemies were not wise enough to cut the thread, and Jupiter and other matters remained the important subjects of discussion. Galileo never deceived himself in this matter. He did not make the error Roger Bacon found upon every hand, and "conceal his ignorance with the pretense of knowledge." Twenty-four years later, blind and feeble, writing about Saturn to a friend, he says: ${ }^{28}$

It will be for the future and for others to make observations, registering the times of mutation, so as to determine accurately their periods-that is, if there will be any persons curious enough to do what $\mathrm{I}$, from the same motive (not knowing how to do better), have done for so long a time.

This is a sorrowful lament but withal that of a man who stands by his guns. He cannot carry on, his mind has grappled with a problem thus far beyond him, but he trusts it still, and he accurately points the path to knowledge. It is the path of science and none other.

This problem was easily resolved by Christian Huygens half a generation after Galileo's death, using a much more powerful telescope.

In the conflict with the Church three stages may be mentioned: the first that in which Galileo had sufficient support from those high in authority to enable him to teach and write unmolested, except for the bitter denunciation of his doctrines by sundry Aristotelians. This period is practically coterminous with his professorship at Padua, under the aegis of the Free State of Venice. The second stage followed this both in time and place. It turned out to be

${ }^{23}$ Ibid. p. 114. 
nothing short of a calamity for Galileo to forego the protection of Venice and subject himself to the intolerance of Rome, as he did when he left Padua for Florence. He pitted his wit against that of the censor and won, but it was a costly victory. His work was approved and printed by papal authority, but the resentment in Jesuitical and other circles was so intense, organized, and powerful that ultimately he was subjected to the Inquisition, vehemently suspected of heresy, forced to recant, and was pledged to silence. The third stage is that of his advanced years, an aging body, a mind alert and resourceful, but cramped by the interdiction that he never discuss or publish matters relating to the motion of the heavenly bodies. In this period he gave birth to his treatises upon dynamics, cohesion, and fraction of bodies. These are the great foundations upon which Newton built. They give evidence of an observing, thinking, analytical mind at work, not surpassed by his astronomical contributions.

Galileo was inquisitive in the finest sense, always experimenting and always thinking, seeing the common things of life, but seeing immeasurably more in them than his fellow-man. He realized as perhaps none before him the nature of an hypothesis. It was not a belief, a doctrine, a dogma, or a fantasy, but a formulation of a law of nature to be investigated and held in case it better (not perfectly) explained phenomena than alternative or prevailing opinion. By observing so closely as to be aware that his hypothesis did not perfectly explain phenomena, Galileo left the door open to further investigation, and thus from the outset his science had a different effect upon men's minds than that of Aristotle. Aristotle's erroneous law of falling 
bodies shackled thought for centuries. Galileo's erroneous explanation of the tides bound no one.

I believe the reason is more in the matter of mental attitude toward the issues in question than due to a difference in times. Galileo was absolutely honest with himself. He never glossed over a difficulty or found it convenient to forget certain inexplicable aspects of a situation. It is true that under pressure he did accommodate his expressed views to those in authority, but we should not condemn him for this. Far better that a living and acting Galileo should express things that he positively believed as though they were merely ingenious bits of speculation, than that they should not be presented at all, which was the alternative. If it were not for these free thinkers who tricked the priesthood, the cardinals, and the Popes, and thereby gained an audience for their doctrines, we might today still be living in the darkness that Roger Bacon found. Great, free, scientific thinkers sprang up upon many hands, but probably none so close to the temporal seat of spiritual power as Galileo. One need not dwell upon the suffering this caused him, but we can regret that he could not know in his days of trial the esteem, reverence, and gratitude of later generations.

Like Galen and Roger Bacon, Galileo was master of an incisive mode of presentation, and redoubtable in debate. He was a man of great energy, having a mind so active that it many times interfered with his sleep. He showed talent in music, drawing, mechanical construction, and manipulation. He had an hypothesis for everything, and a test for every hypothesis. He could reserve judgment, if need be, for years, as in the case of the problem of Saturn. 
He had a remarkable ingenuity in devising experimental tests of an issue, a rather over-developed sense of responsibility to importunate relatives, an abiding love for his serious students and friends, and, finally, a keen discernment of sham and a facile pen with which to tell of it.

The year Galileo died, Isaac Newton was born. During the life spans of these two men were many others, each of whom did his bit in the remaking of a world, in providing a new focus-experience-about which to revolve: John Napier, inventor of logarithms; Francis Bacon; William Harvey, discoverer of the circulation of the blood; Tycho Brahe, careful astronomical observer; Johann Kepler, interpreter of these same observations; Rene Descartes, mathematician and student of dynamics; Robert Boyle, chemist; Pierre de Fermat, early worker in the calculus of probabilities; Brook Taylor; Colin Maclaurin; Abraham de Moivre; Roger Cotes, and the Bernoulli brothers, all mathematicians of high order. Toward the end of this period we find our own Benjamin Franklin, forming a sort of link between the students of mathematics, dynamics, and celestial motion, and the prime movers in the new sciences of chemistry, electricity, geology, and biology.

Of all of these none took such giant strides as Isaac Newton. He was a precocious youth, and well-educated, and in a span of ten years provided the foundations of modern physics and astronomy, and of that most powerful analytical tool of all science, differential and integral calculus. His contribution in any one of these fields is epochal. He laid the foundations of optics, of spectrum analysis, and discovered the law of gravity. Almost as mere incidents in the orderly march of his mind in the interpretation of 
the quantitative facts of physics, with many of which he was familiar, he developed the binomial theorem and the method of fluxions, that is, of the calculus. To this day his contribution is a closed book to most of us, but to the minority engaged in mathematical and experimental science, it is the open sesame to knowledge. The great astronomer Halley is quoted by Voitaire as saying of Newton, "It will never be permitted to any mortal to approach nearer divinity." 29

We can never understand the recesses of his genius, but we can note many things wherein he differs from the ordinary run of mortal men. Let us sit with him under the apple tree and watch an apple fall. What thought arises? "It might have landed on my head." "I wonder if it is wormy." These would not be unusual thoughts, but what came to Newton's mind? As a matter of speculation, we will say that it was about like this: He thought of Galileo's experiment with falling bodies, which resulted in the idea of uniformly accelerated motion. Then he supposed that there was a hole right through the center of the earth, and an apple, in falling, started down this hole. Suppose a vacuum in this hole. The apple goes faster and faster, but not forever, for as Newton knew, an apple started at the other end of the hole would fall the other way. It seems certain that after passing the center of the earth the apple would slow down. Good. The law covering this retardation is the same as that covering the earlier acceleration. Further, right at the middle of the earth, the attraction of gravity would be zero, though the apple

${ }^{23}$ History of Science Society, Sir Isaac Newton, 1928. p. 95 . In paper by Michael Idovrsky Pupin. 
is the same size; in short, we must think of a new property of matter, its mass. The apple's tendency to fall is a variable, depending upon its position with reference to the center of the earth, but this new property, its mass, is constant. We need a principle or two to cover the situation, so Newton formulates his first law of motion: every body persists in its state of rest or uniform rectilinear motion unless compelled to change by forces impressed upon it.

We now see that our apple is shuttling back and forth in this long vacuum tube forever-yes, forever, and without a change. Well, this is a rather fantastic picture, because we have no tube and never can have it; but hold, we do have motion going on forever. It is not oscillatory, but circular or elliptic, for we have the planets revolving about the sun, and satellites about the planets. Can we add to our first law so as to include this circular motion? As a consequence of the first law, a satellite would go off on a tangent unless something prevented it. The thing that prevents it is clearly the body around which it revolves, so there must be a force acting at right angles to the tangent which forever operates and just compensates for the tendency to fly off. We clearly need the following, which is the second law of motion: the alteration of motion is ever proportional to and in the direction of the motive force impressed.

At this stage of the thinking process the apple and the satellites such as the moon are subsumed under the same principle. The line of thought here given, though not of the commonness of the sort, "Is the apple wormy?" is not at all beyond our comprehension. The next stage is more difficult, for in the elaboration of the hypothesis it is found that a new mode of mathematical treatment and statement 
is necessary. Newton knew Kepler's laws that the orbits of the planets were elliptical and that the cubes of the mean diameters of these ellipses are proportional to the squares of the times of rotation. But the reverse problem: assume that the momentum of a body, or its tendency to continue at the same velocity in a straight line, is some function of its mass and velocity, and assume that the attraction between two bodies is some function of their masses and of the distance between their centers (and not only this but some function of the distance between each particle of the one and each particle of the other), then what are these functions in order that the path of the smaller body shall be elliptical? Apparently, assuming that the masses of the bodies were concentrated at their centers, Newton solved this problem in a matter of months and reached his tremendous generalizations that any two bodies attract each other with a force proportional to the product of their masses and inversely proportional to the square of the distance between them. But at this time, 1666, Newton was not himself completely satisfied with his experimental verification.

He did not announce this law for nearly twenty years. Three reasons have been advanced: first, his distaste for argument; second, his attempt to verify it by showing that both the moon and a body at the surface of the earth obey it, was unsatisfactory because of a wrong value for the diameter of the earth; and third, that this attempt was inconclusive to himself, because he was unable for nearly twenty years to solve the problem involving attraction between each particle of a first body and each particle of a second body, as opposed to that between two points- their centers. It is not unlikely that all these reasons operated. 
It was nearly twenty years after his first discovery that he established that attraction between two spheres each outside the other is the same as it would be if their masses were concentrated at their centers. Some years before this Jean Picard had provided a new and more accurate measure of the diameter of the earth. Fortified with these new data a recalculation was made and when a check between reality and theory was indicated, Newton was so perturbed that he had to call in an assistant to finish the calculations. Was there ever a greater moment in a man's life than this? Mathematics, physics, the smallest particles on the earth, the entire solar system, and knowledge of God's intention all snapped together at once.

I include a knowledge of God's intention because Newton was a deist-a very serious deist, who wrote even more extensively upon religion than he did upon science. He took law and order in the world as personal evidence of a God. There was no part of his colossal understanding or of his deep religious faith that was not stirred to its depths by this tremendous discovery. Is not an experience of this sort the greatest intellectual satisfaction that the world can give, and is it not reserved for the scientist alone?

I cannot detail other discoveries made by Newton, but I must mention his lucid statements upon scientific method. He lays down four rules: (1) Parsimony: we are not to assume more causes than sufficient to answer for explaining the observed facts. (2) Similar effects must be assigned to the same cause. (3) Properties common to all bodies within reach of our experiment are to be assumed as pertaining to all bodies-e. g. extension. (4) Propositions in science obtained by wide induction are to be regarded as exactly or 
approximately true until phenomena or experiments show that they may be corrected or are liable to exceptions. ${ }^{30}$

Newton was very modest and retiring. He looked upon himself as a child upon a seashore, picking up a small pebble here, a bright shell there, "while the great ocean of truth lay all undiscovered before him." $\mathrm{He}$ so disliked controversial matters that he delayed publication of important findings, printed theological observations anonymously, and contemplated posthumous publication. His labors seem to be roughly equally divided between the scientific work that more than that of any other man is the foundation of modern science, religious exposition that probably has added nothing to speculative thought, and alchemy, which is the occasion of actual regret in the minds of not a few modern scientists. His alchemical range of information was great, and his experiments very extensive and fruitless.

Is this not an excellent illustration of inability to get blood from a turnip? The trouble seemed to be that in his modesty he followed in this matter the old masters, of whom there were many, as he thought, but, as they were not masters, he went astray with them. In physics much less was written. He built upon Kepler and Galileo and struck forth alone with the result that we all know. As Kepler labored long and fruitlessly with astrology, so did Newton with alchemy. Neither seems to have had the acumen in separating the chaff from the wheat that was possessed by Galileo, who revered no man but Archimedes as his master.

3) Sedgwick, W. T. and Tyler, H. W. A Short History of Science, 1917. p. 295. 
Newton was ill-adapted to hold his own with the philosophers. From experience and from his heart he said ${ }^{31}$

Philosophy is such an impertinently litigious Lady, that a man had as good be engaged to lawsuits, as to have to do with her.

The sort of criticism that must have tried him sorely is illustrated by that of the great Bishop Berkeley, who said: ${ }^{32}$

He who can digest a second or third fluxion, a second or third difference, need not, methinks, be squeamish about any point in Divinity. And what are these fluxions? The velocities of evanescent increments. And what are these evanescent increments? They are neither finite quantities, nor quantities infinitely small, nor yet nothing. May we not call them ghosts of departed quantities?

Bishop Berkeley was not presenting the view of a narrow churchman, but of a broad humanitarian, a view that is found in cultured circles today. Why should one be squeamish about transubstantiation or the immaculate conception if he accepts the "ghosts of departed quantities" and builds a vast superstructure upon them. The very statement of the problem shows the gulf between the two points of view. Had Bishop Berkeley experienced the thrill of Newton when he proved the law of gravity, he could have answered his own question. He would have known that the trustworthiness of science was so incomparably greater than that of authority that he would not even have put the question. Faraday knew the difference. He said: ${ }^{33}$

Ultimately facts are the only thing which we are sure are worthy of trust. ${ }^{31}$ History of Science Society, op. cit. p. 176. In paper by Florian
Cajori.
${ }_{22}$ Sedgwick and Tyler. Op. cit. p. 298.
${ }^{33}$ Jones, Bence. Life and Letters of Faraday, 1870. Vol. I, p. 306. ${ }_{\text {Cajori. }}^{{ }^{31} \text { History of Science Society, op. cit. p. } 176 . \text { In paper by Florian }}$
${ }^{22}$ Sedgwick and Tyler. Op. cit. p. 298.
${ }^{33}$ Jones, Bence. Life and Letters of Faraday, 1870. Vol. I, p. 306. 
Contrast this statement of Faraday's with that of a leader of the opposing school today, Dr. Nicholas Murray Butler. Let me quote from his 1927 report as President of Columbia University. He writes:

Part of the difficulty may be found in the fact that science has been suffering from what may be described as a superiority complex which has prevented it from realizing its true place in the scheme of things. There is certainly no region or realm into which science does not or ought not to aim to penetrate, on the plane in which science moves. But that plane is, as every scholar in the field of human thinking must realize, a subordinate one. It is the plane upon which the world appears as made up not of definite and independent objects, but of indefinite series of changing units whose inter-relations and inter-dependences are all-important and all-controlling. To science no object is independent. Each depends on every other and dependencerelativity - is the controlling principle of the universe. There remains, however, that still higher plane upon which the universe appears as a self-dependent, self-related, self-active totality. It is on this plane that philosophy lives and moves and has its being, and on this plane that art and music and literature find the inspiration and the motive of those insights, aspirations, and intuitions which pave the path to beauty.

... [Further] science has been in large part badly taught and in large part is badly taught today. The sole reliance upon the laboratory method for introducing students to an understanding of scientific method, scientific fact, and scientific accomplishment is well nigh disastrous.

Dr. Butler goes on to describe what he conceives to be the proper method of instruction in science. It is the lecture method, and its outcome would be that the study would "take hold (of the student) ... with redoubled power because he sees himself dealing with a vast and continuing human interest." In other words, it finally attains the value 
to the student that is exactly that of the classics. Its long and respectable history gives it weight. The view is that of Bishop Berkeley over again. True, science has a history that is eminently worthy of study, but this is not the heart of science. Until one has devised an experiment to test a hypothesis, has carried it out and observed carefully, and had the outcome break upon him as new knowledge, he does not know what science is. Had Dr. Butler looked through the telescope in Galileo's stead and seen the satellites of Jupiter and known that at that moment a new universe was given to mankind, would he have advocated the lecture method as a means of inducting students into science? It is inconceivable. Dr. Butler refers to philosophy, art, music, literature, as operating upon "that higher plane upon which the universe is a self-dependent, self-related, self-active totality." This is a fantasy. Enjoy it if you can, but believe it never. The sensed totality is but the shaky structure of a feeble mind. After all "facts are the only thing which we are sure are worthy of trust."

Dr. Butler argues for the interpreting of science. Now this can be done in two ways. One is by a very careful logical analysis of the implications and consequences of established scientific principles and the other is by analogy: as in the universe so in the atom; as phylogenetically, so ontogenetically; as in the mind of man so in that of God. No one doubts the scientific and cultural value of the first type of interpretation, but of the second type, that which leads to extensive similes, grandiloquent expression, and which makes the universe appear to be united in all its parts, a very different tale must be told.

Galen saw but half the truth because his God was com- 
plete and a unit, and, reasoning by analogy, so must also be the body of man. Kepler knew the perfect numbers of the mystics and fixed the numbers of planets and satellites accordingly; and even the great Newton, reasoning by analogy from sound, saw in his spectrum seven colors only, and missed not only the continuity of the infinite gradations between them but also the ultra-violet and the infra-red. It seems no overstatement to say that argument by analogy has been the greatest cause of error and the greatest restriction of vision of scientists of all time. It undoubtedly has been a great asset, too. We cannot do away with it, but it should be employed only in the tentative solution phase of a problem. Its fickle nature is attested by the fact that there are no rules of logic which apply to it. Who would attempt to lay down a set of principles telling when analogy is sound and when it is not?

Reasoning by analogy seems to have been in the past a marked weakness of scientific men. It is so today. Let me quote from Michael I. Pupin. ${ }^{34}$

[The spiritual world and the physical world] are both governed by similar laws which are the precious extracts of human experience. Just as the activities of physical forces have been summed up in Newton's dynamics, Maxwell's electro-dynamics, and Carnot's thermodynamics, so the activities of the spiritual forces have been summed up by Christ in his spiritual dynamics. He formulated its two fundamental laws when he said:

Thou shalt love the Lord thy God with all thy heart, and with all thy soul, and with all thy mind.

Thou shalt love thy neighbor as thyself.

${ }^{34}$ Pupin, Michael I. "Creative Coordination." School and Society, Oct. 29, 1927, Vol. XXVI, no. 670. (An address at the inauguration of William Mather Lewis as President of Lafayette College, Eastern Pennsylvania, October 20, 1927.) 
Employing the language of science, we can say that these two commandments are the message from Christ's spiritual dynamics informing us that creative coordination rules supreme in the spiritual just as it does in the physical world.

The advice for conduct given in this quotation seems to me so fine that I would in no way suggest a modification of it, but I must insist that as an argument the quotation is fallacious. Let me condense the statement. 'Though it will spoil its beauty, it will reveal logic or lack of logic within it. Pupin states that just as Newton provided laws governing physical forces, so Christ provided laws governing spiritual forces. Newton drew his inferences from observable measurable relationships, and every step of his processes has been duplicated many times by subsequent investigators. Whatever was the process of Christ in reaching his spiritual laws, no one has attempted to establish that they can be objectively observed, measured, and verified. Surely it would be a calamity if Dr. Pupin could take faith, hope, and charity out of the process. However beautiful Christ's spiritual laws, they do not rest on the same basis as do the laws of experimental science. It detracts from the peculiar and unique dignity not only of science but also of Christianity to say that they do.

I believe that we need religion, that we need social standards of right conduct, that we need the stabilizing effect of history, custom, and consensus of opinion. But to say that the one source that we have for obtaining new knowledge, namely verified inferences from observation of the world about us, takes an inferior position to these is a position in which I cannot agree with Dr. Butler. Science need doff its hat in subservience to no other discipline of mankind. 
When a scientist attempts to reason by analogy in his own work, he does so at great risk; and when he does it before the public, it may become the occasion of distrust and ridicule. Listen to the following abstract of a paper given at a serious scientific meeting and quoted by a serious journal: ${ }^{35}$

Dr. — extended Sir Arthur's history of mankind back to pelagic times, saying: "We owe our appreciation of dancing, poetry, music, and our sense of rhythm to the actions we made when we were only tiny blobs of jelly flagellates, millions of years ago."

Here is a bit of interpretation. Does Dr. Butler approve of this, and if not, upon what basis does he draw the line? I maintain that the idea here quoted can serve no purpose in the planning of an experiment or in the understanding of man. If it is meant as a joke, it is out of place in the setting in which it appeared, and if meant seriously its only effect is to hold science up to scorn and derision. It is true that the history of science reveals that many eminent scientists have at times drawn no clear distinction between inferences deducible from facts and unsupported speculations, but such confusion is less and less defensible as the corpus of scientific knowledge grows.

An attempt to form a composite picture of mental traits of men of science will show many ill-defined features. There are at least two important reasons for this. First: the traits demanded in one scientific field differ from those in a second. Second: the traits facilitating success in one generation differ from those in a second having different social restrictions. With these two conditioning factors in mind we may still make a few generalizations. My study of

${ }^{35}$ Time, Sept. 12, 1927. 
men of science, a sample of which I have given here, leads me to think that there are no exceptions to the following:

(a) The great man of science is industrious, shows great mental energy, and is persistent on the trail of a discovery.

(b) $\mathrm{He}$ questions authority, at least in the one line of his greatest achievement.

(c) He is apt at drawing inferences, and is therefore ingenious in making hypotheses.

(d) His sense of logic is sound, so that he is perspicacious in making deductions.

(e) $\mathrm{He}$ is a keen observer of natural phenomena.

(f) $\mathrm{He}$ is dependent on observed facts.

(g) $\mathrm{He}$ is inventive in the matter of techniques.

(h) $\mathrm{He}$ is rich in his variety and number of hypotheses.

(i) He is not "inspirational" in his chosen field, i. e., his feet are always on the ground-his hypotheses are always amenable to some test of a factual or observational sort. But he is inspirational in the sense that a vision not the common property of fellow-men urges him on.

The following are common, but not universal, traits of the scientific man:

(j) He lacks personal attachment to a hypothesis- -he will slay his own mental offspring, or if he does not actually kill an erroneous hypothesis that he has given birth to, he will let it die from inattention.

(k) $\mathrm{He}$ is disputatious.

(1) In his person much transfer of training takes place, for he adopts to one field a device, method, or hypothesis drawn from another field.

(m) $\mathrm{He}$ is versatile in his interests, and even in his native abilities.

(n) $\mathrm{He}$ is tolerant.

The following are traits which are not uncommon:

(o) In his person erroneous transfer takes place, for he reasons by analogy without warrant. 
(p) He has a good memory.

(q) He has good mathematical ability, even though mathematics is not his major activity. ability.

(r) He has excellent motor coordination and manipulative

(s) He has a thorough knowledge of antecedent work.

(t) $\mathrm{He}$ has a deep religious feeling.

(u) $\mathrm{He}$ is generous.

(v) $\mathrm{He}$ is precocious in his development.

The following are traits which are not unknown in men of science:

(w) $\mathrm{He}$ is egotistical.

(x) $\mathrm{He}$ is modest.

(y) He has hobbies.

(z) $\mathrm{He}$ is not sociable.

(aa) His ancestors are of more than ordinary distinction.

I have endeavored to draw a bird's-eye picture with the hope of a better understanding of the racial development of science and of its expression within individual scientists, and I have also considered certain things that have held back the race and the individual. The tugs that facilitate forward motion are (1) talents, (2) training, (3) facilities-the first of these is quite likely as difficult to secure today as in the past. The hold-backs that slow down progress are (1) individual stupidity, prejudice, and preconceptions, and (2) social taboos. The first of these are probably as ubiquitous today as in the past. Three things, however, are encouraging for rapid advance in the future: (a) it should be possible to adapt training so as to encourage a scientific type of thinking; (b) it should be possible to provide better facilities for the conduct of scientific work; and (c) it should be within reason to expect that society itself will further lift its taboos upon what men shall think and do. 



\section{APPENDIX A}

(To Lecture III)

Showing that if $i$ and $j$ are weights of two test elements which together make up a test, and if one of these elements responds largely to nature and the other to nurture, then $r_{12}$-the correlation between an early and a late giving of the same test to the same individual-will be a maximum when the ratio of $i$ to $j$ is greater than that of $\sigma_{A}{ }^{2}$ to $\sigma_{a}^{2}$, the variance of that fraction of the test element, mainly influenced by nature, that is due to nature, to the similar fraction of the other test element, provided there is no correlation between early and late nurture fractions of the test elements.

$$
\text { Let } \begin{aligned}
X_{1} & =\mathrm{i}\left(A_{1}+U_{1}+E_{1}\right)+\mathrm{j}\left(\mathrm{a}_{1}+\mathrm{u}_{1}+\mathrm{e}_{1}\right) \\
& =\text { score at early age } \\
X_{2} & =\mathrm{i}\left(A_{2}+U_{2}+E_{2}\right)+\mathrm{j}\left(\mathrm{a}_{2}+\mathrm{u}_{2}+\mathrm{e}_{2}\right) \\
& =\text { score at later age (same individual) }
\end{aligned}
$$

$A$ is that factor of the test element that is due to nature, $U$ to nurture, and $E$ to chance.

$$
\begin{aligned}
& \text { Let }{ }^{r} A_{1} A_{2}={ }_{r} A_{1} a_{1}={ }^{r} A_{1} a_{2}=r_{a_{1} a_{2}}=1.00 \ldots \ldots \ldots \\
& \text { and all other } \left.r \text { 's (except } r_{12}\right)=0 \ldots \ldots \ldots \ldots \ldots \ldots \ldots
\end{aligned}
$$

Let $X_{1}$ be in such units that $\sigma_{1}=1.00$. Also let $\sigma_{2}=1.00$. Then (a) and (b) hold:

$$
\begin{aligned}
& \mathrm{i}^{2}\left(\sigma_{\mathrm{A}_{1}}{ }^{2}+\sigma_{\mathrm{U}_{1}}{ }^{2}+\sigma_{\mathrm{E}_{1}}{ }^{2}\right)+\mathrm{j}^{2}\left(\sigma_{\mathrm{a}_{1}}{ }^{2}+\sigma_{\mathrm{u}_{1}}{ }^{2}+\sigma_{\mathrm{e}_{1}}{ }^{2}\right)+2 \mathrm{ij} \sigma_{\mathrm{A}_{1}}{ }^{\sigma}{ }_{\mathrm{a}_{1}}
\end{aligned}
$$

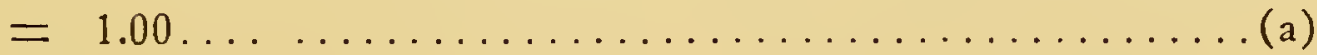

$$
\begin{aligned}
& \mathrm{i}^{2}\left(\sigma_{\mathrm{A}_{2}}{ }^{2}+\sigma_{\mathrm{U}_{2}}{ }^{2}+\sigma_{\mathrm{E}_{2}}{ }^{2}\right)+\mathrm{j}^{2}\left(\sigma_{\mathrm{a}_{2}}{ }^{2}+\sigma_{\mathrm{u}_{2}}{ }^{2}+\sigma_{\mathrm{e}_{2}}{ }^{2}\right)+2 \mathrm{ij} \sigma_{\mathrm{A}_{2}}{ }^{\sigma}{ }_{\mathrm{a}_{2}} \\
& =1.00 \ldots \text {. }
\end{aligned}
$$


As a specific case wherein the variance of one of the test elements is approximately influenced four times as much by nature as by nurture and the other the reverse, we have the following situation:

$$
\text { Let } \begin{aligned}
\sigma_{\mathrm{A}_{1}}{ }^{2} & =.40 \\
\sigma_{\mathrm{U}_{1}}{ }^{2} & =.09 \\
\sigma_{\mathrm{E}_{1}}{ }^{2} & =.01 \\
{ }_{{ }_{\mathrm{a}_{1}}}{ }^{2} & =.09 \\
{ }_{{ }_{\mathrm{u}_{1}}}{ }^{2} & =.40 \\
{ }_{\mathrm{e}_{1}}{ }^{2} & =.01
\end{aligned}
$$

$$
\begin{aligned}
& \sigma_{\mathrm{A}_{2}}{ }^{2}=.40 \\
& { }_{\mathrm{U}_{2}}{ }^{2}=.09 \\
& \sigma_{\mathrm{E}_{2}}{ }^{2}=.01 \\
& \sigma_{\mathrm{a}_{2}}{ }^{2}=.09 \\
& \sigma_{\mathrm{u}_{2}}{ }^{2}=.40 \\
& \sigma_{\mathrm{e}_{2}}{ }^{2}=.01
\end{aligned}
$$

With (1), (2), (3), (4), (a), and (b) as given

$$
r_{12}=i^{2} \sigma_{A_{1}} \sigma_{A_{2}}+i j \sigma_{A_{1}} \sigma_{a_{2}}+i j \sigma{ }_{a_{1}} \sigma_{A_{2}}+j^{2} \sigma_{a_{1}} \sigma_{a_{2}}
$$

The correlation $r_{12}$ is a maximum when

$$
i=1.345
$$

$$
\text { and } j=.1617 \text { (slide rule calculation) }
$$

Thus approximately $\frac{i}{i}=8$

But

$$
\frac{{ }_{A_{1}}^{\sigma^{2}}}{\sigma_{a_{1}}^{2}}=\frac{{ }_{A_{2}}^{\sigma_{2}^{2}}}{\sigma_{a_{2}}^{2}}=4 \text { approximately }
$$

so that the weighting which gives a maximum $r$ is not in proportion to the nature factors of the elements but overemphasizes the greater of these about twice, in case $r$ (nurture) (nurture) $=0$ and it may not overweight them at all, certainly less than twice, if $r$ (nurture) (nurture) is appreciably greater than 0 , and less than $r$ (nature) (nature). 


\section{APPENDIX B}

(To Lecture III)

The numerical results of the investigations of the units yielding maximum correlations are given herewith. In each equation, $y$ stands for the score of the test, and $x$ stands for the score so modified as to yield the maximum correlation.

One population yielding correlation between sibs consisted of 521 pairs: 262 whose records were in Dr. Lewis M. Terman's files, and 259 whose records were in the files of the Iowa Child Welfare Station, all supposedly constituting a fair sampling of the population in general. The rate of change in the modified unit $x$ as compared to that in the original unit $y$ is given by the equation:

$$
\frac{d x}{d y}=2.85-.21 y+.003 y^{2}
$$

This equation was so constructed that

$$
\frac{d x}{d y}=1 \quad \text { when } \quad y=10.25
$$

This was an arbitrary procedure, but does not affect the interpretation, as the ratio of $d x$ for one value of $y$ to $d x$ for a second value is the matter of importance. In the following table, $m_{4.5}$ is the mean for the middle of the fourth grade, as determined from the Stanford Achievement Test age norms for scores expressed in $y$ units. Other subscripts of $m$ have similar meanings for the grades indicated.

$$
\begin{aligned}
& m_{4.5}=10.54 \\
& m_{3.5}=9.38 \\
& \text { Dif. }=1.167
\end{aligned}
$$$$
m_{8.5}=14.54
$$$$
m_{7.5}=13.29
$$$$
\text { Dif. }=1.250
$$

When $y=9.96$

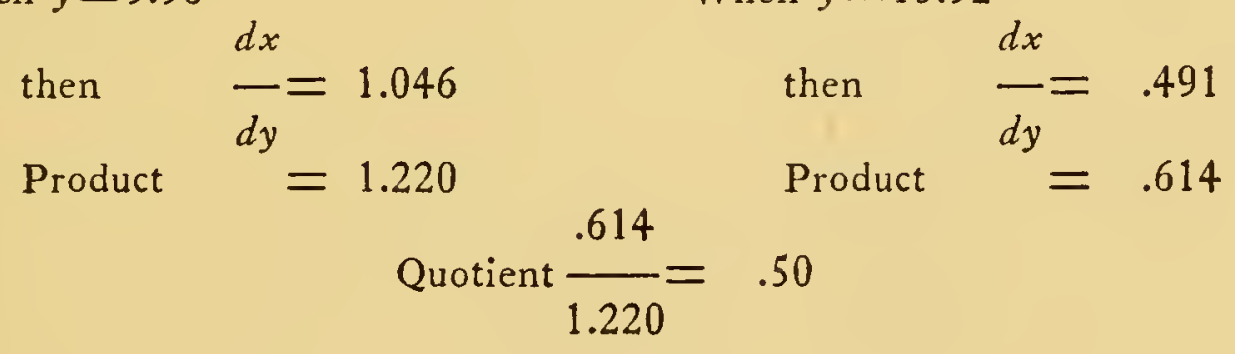


For a population of 231 sibs in the elementary schools of Lodi, California, the following results based upon Stanford Reading Test scores are available:

$$
\frac{d x}{d y}=.85+.0015 y
$$

So constructed that when $y=100$

$$
\text { then } \begin{aligned}
\frac{d x}{d y} & =1.00 \\
m_{8.5} & =190 \\
m_{7.5} & =175 \\
\text { Dif. } & =15
\end{aligned}
$$$$
m_{4.5}=102
$$$$
m_{3.5}=62
$$$$
\text { Dif. }=40
$$

When $y=82$

then $\quad \frac{d x}{d y}=.973$

Product

$$
=38.92
$$

$$
\begin{aligned}
& \text { Product }=16.86 \\
& \text { Quotient } \frac{16.86}{38.92}=.43
\end{aligned}
$$$$
\text { When } y=182.5
$$$$
\text { then }
$$$$
\frac{d x}{d y}=1.124
$$

For a population of 228 sibs in the elementary schools of Lodi, California, the following results based upon Stanford Arithmetic Reasoning scores are available:

$$
\frac{d x}{d y}=1.95-.0095 y
$$

$$
\begin{aligned}
& \text { So constructed that when } y=100 \text { then } \quad \frac{d x}{d y}=1.00 \\
& \begin{array}{l}
m_{4.5}=39 \\
m_{3.5}=29 \\
\text { Dif. }=10
\end{array} \\
& m_{8.5}=93 \\
& m_{7.5}=81 \\
& \text { Dif. }=12
\end{aligned}
$$

When $y=34$

$$
\text { then } \quad \frac{d x}{d y}=1.627
$$

Product

$$
=16.27
$$

When $y=87$

then $\quad \frac{d x}{d y}=1.124$

Product $=13.48$

$$
\text { Quotient } \frac{13.48}{16.27}=.83
$$


For a population of 230 sibs in the elementary schools of Lodi, California, the following results based upon Stanford Computation Test scores are available:

$$
\frac{d x}{d y}=1.475-.0050 y+.0000025 y^{2}
$$

So constructed that when $y=100 \quad$ then $\quad \frac{d x}{d y}=1.00$

$$
\begin{array}{ll}
m_{4.5}=73 & m_{8.5}=131 \\
m_{3.5}=54 & m_{7.5}=120 \\
\text { Dif. }=19 & \text { Dif. }=11
\end{array}
$$

When $y=63.5$

$$
\begin{aligned}
& \text { then } \quad \frac{d x}{d y}=1.168 \quad \text { then } \frac{d x}{d y}=.887 \\
& \text { Product }=22.184 \quad \text { Product }=9.756 \\
& \text { Quotient } \frac{9.756}{22.184}=.44
\end{aligned}
$$

For a population of 348 individuals in the fourth and higher elementary school grades retested with the Stanford Achievement Test after an interval of three years, we have the following results:

$$
\frac{d x}{d y}=1.757-.001 y+.0000001 y^{2}
$$

So constructed that when $y=650$ then $\frac{d x}{d y}=1.00$

$$
\begin{aligned}
& m_{4.5}=330 \\
& m_{3.5}=210 \\
& \text { Dif. }=120
\end{aligned}
$$$$
m_{8.5}=720
$$$$
m_{7.5}=640
$$$$
\text { Dif. }=80
$$

$$
\begin{aligned}
& \text { When } y=270 \\
& \text { then } \frac{d x}{d y}=1.432 \\
& \text { Product } \\
& =171.893 \\
& \text { Quotient } \frac{77.367}{171.893}=.45 \\
& \text { then } \quad \frac{d x}{d y}=.967 \\
& \text { Product }=77.367
\end{aligned}
$$


For a population of 224 individuals in the second and third grades tested with the Stanford Reading, Arithmetic, and Spelling Tests, and retested after an interval of three years, we have the following:

$$
\frac{d x}{d y}=1.195-.00051 y+.00000016 y^{2}
$$

So constructed that when $y=440$

$$
\text { then } \begin{aligned}
\frac{d x}{d y} & =1.00 \\
m_{4.5} & =285 \\
m_{3.5} & =198 \\
\text { Dif. } & =87
\end{aligned}
$$

When $y=241$

$$
\text { then } \begin{aligned}
\frac{d x}{d y} & =1.081 \\
\text { Product } & =94.03 \\
m_{3.5} & =198 \\
m_{2.5} & =60 \\
\text { Dif. } & =138
\end{aligned}
$$

When $y=129$

then $\quad \frac{d x}{d y}=1.132$
Product $\quad=156.2$

$$
\begin{gathered}
m_{8.5}=569 \\
m_{7.5}=513 \\
\text { Dif. }=56
\end{gathered}
$$

When $y=541$

$$
\begin{array}{ll}
\text { then } \quad \frac{d x}{d y} & =.964 \\
\text { Product } & =53.94
\end{array}
$$


INDEX 



\section{INDEX}

Abelard, Pierre, 162

American Association for the Advancement of Science, 141-42

Analogy, 132-33, 178-79, 181 Apollonius, 156

Archimedes, 156, 175

Aristotle, 144-45, 168

Aristotelians, 165, 167

Bacon, Francis, 143-47, 149, 170

Bacon, Roger, 155, 161-63, 167,169

Baldwin, Bird T., 102

Berkeley, George, 176, 178

Bernheim, E., 19

Bernoulli brothers, 170

Bias, 16-19

Bode, B. H., 127

Boyle, Robert, 170

Brahe, Tycho, 170

Bridges, C. B., 29

Brolyer, Cecil R., 108

Butler, N. M., 177-81

Charters, W. W., 113

Concept formation, 124-26

Consensus of opinion, 42-43, 49,52

See also Questionnaire

Copernicus, Nicolaus, 144, 157, 163-65
Cotes, Roger, 170

Courtis, S. A., 110

Credit, Giving, 42-80

Culture, 8-9

Curriculum construction, 36$39,113-19,126-27,130$, 142

Darwin, Charles, 14, 28, 14757

Darwin, Francis, 122

Descartes, Rene, 170

Dewey, John, 26-27, 125-27

Differentiable mental abilities, 111-12, 139

See also Individual differences

Error, 40, 163

See also Probable error

Euclid, 156

Eugenics, 131-42

Evolution, 129-35, 137, 142

See also Eugenics

Experimental method, 10-13, 22-39, 82, 118-24, 126-27, $142,152,155,159-60$, $162,169,173-75,180$

Faraday, Michael, 157, 176-77

Fermat, Pierre de, 170 Forecasting, 33-36, 131

See also Future time Franklin, Benjamin, 170 
Future time, 10-14, 25, 28, 33 See also Forecasting

Galen, 156, 158-61, 169, 178

Galileo Galilei, 2, 18, 144, $155,157,162-70,175$

Galton, Francis, 133

Gibbs, Willard, 147, 157

Growth, 97-101, 104

Halley, Edmund, 171

Harvey, William, 161, 170

Hippocrates, 156, 158-60

Historical method, 10-22, 2728,49

History, 9-10, 120-21, 146, 149-50

Huxley, T. H., 153-54

Huygens, Christian, 167

Hypothesis, 150-152, 168

Independent mental traits

See Differentiable mental abilities

Individual differences, 127-29, $139-40,142$

Induction, 143, 145, 149

Intolerance

See Tolerance

Jesuits, 168

Jevons, W. S., 22

Judgment, 33-43, 106, 12023

See also Questionnaire

Kelley, T. L., 95, 128

Kepler, Johannes, 144, 163-64, $170,173,175,179$
Keynes, J. M., 23

Kilpatrick, W. H., 127

Lamarck, 158

Langlois, C. V., 22

Learning, 128

Literature, 20-21

Logic, 11-13, 159, 179

Lyell, Charles, 157

Maclaurin, Colin, 170

Malthus, T. R., 151

Memory, 28-32

Mendel, Gregor J., 2, 158

Mendel, L. B., 123-24

Michelson, A. A., 25

Mirrielees, Lucia B., vii

Moivre, Abraham de, 170

Moseley, H. G. J., 18

Mozart, Wolfgang A., 18

Napier, John, 170

Native ability

See Nature and Nurture

Nature and Nurture, 30-32,

96-99, 104, 108, 185-86

Newton, Isaac, 131, 143-44, $147,157,168,170-76$, $179-80$

Nurture

See Nature and Nurture

Pasteur, Louis, 124, 144, 147, 157

Philosophy, 11-13

Picard, Jean, 174

Present time, 9-13, 28, 33, 118-19 
Probable error, 25

Pupin, Michael I., 179-80

Pythagoras, 156

Questionnaire, 27-28, 39-83

Ranke, Leopold von, 18

Raphael Santi, 18

Regression, 133-35

Research activities, classification of, $6 \mathrm{ff}$.

Research, methods of, 1-9; subsidized, 3-6

See also Experimental Method, Historical method, Forecasting, Logic

Romanes, G. J., 154

Rugg, H. O., 113

Science, Biological, Physical, Social, 7-9

Scientific method

See Experimental method, Historical method, Forecasting, Logic

Sedgwick, A., 148, 151

Seignebos, C., 22

Sensed differences, 89-95, 104106,110

Shambaugh, C. G., vii

Sidgwick, Henry, 22

Spencer, Herbert, 6, 150

Stanford University, Council of Research in the Social Sciences, vii

Taylor, Brook, 170

Taylor, H. O., 120
Terman, Lewis M., 102

Tests, Construction of, 92-93, 99-100

Thorndike, E. L., 116

Thought, complete act of, 26$27,30,151$

Thurstone, L. L., 111

Tolerance, 140

Traits of Men of Science, 146$48,150-56,161-64,167$, $169-70,174-75,181-83$

Uniform development, doctrine of, 129-30

Units of measurement, 85-112, 187-90

Values, Future See Values, Mental

Values, Mental, 36-43, 49

See also Judgment, Forecasting, Questionnaire

Values, Social

See Values, Mental

Variability, 133-35

Vesalius, 159

Villari, P., 22

Vinci, Leonardo da, 145, 156, 158

Voltaire, 162, 171

Weismann, August, 158

Wiley, W. E., 107

Wilson, Edwin B., 122

Woodworth, R. S., 30

Word Knowledge, 38, 90-93

See also Values, Mental 




n.t. 


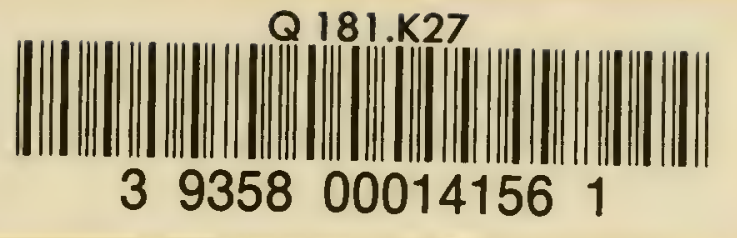

Q181

K27

14156

Kelley, Truman Lee, 1884-

Scientific method; its function in research and in education [by] Truman Lee Kelley -. Columbus, Ohio state University Press, 1929.

vil, 195 p. diagr. $20 \mathrm{~cm}$. 
